University of Louisville

ThinkIR: The University of Louisville's Institutional Repository

\title{
In the words of another: on the promises and paradoxes of rhetorics of empathy.
}

Eric Wallace Leake 1980-

University of Louisville

Follow this and additional works at: https://ir.library.louisville.edu/etd

\section{Recommended Citation}

Leake, Eric Wallace 1980-, "In the words of another: on the promises and paradoxes of rhetorics of empathy." (2011). Electronic Theses and Dissertations. Paper 801.

https://doi.org/10.18297/etd/801

This Doctoral Dissertation is brought to you for free and open access by ThinkIR: The University of Louisville's Institutional Repository. It has been accepted for inclusion in Electronic Theses and Dissertations by an authorized administrator of ThinkIR: The University of Louisville's Institutional Repository. This title appears here courtesy of the author, who has retained all other copyrights. For more information, please contact thinkir@louisville.edu. 


\title{
IN THE WORDS OF ANOTHER: ON THE PROMISES AND PARADOXES OF RHETORICS OF EMPATHY
}

\author{
By \\ Eric Wallace Leake \\ B.A., University of Nevada, Las Vegas, 2002 \\ M.A., University of Nevada, Las Vegas, 2007

\begin{abstract}
A Dissertation
Submitted to the Faculty of the

College of Arts and Sciences of the University of Louisville

in Partial Fulfillment of the Requirements

for the Degree of
\end{abstract}

Doctor of Philosophy

Department of English

University of Louisville

Louisville, Kentucky

August 2011 
Copyright 2011 by Eric Wallace Leake

All rights reserved 

IN THE WORDS OF ANOTHER: ON THE PROMISES AND PARADOXES OF RHETORICS OF EMPATHY

\section{By}

Eric Wallace Leake

B.A., University of Nevada, Las Vegas, 2002

M.A., University of Nevada, Las vegas, 2007

A Dissertation Approved on

July 28, 2011

by the following Dissertation Committee:

Bronwyn T. Williams

Dissertation Director

Beth A. Boehm

Brian Leung

Nancy Potter 


\section{ACKNOWLEDGMENTS}

This project began in a conversation with my director, Dr. Bronwyn Williams. His kind and knowledgeable guidance has been always invaluable. I also want to thank the members of my committee for their encouragement, advice, and questions, which have pushed me to consider more thoroughly rhetorics of empathy. As always, I have relied most heavily upon my family and friends in this and in everything else. I wish to dedicate this dissertation with much love and appreciation to them and to all of those who have taught me so much about empathy. 


\title{
ABSTRACT \\ IN THE WORDS OF ANOTHER: ON THE PROMISES AND PARADOXES OF RHETORICS OF EMPATHY
}

\author{
Eric Wallace Leake
}

July 28,2011

Empathy has been commonly evoked within rhetoric and composition as a way to understand audiences and as a classroom ethic. This dissertation goes further in defining rhetorics of empathy, analyzing the uses of rhetorics of empathy in political and social discourse, and proposing how rhetorics of empathy might inform the ways we teach reading and writing. The first chapter defines rhetorics of empathy through a survey of empathy's place in the rhetorical tradition, including Aristotle's theories of emotion, ideas of compassion in the Scottish Enlightenment, and Kenneth Burke's concept of identification. This rhetorical history is combined with contemporary understandings of empathy from developmental psychology and moral philosophy. The resulting definition is of rhetorics of empathy as means of persuasion notable for combining the cognitive and the affective within our perspective-taking faculties, social relations, and moral judgments. The importance of rhetorics of empathy in political discourse is shown in an analysis of Barack Obama's speeches, which both promote and perform positions of empathy. Obama's speeches are further shown to employ empathy through allegory, particularly in the telling of Obama's own story as an occasion for empathizing with multiple American identities. A series of first-person accounts of the nearly and newly 
homeless from the Las Vegas Sun are used to illustrate the contested conditions of rhetorics of empathy based upon readings of suffering, victimhood, and the overlap between self and other. An argument then is made for composition pedagogies that work with empathy as rhetorical appeal and as a disposition that can be cultivated through habits of reading and writing. The proposed pedagogies include an attention to perspective-taking and the perceived human reality of issues. They also require an awareness that empathy is always at best an approximation, one inherently tied to differences in experiences and social relations. This dissertation maintains at the end that rhetorics of empathy are valuable precisely because of the paradoxical questions they foreground, those of the cognitive and the affective, our relationships and responsibilities to one another, and the critical necessity of recognizing our always present differences alongside a shared humanity. 
TABLE OF CONTENTS

PAGE

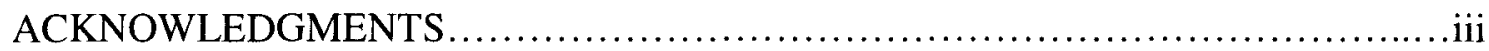

ABSTRACT.

iv

AN INTERDISCIPLINARY SURVEY AND DEFINITION OF RHETORICS

OF EMPATHY ..............................................................................

Ways of Thinking and Feeling, Reading and Acting ...........................

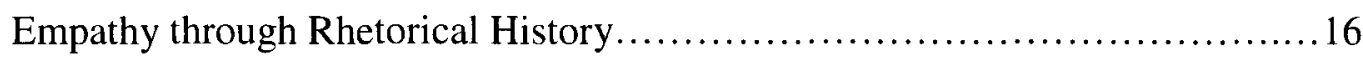

Rhetorics of Empathy within Writing Studies...............................33

EMPATHY AS THEME AND RHETORICAL MEANS IN THE SPEECHES

OF BARACK OBAMA ..............................................................40

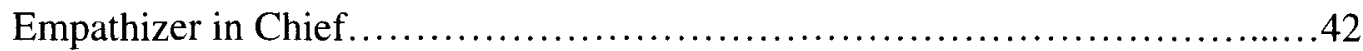

Empathy and the Personal as Political Allegory............................55

A Nation Empathizing with its Multiple Selves..............................72

"I Feel Your Pain": Political Expectations and the Limits of Rhetorics of

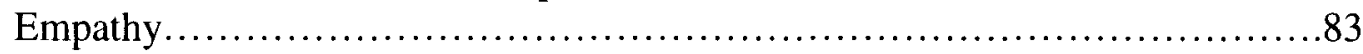

"SHOULD YOU ENCOUNTER": CONTESTED APPEALS AND THE

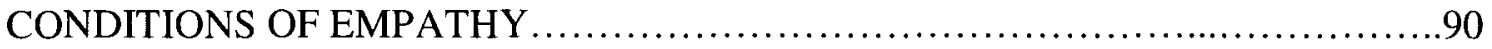

The Conditions of Empathy ...................................................

The Display and Appraisal of Suffering ....................................103

Questions of Responsibility and Victimhood..............................112

Recognizing a Self-Other Overlap......................................119

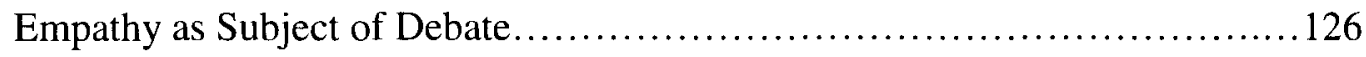


At Stake in Rhetorical Conditions of Empathy........................... 133

WRITING PEDAGOGIES OF EMPATHY: A TAXONOMY AND PROPOSALS...137

Empathy as Moral Virtue...............................................139

The Empathic Teacher............................................. 144

Reading Characters in Fiction and Nonfiction.......................... 146

Teaching Empathy as Rhetoric.................................... 153

Teaching Empathy as Disposition.................................... 163

The Messy Work of Schooling the Emotions............................ 172

THE PARADOXES AND NEEDS OF A CRITICAL EMPATHY ...................178

Identifying with Self and Other.......................................... 181

In Another's Shoes: Presence and Absence................................. 188

Both Universal and Particular........................................ 192

The Necessary and Constant Critique of Empathy......................... 198

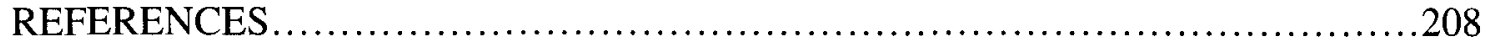

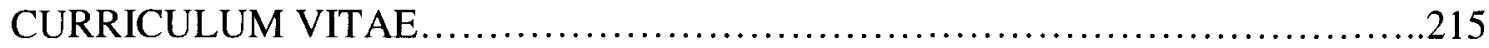




\section{CHAPTER I}

\section{AN INTERDISCIPLINARY SURVEY AND DEFINITION OF RHETORICS OF EMPATHY}

Empathy has entered our common conversations without ever really being introduced or defined. That may be one reason why it is so generally evoked, because empathy works as shorthand for caring or feeling or concerning ourselves with others. The common evocations of the term speak to the importance of establishing what I mean by "rhetorics of empathy." To do so I first survey how empathy is discussed within moral philosophy and psychology. I then focus upon empathy's place among related ideas within rhetorical history. I update this review by addressing empathy's current place within rhetoric and writing studies, a place that I will elaborate upon throughout the ensuing chapters. I arrive at a definition of rhetorics of empathy as means of persuasion notable for combining the cognitive and the affective within our perspective-taking faculties, social relations, and moral judgments. To arrive at that definition, and to do so within these limited pages, I am unable to pursue so many of the interesting detours offered by theories of empathy. My focus throughout is on empathy as a rhetorical concept, one that holds critical implications not only for how we persuade one another but for how we understand our relationships as we speak and read and write in the words of another. 


\section{Ways of Thinking and Feeling, Reading and Acting}

Empathy is thought to be deeply rooted in what it means to be human.

Primatologist Frans De Waal argues that empathy is not only part of human nature but also part of our natural ancestry. He has observed what he considers to be empathy in chimpanzees and the ways they relate to one another. Empathy all starts and coincides, De Waal argues, with maternal care. More recently, the discovery of mirror neurons has created renewed interest in empathy. Mirror neurons describe a process by which one's own mental state "mirrors" that of an observed other. "Mirror neurons undoubtedly provide, for the first time in history, a plausible neurophysiological explanation for complex forms of social cognition and interaction," writes Marco Iacoboni, a leading neuroscientist in the study of mirror neurons (5-6). "They bind us with each other, mentally and emotionally," he adds, explaining that mirror neurons help us to read the facial expressions and emotional states of others in moments that constitute "the foundation of empathy and possibly of morality, a morality that is deeply rooted in our biology" (4-5). There is much exciting work occurring in the area of mirror neurons, especially in terms of how mirror neurons function with context and social environment. Although I value the contributions that fields such as primatology and the study of mirror neurons bring to considerations of empathy, my focus in this project is the rhetorical work of empathy. In that regard, and because I am not qualified as a neuroscientist, exciting concepts such as mirror neurons here seem most useful in their explanatory power as metaphors for how we understand and interact with one another. I am more inclined to follow the lead of Daniel M. Gross, who argues for a rhetorical approach to the study of emotions as not merely personal and internalized but as constituted through 
social relations. He suggests that "subjective experiences such as emotion have an essential social component and are best treated with social analysis of the sort developed in the rhetorical tradition" (33-34, emphasis original).

Although empathy is thought to be part of our biological inheritance, empathy's introduction in our vocabulary is fairly new. The word empathy does not enter the English language until the early twentieth century when it is introduced from the German Einfühlung, literally "feeling into" (Keen Empathy and the Novel 39). Predecessors and close cousins to empathy include sympathy, compassion, and pity. There is much overlap within these terms. That overlap itself points to the necessity of differentiating empathy from related ideas. Empathy's closest relative terms, and thereby the most useful from which to distinguish it, are sympathy and compassion. I start with these terms and address pity later.

Sympathy is often used interchangeably with empathy, although empathy is currently more the vogue of the two terms, seeming, I think, more sophisticated and less sentimental. Both sympathy and empathy have similar Greek etymologies as "with" or "in" "feeling." The primary distinction is in perspective and position relative to another. While sympathy is considered feeling for another, empathy is better understood as feeling with another. In defining the terms, Keen writes, "I distinguish the spontaneous, responsive sharing of an appropriate feeling as empathy, and the more complex, differentiated feeling for another as sympathy" (Empathy and the Novel 4). Sympathy would thus build upon an initial empathic response. Sympathy goes beyond empathy by including supportive concern for another; it is more of a social, personal, and political commitment that follows empathy. I understand empathy in Keen's formulation as the 
more spontaneous emotion, while sympathy arises in response to empathic arousal. That basic point is also made by moral philosopher Arne Vetlesen when he critiques Max Scheler's formulation of sympathy as based on love: "We must insist that sympathy rests not on love but on empathy and that our capacity for empathy can be directed to persons who are not unique to us and whom we do not love" (148, emphasis original). Vetlesen further describes empathy's connection to sympathy in defining empathy as "humanity's basic emotional faculty, a specific manifestation of which is sympathy; being a particular feeling, sympathy is facilitated by the basic faculty of relating to others, which I term empathy" (148). We are left with a definition of empathy distinguished from sympathy in which empathy is primarily reactive to the situations of other and precedes sympathy. Empathy in this formulation is the basic way that we relate to one another prior to making commitments based upon that relationship.

Like sympathy, empathy is generally in response to the suffering or pain of another, but that does not always have to be the case. For example, we can empathize with someone's happiness. This is part of the distinction that Martha Nussbaum makes between empathy and compassion. She defines compassion as necessarily including an emotional component for somebody who is suffering. Empathy, on the other hand, is understood by Nussbaum as more of an imaginative projection of another's position, not necessarily concerned with suffering, and not necessarily including emotional content. In Nussbaum's definition, "Empathy is simply an imaginative reconstruction of another person's experience" (Upheavals of Thought 302). Like Vetlesen in his positioning of empathy as preceding sympathy, Nussbaum argues that empathy is not requisite for compassion. "In short," Nussbaum writes, "empathy is a mental ability highly relevant to 
compassion, although it is itself both fallible and morally neutral" (333). Nussbaum does, however, immediately acknowledge that in its basic realization of another's humanity and perspective, empathy is not entirely morally neutral. It is morally significant simply to consider the perspectives of another person, to extend that level of human regard. Nussbaum's definition is at odds with those of others who would define empathy affectively and as a means of accessing the moral - as I do-but her definition is useful nonetheless as a means of distinguishing empathy and emphasizing its cognitive element and special position relative similar emotions and social commitments.

The concept of sympathy building upon empathy adds an important rhetorical quality to definitions of empathy at the level of commitment leading to action. This is evident in the explanation of empathy provided by ethicist Douglas Chismar, who writes of the difference between empathy and sympathy,

To empathize is to respond to another's perceived emotional state by experiencing feelings of a similar sort. Sympathy, on the other hand, not only includes empathizing, but also entails having a positive regard or a non-fleeting concern for the other person...A "sympathizer" is one who goes along with a party or viewpoint, while an "empathizer" may understand, but not agree with the particular cause. (257)

Sympathy here is a position where one has been persuaded to another's view or cause, so that in witnessing another's situation one not only understands that situation but aligns oneself in order to amend the situation. This move toward persuasion-which would precede action, supposedly that of the altruistic sort-begins with the experience of empathy. Sympathy then may be understood rhetorically as a progression of empathy in a move toward solidarity and action. My interest is focused on empathy, however, as the more fundamental concern. Although I will not always clearly delineate between empathy and sympathy along the lines of the differences framed here, I do think the 
initial distinctions important for the ways that they emphasize the rhetorical work that begins with empathy.

Empathy has been the subject of much consideration and sometimes conflicting definitions. A full list of definitions would be quite lengthy. A survey of the more important ones, in particular that offered by Vetlesen, provides a solid composite understanding of what empathy is. Keen defines empathy as "a spontaneous sharing of feelings, including physical sensations in the body, provoked by witnessing or hearing about another's condition" (Empathy and the Novel $\mathrm{xx}$ ); and as "the spontaneous, responsive sharing of an appropriate feeling" (4). There are four important elements to this definition: that empathy is spontaneous, also includes physical sensations, and is provoked by another's situation, in witnessing or hearing about it; this creates further opportunities for empathy as mediated by language and distance. Compare Keen's definition of empathy to that of philosopher Adrian Piper, who writes,

To empathize with another is to comprehend viscerally the inner state that motivates the other's overt behavior by experiencing concurrently with that behavior a correspondingly similar inner state oneself, as a direct and immediate quality of one's own condition. Empathy, in turn, requires an imaginative involvement with the other's inner state because we must modally imagine to ourselves what that state must be as we observe her overt behavior, in order to experience it in ourselves. (qtd. in Walton 81)

Piper's definition, like that of Keen, focuses on the visceral quality of empathy and the spontaneous or concurrent sharing of feelings or inner states. The crucial addition of Piper's definition, echoing that of Nussbaum, is the imaginative aspect of empathy. That imaginative involvement is responsible for much of the promises and liabilities of empathy in making leaps and taking risks. It further opens the door for empathy as invention and artifice; it also speaks to the interest in empathy by those in literary studies. 
Empathy fundamentally is always a work of the imagination, even when it is not constituted by a conscious imaginative act. As an act of the imagination, empathy is also fundamentally social in how it is imagined. Empathy works to bridge differences, but there are always opportunities for errors in this bridging. One's own inner state and that of another may be at best corresponding but never congruent. This is a point that I will make repeatedly, that empathy is always an imaginative action, an approximation of another's perspective, and that a thoughtful critique and employment of empathy is based in that knowledge that one will never be the other and can never fully enter another's perspective. Indeed, as Nussbaum writes, “This awareness of one's separate life is quite important if empathy is to be closely related to compassion: for if it is to be for another, and not for oneself, that one feels compassion, one must be aware both of the bad lot of the sufferer and of the fact that it is, right now, not one's own body" (Upheavals of Thought 327). If one starts to identify oneself completely with the suffering other, then the other is erased and empathy is only empathy for oneself. In these ways empathy depends upon difference.

Folklorist Amy Shuman is thoughtful in outlining the promise of empathy while also proposing a sustained critique. She starts with her definition of empathy as "the act of understanding others across time, space, or any difference in experience" (4). Here Shuman is picking up on a quality mentioned by Keen and others, which is that another does not have to be in one's immediate physical presence in order for there to be empathy. Psychologists as well as common experience tell us that we most readily empathize with those whose presence is immediate: the person on the street, our neighbors and colleagues at work, the friend or family member. If somebody cannot be 
present, then the more visceral the sight or the sound and the more felt the emotion-the closer they come to being present - the more powerful the empathic identification. But presence is not a requirement, especially in our age of immediate audio and video communication; and even presence can be an invention in the sense of a character in a story. As Shuman notes, we always empathize across differences in experiences. Sometimes those differences are also temporal and spatial.

More than any other definition of empathy, that offered by developmental psychologist Martin Hoffman acts well as a starting point toward an emerging consensus in defining the concept. Hoffman reviews much of the psychological literature on empathy in outlining what he determines are the five modes of empathic arousal; three of which are preverbal and essentially involuntary, those being mimicry, conditioning, and association; and two of which are what he calls the "higher-order cognitive modes" of mediated association and role- or perspective-taking (5). I am most interested in Hoffman's higher-order cognitive modes. For the purposes of this first chapter, Hoffman's general definition of empathy is useful, and that is "empathy defined as an affective response more appropriate to another's situation than one's own" (4). Like others, Hoffman is defining empathy as the approximation of congruency between one's own and another's response to a situation or inner state or feeling. There is a shared perspective or interest or common humanity here. This quality speaks to necessary relationships of selves and others that are always already part of empathy. It is what Mark Bracher, drawing from the work of Nussbaum and others, describes as the "Self-Other overlap," because, he writes, "To feel sympathy or compassion [or empathy], one must experience one's own being as in some way bound up with the suffering of the Other" 
("How to Teach" 369). Likewise, in his earlier definition of empathy, Carl Rogers emphasizes that empathy requires awareness of another's perception "but without ever losing the recognition that it is as if I were hurt or pleased and so forth" (A Way of Being 140-141, emphasis original).

The other important quality of Hoffman's definition is his emphasis on the affective as characterizing the type of response one has in empathy. Through this emphasis, attention to empathy can be read alongside the larger shift of attention to affect throughout the humanities and social sciences. Hoffman's focus on affect does not mean to relegate empathy to the purely affective. Instead, Hoffman works to do just the opposite in explaining how empathy works as part of larger cognitive processes that combine social and moral principles with affective charge. He writes of what empathy brings to cognitive processes in terms of pairing the more immediate and felt charges of empathy with the more abstract and considered workings of moral principles. This is at the center of his work on empathy, and it is a way I which empathy works from the more immediate affective to the more social emotive. In Hoffman's terms,

What do moral principles gain from the bond with empathy? My hypothesis is that abstract moral principles, learned in "cool" didactic contexts (lectures, sermons), lack motive force. Empathy's contribution to moral principles is to transform them into prosocial hot cognitionscognitive representations charged with empathic affect thus giving them votive force. How is this accomplished? I suggest that people in a moral conflict may weigh the impact of alternative courses of action on others. This evokes images of others' being harmed by one's actions; these images arouse empathic distress and anticipatory guilt; the images and empathic affects activate one's moral principles. The concurrence of empathy and principle creates a bond between them, which gives the principle an affective charge. (239)

Here empathy is the crucial component that makes moral principles "hot," thereby making them matter by giving them affective force and charge. Hoffman's mechanism 
for this action is based upon cognitive scripts and induction. Most important for consideration, however, is the result of this process and its importance for building a definition of empathy that includes affective, cognitive, moral, imaginative, and social elements. Hoffman's connection of moral principles to affective charge is similar to Vetlesen's position that empathy is a fundamental means of accessing the moral by understanding the human realities of an issue and Nussbaum's basic acknowledgement that empathy is not fully morally neutral as an imaginative exercise because the simple act of recognizing another's humanity includes an ethical component. I am further reminded of Brian Massumi's definitions of affect and emotion. For Massumi, "affect is intensity" and "Emotion is qualified intensity, the conventional, consensual point of insertion of intensity into semantically and semiotically formed progressions, into narrativizable action-reaction circuits, into function and meaning. It is intensity owned and recognized" $(27,28)$. The moral principles that Hoffman writes about act like the qualifications and narrativizations that Massumi mentions in bonding with the affective charges of empathy. Here Hoffman aligns empathy more strongly with affect, but the important part to me is the socially constituted bonding that contributes to the motive force of empathy. This is how empathy moves people. And, as Gross notes in connection to witnessing another's grief or joy, "There is ultimately no purpose for emotion other than to move people" (173). As a final observation, also apparent in Hoffman's passage is the importance rhetorics of empathy hold for pedagogies, particularly those in writing studies, as empathy is credited with connecting moral principles to prosocial action. Much of the current interest in empathy is fueled in part by the so-called empathyaltruism hypothesis. The basic idea is that empathy leads to altruistic, or prosocial, 
actions. I should note, altruistic and prosocial do not always mean the same thing. As defined by Kristen Monroe, altruistic actions are "designed to benefit another, even at the risk of significant harm to the actor's own well-being” (4). Prosocial is defined on the American Psychological Association web site, with reference to Gerrig and Zimbardo, as characterizing "behaviors that are carried out with the goal of helping other people." The basic idea of the empathy-altruism hypothesis is that by empathizing with the poor, for example, I am more likely to take prosocial or altruistic actions to alleviate their poverty and suffering, be those actions ones that address poor individuals or those that address the more problematic structural causes of poverty. This empathy-altruism hypothesis is central to contemporary understandings of empathy and fuels much of their debate. The hypothesis is most fully addressed in C. Daniel Batson's work, notably The Altruism Question. The basic question is whether genuine empathy leads to altruistic actions that benefit the perceived other or whether it only alleviates the distress of the perceiver. The question then is, does one give to the needy in order to benefit the needy or to relieve one's own distress at facing the reality of the needy? Batson concludes that genuine empathy is possible and that it does lead to altruistic actions. As Michael Slote summarizes Batson's argument, the observer who helps could just as easily close her eyes and walk away to relieve her own stress at seeing the suffering of another. But she does not necessarily do so. Instead, she acts to relieve the suffering, thereby demonstrating altruistic behavior. Hoffman similarly argues for this understanding of empathy. Building upon his idea of empathy as coupling hot affect with moral principles, he writes,

I hypothesize that when principles are coupled with empathic affect they acquire an affective charge, along with the affect's motive property. They are then stored in memory as prosocial, affectively charged representations of "hot" cognitions, which can be activated on witnessing a violation. A 
simple three-fold prediction from this hypothesis is that empathy relates to prosocial action; upholding a prosocial moral principle relates to prosocial action; and empathy plus principle relates to prosocial action to a greater degree than either alone. (240)

Empathy thus provides the motive force for people to be moved to prosocial action. The relationship between empathy and altruism in this formulation is such that empathy provides the affective force for altruism. Hoffman argues that neither empathy nor moral principle alone contribute so significantly to prosocial actions. It is only through the relationship of empathy and moral principles, with empathy providing the force and moral principles the direction, that one is so moved to prosocial actions. The exact terms of the relationship between empathy and altruism and prosocial actions are subject to much debate. For example, Monroe defines empathic motivation as including both affective and cognitive components that allow for altruistic influences, which can be conscious or unconscious resulting from habits, learned values and desires, and processes of socialization (13). In this understanding, the relationship in the empathy-altruism hypothesis is allowed to flip so that unconscious altruistic habits influence empathic motivation, although the important link between empathy and altruism remains intact.

Although positing a direct relationship between empathy and altruism is attractive, Keen remains cautiously skeptical, especially empathy leading to altruistic behavior in areas of empathic reading. Her study of empathy and novel reading does not start with the hopeful assumption of the empathy-altruism hypothesis. Instead, Keen writes,

I do not assume that social good necessarily comes of empathic reading. Novels' intellectual and emotional influences may certainly lead to socially consequential results, but good effects of novel reading ought to be analyzed in context with neutral and negative effects. Empathic reading 
experiences that confirm the empathy-altruism theory, I argue, are exceptional, not routine. (Empathy and the Novel 65)

Keen's reservations are important to writing studies because she specifically addresses the empathy-altruism hypothesis in terms of reading, although here her attention is focused on novels. She is right to be reserved. The promise and feel-good quality of embracing empathy makes the empathy-altruism hypothesis an attractive position for those arguing the benefits of literary and other forms of reading and the humanities in general. The assumption of those benefits should nevertheless be guarded against in case the benefits of imaginative empathy are overstated. Part of the reason the hypothesis remains debated is due to the difficulty in testing it. Batson et. al. have conducted studies showing that in reading personal appeals targeting empathy, subjects are more likely to make decisions to benefit the social groups of those they empathized with. But despite their promise, these are somewhat limited experiments conducted under conditions unlike those Keen is addressing. In the case of empathic novel reading, for example, how exactly does one limit, isolate, and determine the consequences of empathic reading and altruistic actions through the course of a day or a year, an education or a lifetime? How does one do so with classroom readings and assignments, which are not Keen's focus? The best efforts to address these concerns and the promises of empathy are hopeful while also grounded in skepticism, a balance of cautious optimism that I try to maintain.

Keen's work in empathy and the literary offers an opening to begin considering empathy within rhetoric and composition. She acknowledges that readers and authors experience empathic reactions in their engagements with fiction. Indeed, it is this quality of character identification and associated feelings that many readers and authors seek in their engagement with fiction. The difficulty in testing the relationship between empathy 
and the reading or writing of fiction is one of cause and selection. Citing the work of psychologist Tammy Bourg, Keen notes that there is a correlation between empathy and reading as empathic ability is an indicator in children of future reading achievement (Empathy and the Novel 88). The question then is do empathic people simply make better readers or does reading make for more empathic people? A similar question can be applied to authors, as writers of fiction test higher for empathy than does the general population (125). In addition to questioning the relationship between reader empathy and altruism, Keen doubts whether empathic reading alone is enough to deliver on the hopes of those advocating reading literature as a means of developing empathy for more responsible citizenship or social transformation. She does, however, point to where rhetoric and composition might contribute to the conversation in her acknowledgement of the importance of pedagogy. "What empathic reading by itself may not accomplish, however, a teacher or guide may still achieve, if one considers the link between novel reading and active steps on behalf of real others desirable," Keen writes (147).

Pedagogy is beyond the scope of Keen's analysis, but it is there that empathic reading and writing may hold the greatest promise. Keen is also unconcerned with nonfiction texts or with how empathy may be employed in types of writing other than fiction. I expect that nonfiction texts may be even better at engaging empathy because people most readily identify with, care about, and may be moved to act in the benefit of those whose suffering they understand to be real rather than fictional. In fact, the danger with this kind of empathy may be that it is too forceful and that readers may push against it for fear of over-arousal, just as somebody watching a Save the Children commercial might change the channel because he or she cannot bear to see the children suffering. 
These are concerns with empathy as rhetoric, as engaged in nonfiction texts, as practiced in forms of writing other than narrative fiction by professional authors, and as a part of a pedagogical strategy. I take up questions about rhetorics of empathy and pedagogy in the fourth chapter, where I provide a taxonomy of empathy pedagogies and propose two pedagogies specific to the writing classroom, those of empathy as rhetoric and empathy as disposition.

There are many more definitions of empathy that could be examined here. For the sake of time and focus, those collected above should be sufficient to arrive at an understanding of empathy beyond its colloquial use as simply caring or kindness or thinking about the views and experiences of others. Taking elements from these definitions we are left with a concept of empathy that is heavily based in affect and provided social meaning through the emotions, that thus combines the cognitive with the affective, that engages the imagination, that is aroused directly or through the mediation of language across space and time, that informs and is informed by moral principles, that is part of a process of perception and judgment, that is hypothesized to contribute to altruistic actions, and that depends upon an idea of a common humanity and the self-other overlap but that also requires the critical recognition of the irreducible differences between self and other. This provides quite the starting point and a concept of empathy that will become more focused as I move toward its rhetorical dimensions and uses. Rhetoric and writing instruction are implicated throughout these qualities of empathy. As such an understanding of empathy indicates, the topic of empathy — especially rhetorics of empathy-is charged with questions and concerns about differences and power relations, as in who gets to empathize and who gets to be empathized with. To echo 
Rogers's sentiment in developing his own definition of empathy, "Perhaps this description makes clear that being empathic is a complex, demanding, and strong-yet also subtle and gentle-way of being" (A Way of Being 143). We can add that is also a way of rhetoric.

\section{Empathy through Rhetorical History}

As with so many topics in rhetoric and composition, we can start with Aristotle, who does not treat empathy directly-there was no equivalent term at the time-but does provide a foundation for considering emotional appeals in connection with cognition, morality, and persuasion to action. The standard textbook treatment of emotional appeals is based upon a reading of Aristotle in which emotions are at odds with reason. Such a reading can be traced to the very opening of Aristotle's Rhetoric, where he writes, "The arousing of prejudice, pity, anger, and similar emotions has nothing to do with the essential facts, but is merely a personal appeal to the man who is judging the case" (2). Emotional appeals are then positioned as something that is added to facts, and in time they begin to be seen as suspect. More recent scholarship, however, has pushed against this interpretation. Douglas Walton, for example, begins his work on Appeal to Pity by noting, "The argumentum ad misericordiam, or (literally) argument to pity, usually translated as 'appeal to pity,' has, for the last century or so, been treated by the logic textbooks as a fallacy. However, this rather one-sided view of arguments based on appeal to pity has recently been challenged in the literature on argumentation" (xiii). Within composition, which Laura Micciche argues is due for a "concept undoing" in its thinking of emotions, reason and emotion often still are presented as at odds. As Micciche 
observes, 'The 'emotional appeal,' as delineated through Aristotle's psychology of emotions, frequently operates as tacit shorthand for manipulation, excess, and irrationality - a disreputable source about which we should remain suspect" (Doing Emotion xiii).

In Aristotle on Emotion, W. W. Fortenbaugh further argues against this common misinterpretation of emotion's place within Aristotle's work. Instead, Fortenbaugh writes, "Aristotle's analysis of emotion made clear the relationship of emotion to reasoned argumentation. By construing thought or belief as the efficient cause of emotion, Aristotle showed that emotional response is intelligent behavior open to reasoned persuasion" (17). Fortenbaugh focuses upon Aristotle's treatment of anger, but his overview of Aristotle's treatment of emotion is an effort to correct the historical record in rhetoric that treats emotion as suspect. The suspicion of emotional appeals as "charms and enhancements" is attributed by Fortenbaugh to Plato's characterization of the sophists Thrasymachus and Gorgias (17). In Fortenbaugh's summary,

Viewed as an affliction divorced from cognition, emotion was naturally opposed to reason and conceived of as something hostile to thoughtful judgment. It was Aristotle's contribution to offer a very different view of emotion, so that emotional appeal would no longer be viewed as an extrarational enchantment. Once Aristotle focused on the cognitive side of emotional response and made clear that an emotion can be altered by argument because beliefs can be altered in this way, it was possible to adopt a positive attitude toward emotional appeal. (18)

Before speaking to this quote, I want to add one more by Fortenbaugh, in which he comments upon Aristotle's attention to the body, particular that of audiences of tragedy. "Aristotle adopted an inclusive view of emotional response. He recognized both its cognitive and its bodily aspects," Fortenbaugh writes (21). These are important considerations in a history of rhetorics of empathy because so much of our current 
understanding of empathy includes the physical and bodily experiences of emotions and the perception of the emotional and bodily states of others. Aristotle had already identified those qualities as key components of a rhetorical theory of emotion. He also provided a foundation, as seen in the longer quote above, that related emotional persuasion to cognition, a modern corrective to the still persistent idea that emotional appeals are somehow debased. These historical arguments for a positive attitude toward emotional appeals and for combining the emotional, the physical, and the cognitiverational are especially important to empathy because one of its hallmarks within emotion is its combination of these qualities. Furthermore, to recognize that emotions can be altered by argument, as Aristotle does, is to recognize that emotions are socially constituted. This is similar to the understanding of emotions offered by Gross, Massumi, and others who locate emotions not in the merely personal but in social relations, interpretations, possibilities, and emotional economies.

The place where Aristotle comes closest to addressing empathy is in his consideration of pity. Walton notes that Aristotle's concept of pity "is based on a mental attitude related closely to empathy, because it requires that the pitying party be able to see himself (or one of his friends) in the same kind of distressing situation as the pitied party" (51). Indeed, many of the elements and conditions of empathy are evident in Aristotle's treatment of pity. The bulk of that treatment is found in his Rhetoric, where Aristotle defines pity as "a feeling of pain at an apparent evil, destructive or painful, which befalls one who does not deserve it, and which we might expect to befall ourselves or some friend of ours, and moreover to befall us soon" (69). Like empathy, then, pity requires that we see some continuity or shared possibility in our situations and emotional 
experiences and those of others. As Aristotle adds, "Generally, we feel pity whenever we are in the condition of remembering that similar misfortunes have happened to us or ours, or expecting them to happen in future" (70). Pity is also defined by social position, as Gross would note, because pity is felt for one who does not deserve what has befallen him. If one's social position is such that one is determined to deserve an otherwise pitiful fate, then pity may be withheld. Who is entitled to pity and who is not is a social question. Unlike empathy, pity is concerned exclusively with suffering and whether it is deserved. Aristotle goes on to outline the rhetorical conditions which are most conducive to feeling pity. The first is that we are like those whom we pity, which is Aristotle's way of recognizing what Hoffman calls the familiarity bias in empathy. In Aristotle's words, "The people we pity are: those whom we know, if only they are not very closely related to us-in that case we feel about them as if we were in danger ourselves... Also we pity those who are like us in age, character, disposition, social standing, or birth; for in all these cases it appears more likely that the same misfortune may befall us also" (70).

Aristotle continues to outline the rhetorical conditions of pity by emphasizing the importance of personal narratives and details, the sight of bodies and evidence of suffering, and a general proximity to the event and the sufferer in eliciting pity. He writes that

those who heighten the effect of their words with suitable gestures, tones, appearance, and dramatic action generally, are especially successful in exciting pity: they thus put the disasters before our eyes, and make them seem close to us, just coming or just past... so too therefore are the signs of suffering - the garments and the like of those who have already suffered; the words and the like of those actually suffering - of those, for instance, who are on the point of death. For all this, because it seems close, tends to produce pity. (Rhetoric 70-71) 
There is a direct correlation here with rhetorics of empathy and the ways in which they also depend upon perception of the physical and emotional, the use of personal narratives and details, and proximity both in terms of location (or sight) and in terms of relation or significance. This is not to say, however, that Aristotle's idea of pity and a contemporary understanding of empathy are largely equivalent. Empathy has a more significant cognitive component and is not restricted to emotions of suffering and sorrow in the way that pity is because if defined as sharing another's emotional or affective state, empathy can include joy or ennui as well as sorrow. Aristotle's pity is closer to what we would call compassion as a way of feeling for somebody. Empathy may be a component of compassion, but compassion, like sympathy, requires a different commitment on the part of the one who feels compassion and a different position on the part of one who receives another's compassion. Plus, in our contemporary use of the term, pity has troubling connotations of condescension and privilege, power and meekness, reflecting differences in social status that nonetheless are still at work. Many of these troubling questions are shared with empathy - and are part of what makes empathy such a useful lens of investigation—but without the more negative inheritance of pity.

Regarding empathy as a form of moral judgment, Aristotle's concept of morality centers upon a virtuous mean that requires more than simply rational thought. In The Nicomachean Ethics Aristotle argues that rationality is part but not the entirety of moral judgment when he writes, "But up to what point and to what extent a man must deviate before he becomes blameworthy it is not easy to determine by reasoning, any more than anything else that is perceived by the senses; such things depend on particular facts, and the decision rests with perception" (47). Nancy Nyquist Potter notes that for Aristotle, 
morality involves having the right feelings in concert with the right judgments, leading to an understanding of empathy as combining both ("Can Sex Offenders Learn" 61). This is related to Aristotle's idea of the virtuous mean, which includes a consideration of the passions as well as of rationality and actions. In Aristotle's terms, "Now virtue is concerned with passions and actions, in which excess is a form of failure, and so is defect, while the intermediate is praised and is a form of success; and being praised and being successful are both characteristics of virtue. Therefore virtue is a kind of mean, since, as we have seen, it aims at what is intermediate" (38). Potter further builds upon Nussbaum's work to argue for an interpretation of Aristotle's concept of suggnome (judging with) as meaning "to perceive particulars and make judgments accurately, we must see things from the other's point of view, for only then will be begin to comprehend what obstacles that person faces" ("Moral Tourists" 212). This relationship between perception and morality, and emotions and reasoning, as each of the two interact and inform and support one another, has been picked up many moral philosophers who argue against a supposed supremacy of rationality. Philosophers such as Nussbaum and Slote attempt to situate an ethics of care and empathy at the center of ethical philosophy. Similarly, Vetlesen correlates reason and emotion to respect and concern. He argues for a reconsideration of the relation between the two in order to challenge the usual hierarchy of reason over emotion. In Vetlesen's description of his project:

Thus, a central aim is to question the assumption of inferior status assigned to human emotional capacities in this hierarchy. We need to investigate whether the mutual inclusion seen to obtain in the relation between respect and concern does so in the case of reason and emotion as well. Specifically, we need to ascertain whether a balance between our cognitive powers and our emotional powers is required for moral performances to be successful. I speak, therefore, of the interplay I see between the faculties of reason and of emotion in moral performance. (3) 
Vetlesen may be read here as echoing some of the same concerns as Micciche, Fortenbaugh, and Walton in asking for renewed attention to the role of emotions. In terms of the history of rhetorics of empathy, Vetlesen can also be read as making a move similar to that of Aristotle in arguing for the interplay of emotions, reason, and morality. For Vetlesen, neither the cognitive nor the emotional alone provide for successful moral performances. They do so only through their working together, as moral principles and affective charges likewise contribute to prosocial actions in Hoffman's formulation. Empathy is intertwined with ideas of benevolence and pity as philosophy merges with theology in the middle ages. These ideas differ from empathy in empathy's attention to identification and the experience of emotions with rather than for another. Not until the Scottish Enlightenment do we approach something closer to our current understanding of empathy. There still was no word for empathy at the time, so we instead turn to considerations of sympathy. David Hume may be most famous for his theoretical development of sympathy. In defining sympathy, Hume writes, "No quality of human nature is more remarkable, both in itself and in its consequences, than that propensity we have to sympathize with others, and to receive by communication their inclinations and sentiments, however different from, or even contrary to our own" (316). Hume posits that sympathy is responsible for holding society together and for establishing national character. In this way his characterization of sympathy is similar to Hoffman's description of empathy as "the glue that makes social life possible" (3). As with Aristotle's definition of pity and contemporary theories of empathy, Hume's concept of sympathy depends upon some shared likeness of human experiences. Hume adds the importance of a shared likeness in appearance and ways of thinking: 
Now 'tis obvious, that nature has preserved a great resemblance among all human creatures, and that we never remark any passion or principle in others, of which, in some degree or other, we may not find a parallel in ourselves. The case is the same with the fabric of the mind, as with that of the body. (318)

Within this comment on resemblance is an emphasis on the importance of physical appearance and the foundation of a theory of mind that allows us to attempt to enter the perspectives of others. Both of these remain critical to modern theories of empathy. Furthermore, Hume realizes that the role of resemblance contributes to a familiarity bias when he writes:

Accordingly we find, that where, beside the general resemblance of our natures, there is any peculiar similarity in our manners, or character, or country, or language, it facilitates the sympathy. The stronger the relation is betwixt ourselves and any object, the more easily does the imagination make the transition... (318)

Hume's sympathy is a function of the imagination, and the greater the resemblance of one's nature with that of another, the easier the work of the imagination. In these ways Hume's concept of sympathy is a prominent forerunner to modern theories of empathy.

Hume's concept of sympathy is distinguished by his attention to its role in transmitting emotion. Here he differs with modern theories of empathy that, while recognizing an affective role in empathy, do not view empathy as a means of emotional transmission so much as one of understanding and moral judgment. As Hume describes the process of transmission,

When any affection is infused by sympathy, it is at first known only by its effects, and by those external signs in the countenance and conversation, which convey an idea of it. This idea is presently converted into an impression, and acquires such a degree of force and vivacity, as to become the very passion itself, and produce an equal emotion, as any original affection. (317) 
Hume's understanding of sympathy here is as a socially transmitted and experienced emotion, which is important for rhetorical considerations of empathy as operating socially and politically. As Gross writes, "Sympathy, for Hume, is less a matter of inborn humanity than relative proximity: sentiments are communicated by way of perceived contiguity-who is in and who is out" (126). The key in the above passage by Hume is that the idea becomes itself the very same passion, which is taking the idea of sympathy further than that of empathy as we understand it. There is the pairing of idea and passion within empathy, but not so that the very passion of another is duplicated. This speaks to Hume's notion of the role of sympathy relevant the emotions. Important to Hume's concept of sympathy is his argument that sympathy itself is not an emotion but a means of understanding the emotions of others. As Bernard Wand summarizes Hume's position, “sympathy itself is not a passion. It is merely the conversion of an idea of another's passion into the passion itself" (276). Wand adds, "It is merely through the mechanism of sympathy that we are enabled to experience the passions of others. Sympathy has no content of its own" (276). Sympathy is thus a social mechanism. This definition of sympathy echoes modern definitions of empathy, such as those offered by Nussbaum and Hoffman, that define empathy itself as emotionally neutral, as itself a mechanism. Also important to note, as Wand does, is Hume's position that "sympathy with the feelings of others evokes our moral sentiments" (279). Or, as Gross states it, "As opposed to those myriad philosophers who derive moral principles from reason, God-given or natural, Hume derives moral principles from passion" (130). For Hume, reason is a slave to the passions and is insufficient to move people to action. And sympathy is a means of 
accessing moral considerations, much as Vetlesen argues that empathy allows us access to the human reality and thereby the moral concerns in a situation.

Hume's fellow philosopher George Campbell continues to take sympathy and compassion in a rhetorical direction in his Philosophy of Rhetoric. In what Don Burks considers the most significant passage in the work, Campbell writes, "Consider seriously, and you will find that it is not in the smallest degree more manifest, that another and not ourselves is the object of our resentment when we are angry, than it is that another and not ourselves is the object of our compassion when we are moved with pity" (qtd. in Burks 15). Burks deems this passage significant because in it Campbell is moving away from a dominant egoistic philosophy to one more other-directed. This is a philosophy that also views the emotions more socially since they are only experienced in relation to others. Earlier definitions of sympathy and compassion required that the observer see herself as potentially in the same position as the sufferer. This is a social and imaginative quality of empathy that remains, and I think rightly so. We have to assume some overlap between another's feelings and the potential for our own if we are to understand those feelings. In Campbell's formulation, our sympathy is not directed at ourselves as imagined in another's situation, what Hoffman terms "self-focused role-taking" (54). Instead we are moved by imagining the situation of the other in Hoffman's "otherfocused role-taking." Here part of what Campbell is doing is beginning to describe the differences in self- and other-directed sympathy, although he does not describe it directly along those lines. Campbell also acknowledges the important role that sympathy and compassion play in persuasion. As Burks summarizes, "Campbell insists there can be no persuasion without appeal to the passions because knowledge of a fact does not move us 
unless there is a feeling response to it" (16). He quotes Campbell in writing that sympathy "is that quality of the soul which renders it susceptible of almost any passion, by communication from the bosom of another" and "sympathy is one main engine by which the orator operates on the passions" (16). Here sympathy is not just a rhetorical strategy but a rhetorical necessity as reason alone is insufficient for persuasion, much as it is in Hume's philosophy. The understanding of sympathy and compassion developed by Hume and Campbell—-that sympathy is a means of understanding, transmitting, and feeling another's emotions; that sympathy is emotionally neutral; that sympathy depends upon proximity and likeness and human similarities within social conditions; that sympathy may be self- and other-focused; and that sympathy is a vital rhetorical forceprovides a foundation for a theory of rhetorics of empathy, even though "empathy" was not yet in the lexicon.

Empathy goes on to become a core concept in rhetorical theory. Dennis Lynch writes that "Empathy used to be at the center, at the heart, of rhetorical studies" (5). As outlined by Lynch, empathy has been widely interpreted as a tool of invention, as a type of rhetorical appeal, and as a necessary condition in the very context of argument. He notes that Perelman and Olbrechts-Tyteca incorporate ideas of empathy in their revisionist reading of classical rhetoric through their idea of the "framework of the argument," in which empathy is a necessary condition for persuasion to take place. Empathy is not a significant part of their framework, but Perelman and Olbrechts-Tyteca do align their rhetoric with psychology and speak of the necessity of accounting for "psychological and social conditions in the absence of which argumentation would be pointless and without result" (14). This form of rhetorical empathy is more about 
empathizing as a means of audience awareness rather than as a rhetorical strategy of targeting or employing persuasive empathy, but it does ask for an accounting of the psychological and social conditions that inform positions and experiences of empathy. More importantly, like Micciche and others, Perelman and Olbrechts-Tyteca propose their new rhetoric as a corrective to the supremacy of Cartesian logic. They argue against the dichotomy of rational and irrational arguments, labeling such divisions of human faculties "completely artificial and contrary to the real processes of our thought" (3). Perelman and Olbrechts-Tyteca reference empathy's original terminology in German when they write of "suprarational sources of certitude such as the heart, grace, 'Einfuehlung,' or Bergsonian intuition" (3). We can read empathy—or "Einfuehlung"here as a means of understanding that is not counter to rationality but also not directly answerable to it and indeed perhaps preceding and informing it. In focusing upon the role of psychology in rhetoric and on the importance of rhetorical and social factors not defined by the limits of rationality, Perelman and Olbrechts-Tyteca move rhetorical theory in a direction more amenable to theories of rhetorics of empathy.

Burke likewise contributes to a reevaluation of the rhetorical work of empathy through his theory of identification, which may be understood as a psychological element of empathy. Burke's concept of identification resembles empathy in its attention to persuasion acting not only through logic but through the sense that the speaker identifies with the audience and the audience with the speaker. For Burke, this process of identification is not so much a single rhetorical event but more often the product of what he calls "a general body of identifications that owe their convincingness much more to trivial repetition and dull daily reinforcement than to exceptional rhetorical skill" (24). 
Burke develops identification through a tradition of Aristotelian rhetoric and famously places identification at the very core of persuasion, writing, "You persuade a man only insofar as you can talk his language by speech, gesture, tonality, order, image, attitude, idea, identifying your ways with his" (55). Perhaps Burke's most useful contribution through identification—especially in terms of empathy and difference-is his attention to the necessity of difference in order for identification or any act of communication to take place. As Burke writes, and as I argued earlier in connection with Nussbaum, "For one need not scrutinize the concept of 'identification' very sharply to see, implied in it at every turn, its ironic counterpart: division. Rhetoric is concerned with the state of Babel after the Fall" (23). Burke's insight here is that identification is only possible if there is some difference beyond which one might identify, some division that gives cause for seeking in rhetoric some similarities and understanding with difference. The same applies in empathy, as there is no need or possibility for empathy if there are not also differences for one to empathize across and a different individual to empathize with. Even selfempathy cannot be immediate but requires some difference in selves across time or space or temperament. This is not to say that Burke's idea of identification is equivalent to empathy. Burke's identification is limited as he is more concerned with the political and imaginative possibilities of identification and does not account for the role of emotions and the possibilities of altruistic action, which are central qualities to a rhetorical concept of empathy. I further consider Burke's identification in terms of empathy in the next chapter, when I focus on the political work of rhetorics of empathy within the speeches of Barack Obama, and in the final chapter where I address the limitations and paradoxes of rhetorics of empathy. 
Empathy is also evident in rhetorical conceptions of dialogue. The two standout figures here are Rogers and Martin Buber. Although they have slightly different takes on the idea, both reference empathy in their dialogic theories. In comparing Rogers and Buber, Ronald Arnett attends to the distinctions between their understandings of dialogue and their relationships to empathy. Arnett argues that while Rogers is more concerned with subjective experience-as one attempts an understanding of another's subjective experience-Buber was more interested in the objective and the nature of the dialogue itself, including the spaces between the interlocutors. As Arnett summarizes the differences between Buber and Rogers,

Buber rejects empathy, because he fears one giving up identity to make contact with another. I am aware that Rogers qualifies his understanding of empathy with the "as if" assumption, one attempts to understand another's world "as if" it were one's own... Indeed, Rogers' view of empathy may be the closest psychological discussion akin to Buber's viewpoint. But...the concepts are separate and distinct. (368)

Rogers further places a rhetoric of empathy at the center of his communication theory. He argues for it in contrast to a traditional notion of rhetoric as adversarial. Rogers find the major barrier to communication to be "this tendency to react to any emotionally meaningful statement by forming an evaluation of it from our own point of view" ("Communication" 315). Without using the word "empathy" here, he proposes a communication strategy that nonetheless is very much grounded in empathy:

Real communication occurs, and this evaluative tendency is avoided, when we listen with understanding. What does that mean? It means to see the expressed idea and attitude from the other person's point of view, to sense how it feels to him, to achieve his frame of reference in regard to the thing he is talking about. ("Communication" 315 , emphasis original)

Rogers's work on empathy is based upon the relationship between therapist and client in a clinical context. The importance of the therapeutic context remains central to Rogers's 
understanding of empathy. In an interview with Nathaniel Teich, Rogers rejects

definitions of empathy as rhetorical as well as the rhetorical use of empathy, saying,

I regard (the use of Rogerian principles for argumentation) as quite the opposite of my thinking. And I also regard it as a perversion of my thinking. My belief is that, by extending sensitive empathy to another person, it enables him or her to come forth and gain a better understanding of himself and what direction he's going. (55)

It is important when considering Rogers's ideas of empathy to do so in light of their intended use, in this case to aid a client in achieving self-understanding and change through therapy. Rogers's definition of empathy is centered much more on listening and understanding. It is not about persuasion but about the possibility for change in interpersonal relationships. Empathy, for Rogers, is a means of understanding not only cognitively but also emotionally by adapting to oneself another's frame of reference. In the same interview he says, "Significant empathy, I think, has more to do with feelings, not so much with intellectual contents. A lot of intellectual ideas are held with passion, and that passion needs to be understood" (59). Like Hume and Campbell, Rogers here is suggesting that passion at the least influences reason. He distinguishes understanding from identification by emphasizing the as if distance that is always included in empathic understanding. Rogers's use of identification in this instance is more in concert with psychological ideas of identification than rhetorical ones, such as those developed by Burke.

Although Rogers is not directly concerned with the rhetorical use of empathy outside of the therapeutic context - and even rejects the role of empathy in the employ of argumentation - he does offer much of use in defining rhetorics of empathy and their potential. Rogers focuses on empathy as an emotional perspective, as a means of 
understanding, and as potentially transformative in how it can change people and their interpersonal relationships. He understands empathy to be a powerful position of listening. My use of empathy as a rhetorical term differs from Rogers in that, like other rhetoricians, I see empathy as having persuasive applications beyond interpersonal relationships and attempts at understanding, as important as those are. I also define empathy as including cognitive as well as emotional components-indeed, I think it difficult to divide the two-while Rogers is more concerned with the emotional qualities, perhaps in effort to push against dominant rational values. I prefer to look at how empathy functions in social and political contexts, as that is where I see it holding the greatest rhetorical significance. I also think that Rogers, in his focus on the therapeutic, undervalues the role of empathy as a means of analysis towards decisions and actions, particularly as it informs moral judgments and the ways that we read others. I further consider such a function of rhetorics of empathy, especially how the conditions of empathy are subject to debate, in the third chapter where I examine a series of newspaper articles written from the perspective of a man on the verge of homelessness.

Rogers's influence and his attention to empathy have had a significant influence in more current rhetorical theory, even though Rogers did not view his theories as having such purchase. Peter Elbow, for example, offers his believing game as a positive alternative to the traditional doubting game, much as Rogers offers his communicative theory as an alternative to a rhetoric of argumentation through criticism and competition. Elbow has come to see the believing game as the core of his work. He describes it as the disciplined practice of trying to be as welcoming or accepting as possible to every idea we encounter: not just listening to views different from our own and holding back from arguing with them; not just trying to 
restate them without bias; but actually trying to believe them. We are using believing as a tool to scrutinize and test. (1)

Elbow's believing game differs from Rogerian rhetoric in important ways-the reference to "not just trying to restate them without bias" is one of those-but more importantly it includes a rhetoric of empathy. The move to not only understand other points of view but to try to believe them is at heart an exercise in empathy; it is an attempt to enter as fully as possible into another's perspective and even another's experience of holding that perspective. Elbow recognizes that such a move has cognitive, phenomenological, emotional, and physical qualities. He advises that one "eat like an owl: take in everything and trust your innards to digest what's useful and discard what's not" (1). Although a metaphor, the idea to "trust your innards" is a nod to ways thinking beyond the purely cognitive to include the emotional and physiological. This is not to reduce Elbow's method to purely trusting your gut. Elbow stresses the methodical nature of the believing game as a form of critical inquiry into the value of ideas, all of which is based upon a clear move toward a rhetoric of empathy. Similar moves to rhetorics of empathy may be read in Krista Ratcliffe's idea of "rhetorical listening" and Wayne Booth's advisement that we try to "dwell" in an idea before determining whether to accept or reject it, an idea that influences Elbow's believing game. I further consider Ratcliffe's "rhetorical listening" in relationship to Elbow and Rogers in the fourth chapter when I propose a pedagogy of empathy as rhetoric.

I could continue to trace rhetorics of empathy throughout the rhetorical tradition, but I think some of the most vital lineages have been outlined. Beginning with Aristotle and continuing through Hume and Campbell, and later Burke and Rogers and Elbow, we see a history of the rhetorical importance of empathy. It is used as a way of expanding 
notions of belief, as a more holistic way of thinking about emotions in connection with cognition and the body and morality, and as an alternative means of communication and evaluation beyond the standard argumentative critique. Most of the rhetorical history of rhetorics of empathy does not deal with empathy directly but through related ideas, such as sympathy and identification. This is due in part to empathy's rather recent arrival as an identified concept. Much of the rhetorical history also fails to take sustained account of how empathy has been theorized in disciplines outside of rhetoric. Some of the most interesting work in these fields—particularly psychology and philosophy—has been recent. Indeed, empathy itself is a recent enough term that its implications for rhetoric have not been fully investigated. The definition of rhetorics of empathy that I propose here considers empathy's rhetorical as well as psychological and philosophical values. As to the focus of this project, I understand empathy's rhetorical use principally to be in how it is used socially and politically, and in what it allows us to achieve as we read and write one another and conduct analysis within and beyond the writing classroom.

\section{Rhetorics of Empathy within Writing Studies}

As empathy has garnered greater attention, so too has it attracted increased scrutiny and criticism. Criticism of empathy within literary and writing studies is not yet common but is important and adds much to our understanding to the term and its place within the discipline. This criticism usually takes the form of a guarded caution or critique, such as proposed by Shuman and Lynch. As Lynch notes, postmodern critiques of empathy in moral principle have led to a discrediting of empathy as a rhetorical concept. Theresa Kulbaga, for example, cautions against a full embrace of empathy as a 
rhetorical force for social good. In her analysis of the rhetoric of empathy in Azar Nafisi's memoir Reading Lolita in Tehran, Kulbaga writes that empathy fits a "neoliberal feminist rhetoric of freedom and choice" that champions American ideals, ignores important cultural distinctions and social constructions, and otherwise uses empathy as a political sales pitch (516). Kulbaga's critique serves as an example of one of the disciplinary rifts in studies of empathy, as outlined by Keen. Psychologists tend to subscribe to an idea of some foundational universality to human emotions, while scholars in other disciplines understand emotions as not only culturally interpreted and expressed but as thoroughly constructed by culture and social conditions (Empathy and the Novel 114). This division is echoed in the historical disciplinary split in composition and rhetoric between expressivist theories and social constructivism. Studies considering emotion, such as empathy, may offer one way to help mediate such divisions to the degree that such studies force a consideration of the relationship between the personal and the social, the cognitive and the affective. Even so, there are important and valid concerns on the limitations and uses of empathy, such as ideas of false and failed empathy and a proper and necessary recognition of difference and power relations. As a rhetorical effect and strategy, empathy should not be assumed to contribute automatically to the social good.

One way through differing opinions on empathy is to follow the lead those who argue for the value of critical empathy. Lynch, for example, concludes that empathy is too weak to be the foundation of rhetoric but is useful for foregrounding its own limitations and obstacles for understanding because "it is precisely through the obstacles that we learn how to better use the tools we presently have for understanding one 
another" (20). Lynch's proposition is similar to ideas of "critical compassion" (Matthew Newcomb), "critical affirmation" (Cornel West, addressed in Min-Zhan Lu), "critical empathy" (Todd DeStigter), and a "critique of empathy" (Shuman) for using rhetorics of empathy both as a means to approach understanding and as a means to continually question the assumptions and uses of that approach to understanding. A critique of empathy, Shuman argues, shifts attention to the tensions of the personal and the social, between the empathizer and the empathized. These are questions of understanding and ethics. As Shuman writes, "Storytelling needs a critique of empathy to remain a process of negotiating, rather than defending, meaning" (5). Shuman proposes a critique of empathy allows opportunities for asking some of the questions that get to the heart of how we understand—or empathize—with one another in our ways of reading and writing one another. A critique of empathy is a move to keep open and in the foreground questions about power and responsibilities and negotiated meaning. A critique of empathy reminds us that empathy is always empathy in / with / across / and among differences. I further argue in the last chapter for the usefulness and necessity of a critical empathy.

The questions highlighted by rhetorics of empathy are questions that we already should be asking ourselves in rhetorical and pedagogical contexts. Kristie Fleckenstein, for example, argues that "the experience of sharing another's suffering is essential to deliberative discourse, to negotiation, and to persuasion in the public sphere" (714). Fleckenstein extends empathy to the wider public sphere and to include movements toward social justice. Her attention to suffering aligns empathy more with a somewhat restricted idea of compassion or sympathy. Still, such an idea of empathy is based in part 
upon the empathy-altruism hypothesis in the idea that empathy is one way people are moved to pursue social justice agendas, signaling empathy's importance both as an instrument of motivation and as a rhetorical and political strategy. Those suggesting a critique of empathy_or, in Fleckenstein's case, that empathy be reconceived as a significant player in the public sphere-are arguing for greater disciplinary attention to empathy. This attention to rhetorics of empathy may be understood as part of larger shifts within the field of rhetoric and composition, particularly the so-called "affective turn" and reconsideration of the personal. Micciche lists four factors that prompt greater disciplinary attention to emotion: [1] "the absorption of feminist thinking into mainstream composition discourse," [2] "the effects of rereading classical rhetoric in pursuit of revisionary histories and renewed understandings of rhetorical concepts," [3] "the continued influence of interdisciplinary scholarship in composition studies," and [4] "the increasing presence of bodies in composition scholarship" (Doing Emotion 17). She mentions empathy as one way for people to begin blurring the reason-emotion binary when she writes, "Surely we can show emotion, perhaps especially empathy, while 'reasonably' weighing competing ideas in search of a solution" (3-4). Micciche does not herself, however, continue to explore the particular relevance of empathy as part of an affective turn.

What Micciche does do is provide a useful example of how to consider emotion within writing studies, a mode of analysis readily extended to rhetorics of empathy. Her project is similar to that of Gross, who writes of rhetorical studies of emotion, "As opposed to the philosophy that posits language as a mirror of nature, rhetoric is an inventive attitude toward language and the world, where 'emotion' names one important 
way in which language and the world connect" (15). Rhetoric is thus concerned with the social constitution and work of emotion. Similarly, Micciche describes the important distinction between "the study of emoting, or the expression of feeling, and that of rhetorics of emotion, or emotion as a performative that produces effects" (Doing Emotion 1). The same distinction can be made between the study of empathizing and the study of rhetorics of empathy as producing effects within social circumstances. These lines are not always so well defined-as displays of empathizing can themselves be used for rhetorical effect as ethos-but in general I am not so interested in empathy as an emotion but in empathy as instrument and target of rhetorical affects and strategies, as possible moves to actions, beliefs, and identification among writer and reader and world. Often the consideration of rhetorics of empathy is a consideration of discourse about empathy. One example of such an analysis is Kathleen Woodward's excellent essay on compassionate conservatism in which empathy is treated as a topic of discourse rather than as a means and strategy of discourse. Rhetorics of empathy may be distinguished from other emotional appeals by those moves to identification and moral judgment through attention to the human dimension of a situation. Rhetorics of empathy may include a demonstration of empathy as a form of ethos. Rhetorics of empathy can be false and may allow one to feign that such an empathic move has taken place. Micciche writes that "to speak of emotion as performative is to foreground the idea that emotions are enacted and embodied in the social world. It is also to posit emotions as between people and between people and things" (1-2). The value of such a position for this study of rhetorics of empathy is that it allows a rhetorical consideration of empathy as interactional, as 
historical, and as existing in the social world and in the relationships between people, circumstances, communities, and mediums.

Finally, then, we arrive at an adequate point to define rhetorics of empathy. What exactly are rhetorics of empathy? As earlier stated, rhetorics of empathy comprise a mode of argument notable for simultaneously combining the cognitive and the affective in targeting our perspective-taking faculties and moral judgments. They include attempts to move ourselves and others toward altruistic action based upon empathic identifications worked through discourse and writing. Rhetorics of empathy may be false as well as feigned as a means of getting others to identify empathically or as a strategy of displaying oneself to be empathically engaged. They are based in part upon rhetorical concepts of pity, sympathy, and compassion, but go further than those in acknowledging a cognitive component and in going beyond feelings of suffering and the resultant commitment to redress. Rhetorics of empathy are empowered and simultaneously limited by their dependence upon personal details, proximity, and likeness. Some level of common humanity is assumed within rhetorics of empathy, just as there is need for some shared humanity, or self-other overlap, within empathy itself. But rhetorics of empathy also depend upon recognition of the differences between individuals. To omit that recognition is to turn empathy into simply self-identification, akin to narcissism, as one assumes the perspectives of others are essentially the same as those one imagines for oneself. Rhetorics of empathy are determined in part by the social positions of those who would empathize, those who would be empathized with, and those who would speak and help define the terms of the relationships. While not themselves loaded with emotional 
content, rhetorics of empathy are a means of targeting and engaging the emotions. Within rhetoric and composition, rhetorics of empathy may be considered part of the discipline's larger "affective turn" as we turn again to what Aristotle noted so long ago, that affect is as much a part of rhetoric as is logic. Perhaps most importantly for those who inherently value empathy, rhetorics of empathy are also a way to put people and the lived daily experiences and emotions of people back in the center of rhetoric and education. To echo Nussbaum, although empathy itself may be mostly value-neutral, there is undeniable value in the work of empathy, including the reading and writing and teaching of it. This is part of what Rogers so appreciates about the transformative potential of empathic listening. To acknowledge another person's distinct emotions and experiences is acknowledge another person's humanity. 


\section{CHAPTER II}

\section{EMPATHY AS THEME AND RHETORICAL MEANS IN THE SPEECHES OF BARACK OBAMA}

The concept and contested meaning of empathy captured headlines in the summer of 2009 when Barack Obama said he would seek to appoint to the Supreme Court a justice with empathy. "I view that quality of empathy, of understanding and identifying with people's hopes and struggles, as an essential ingredient for arriving at just decisions and outcomes," he said at a White House press briefing ("Press Briefing"). While many left-leaning observers interpreted empathy as a way of acknowledging one's own prejudices in attempting to see issues from another's perspective, those on the right ridiculed the term as soft and as a form of bias. "Crazy nonsense empathetic! I'll give you empathy. Empathize right on your behind!" Michael Steele, then the chairman of the Republican National Committee, said on the Morning in America radio show (qtd. in Lithwick). Obama was introducing a legal and ethical idea of empathy into a political context, a move that demonstrated empathy's political significance, both as concept and as a means of judgment.

This was not the first time that Obama had emphasized empathy in civic life.

Empathy is a longstanding concern in his writing and speeches, as he has cited empathy as a principle component of his personal and political philosophies. The speeches of 
Obama offer a valuable opportunity to see how rhetorics of empathy are performed in a political context and broadcast on a national level. In this chapter I focus upon Obama's speeches in order to better understand the work of rhetorics of empathy at those national and political levels. I first attend to empathy as a theme, focusing on portions of Obama's book The Audacity of Hope and his speech "The Great Need of the Hour," delivered at the Ebenezer Baptist Church in Atlanta. Obama identifies empathy both as a guiding principle and as a means to social action. Furthermore, he performs as an empathizer, which is critical for establishing his ethos and identity as one who understands and is able to be understood by multiracial America. I then focus upon Obama's speeches in his push for healthcare reform in order to demonstrate how Obama employs personal stories, most notably that of Natoma Canfield, in an effort to use allegory and empathy to make real and morally significant the human dimension of a political issue. I finally turn to Obama's much praised speech on race, "A More Perfect Union," to consider the ways in which he offers his own story and identity as examples and sites of empathy. I end with some thoughts on the limits and criticisms of rhetorics of empathy—taking "I feel your pain" as a site of departure—as being merely performance and as a way to avoid responsibility for political positions and policies, because rhetorics of empathy create expectations of commitment and authenticity that can be difficult to maintain.

Throughout this analysis I pay attention to how rhetorics of empathy help us understand the political rhetoric of Obama, as well as how Obama's speeches add to an understanding of rhetorics of empathy as political theme and means. As George Lakoff has argued, much of contemporary political discourse centers upon emotional response, identification, and moral judgments. Rhetorics of empathy provide valuable insight into 
that process through the ways in which empathy combines those same qualities of emotion, identification, and moral judgment in leading to persuasion. In return, by analyzing rhetorics of empathy at the national and political levels, we are able to witness how they operate in attempting to reach the widest possible audience. This is a rhetorical strategy akin to what Keen defines in a literary context as "broadcast strategic empathy." The rhetorical work of empathy is important here because instead of trying to move his audience to empathize with him-a rhetorical strategy which is the focus of the next chapter-Obama is attempting to perform empathy and to promote empathy. He is, in other words, attempting to showcase himself as an empathizer and to use empathy in service to his electoral and political agendas.

\section{Empathizer in Chief}

Two goals are immediately apparent in Obama's reliance of empathy as a theme. The first is to promote empathy as a cultural value, and the second is to perform the value that he is promoting so that he may be seen as a great empathizer. These goals support one another because a greater cultural and political valuation of empathy contributes to greater estimation of a politician who is seen as an empathizer. And the successful performance of empathy by a popular politician adds to the cultural appreciation of the concept as holding political and social relevance, because empathy is en vogue and is rarely argued against--Steele's criticism withstanding — as a cultural value. Both of these goals are evident in the writing and speeches of Obama.

He is not the first politician to promote himself through empathy. Much of politics is about likability and one's ability to relate to general population and, conversely, the 
ability of the general population to relate to the politician. An entire chapter or book could be dedicated to the efforts of politicians to say "I am like you" and "I understand you," which are ways of saying "I empathize." Franklin Delano Roosevelt had his fireside chats so that he might appear the congenial uncle. Jimmy Carter wore his sweaters. Presidential candidates have campaigned on their personal stories, especially those that highlighted their ordinary roots and, by extension, their ability to empathize with people. So we have Carter the peanut farmer and Bill Clinton's modest upbringing in Arkansas. The classic example of political rhetorics of empathy is Bill Clinton's 1992 campaign remark, "I feel your pain." Writing for Slate, John Dickerson calls this the "empathy tactic." He traces the phrase back to Jimmy Carter, who in his 1976 campaign promised to be "a president who's not isolated from the people, but who feels your pain" (qtd. in Dickerson). I will return to Clinton later. More recent examples include John Edwards's story of being the son of a millworker and, of course, Obama's story of being raised by a single mother and his grandparents. Empathy also explains the success and popularity of George W. Bush, the candidate whom many voters said they would most like to have a beer with, and Sarah Palin, who appeals to a segment of mainstream America because they see themselves and their lives and values reflected in her, expecting that she sees the same. Part of this empathic appeal corresponds to an animosity against perceived elites. That is why significant blows to the Edwards and Palin candidacies, to cite but two examples, were the revelations of expensive haircuts and wardrobe budgets, respectively. Yes, these revelations may have reflected upon their judgments and senses of value. More significantly, however, they undercut empathy through personal identification. 
Woodward describes what she calls "the presidential politics of empathy" (109). Woodward is referring not just to the idea of empathy but also the need for a politician to appear as one who empathizes with the situations of others, not limited to those who can write large campaign donations. Such a performance of empathy is part of a rhetorical strategy of ethos, which Risa Applegarth reminds us is always dependent upon social constraints and social status and is a question of audience perception more than a speaker's demonstration of inherent personal qualities (48). Woodward references in particular the campaigns of Clinton and George W. Bush with his "politically astute appropriation of the discourse of compassion" and his promotion of "compassionate conservatism" (110). Were she not writing before Obama's presidential run she surely would have referenced him as well. "We're living in a cultural moment in which a new economy of the emotions is emerging," Woodward adds (110). This is a political economy that is exemplified in part by "the emergence of the sensitive man, the development of the man of feeling. His emotional portfolio includes sympathy, a sentiment that is becoming a new form of emotional correctness in the political sphere" (110). The pushback against Obama's empathy criteria for justices signals some resistance to the acceptance of empathy and compassion as important stated political values, at least among political opponents. To be against compassion or empathy is supposed to read as though one is clear-minded, unsentimental, and serious. However, the trend in valuing politicians based upon their ability to empathize and relate to the general public —as witnessed in the discussion of who best to have a beer with, and the derision at Obama's public bowling performance-demonstrate the enduring importance of political empathy. In these ways politicians are valued not so much for their technical 
knowledge or diplomatic capabilities so much as their ability to relate to or empathize with an average citizen. Nussbaum moves beyond the "beer test" in her argument for the importance of empathy in political leaders: "We should demand political leaders who display the abilities involved in compassion, who show not just mastery of pertinent facts about their society and its history, but also the ability to take on in imagination the lives of the various diverse groups whom they propose to lead" ("Compassion" 51). This places a premium upon empathy if not as a political value to be upheld then at least as a character trait of politicians. The politician best able to perform as an empathizer is one best able to capitalize on the critical and public desire that our political leaders be empathic. Obama follows this pattern of the "presidential politics of empathy" but differs in significant ways. He not only wants people to empathize with him, and to show that he empathizes with them as well, but he actively and explicitly promotes the concept of empathy. He incorporates the personal stories of others in his speeches not only to demonstrate empathy but in order to move his audience to understand the human dimension of issues through empathy with the lives affected. And he tells his personal story not only as one that enables empathy but as one that serves as an allegory for the nation.

The promotion of empathy as a value would seem easy, as empathy is not something that most people would argue against. Empathy acts-problematically at times-as an unopposed good. But this has started to change in political discourse with the Republican response to Obama's promotion of empathy as a vital quality for a Supreme Court appointment. Empathy is now somewhat of a contested term and value, even if it remains an expedient political means, leading Peter Baker to observe in a New 
York Times article that Obama went on to avoid the term "empathy" in discussions of his second Supreme Court nomination. The term "became radioactive," Baker writes, adding that instead Obama said he preferred a justice with "a keen understanding of how the law affects the daily lives of the American people," or, empathy in other words. The shift in verbiage demonstrates that even when not using the word "empathy," Obama is still promoting the concept.

Obama provides a personal definition of empathy in The Audacity of Hope. He writes that he appreciates empathy more and more as he gets older and that it is at the heart of his moral code. Empathy is how he understands the Golden Rule, he writes, "not simply as a call to sympathy or charity, but as something more demanding, a call to stand in somebody else's shoes and see through their eyes" $(66)$. He shows some consideration of empathy in not simply conflating it with sympathy but in treating empathy as a means first of perception or understanding. Empathy for him is a distinct moral practice. The evocation of the Golden Rule is also notable because Obama sees empathy as amending or adding to the Golden Rule. This understanding of empathy is instructive because the Golden Rule is commonly employed in political rhetoric as a moral metric, by liberals as well as conservatives. "Empathy is the basis of a major conception of morality," Lakoff writes in Moral Politics (114). He likewise compares empathy to the Golden Rule in order to divide the Golden Rule into two forms, one stronger and one weaker. About the weaker and more traditional form, Lakoff writes, "To conceptualize moral action as fully empathetic action is more than just abiding by the Golden Rule, to do unto others as you would have them do unto you" (114-115). Because people have different values, desires, and experiences, a stronger Golden Rule informed by a more critical empathy would be: 
"Do unto others as they would have you do unto them" (115). The distinction here parallels Hoffman's difference between self- and other-focused perspective-taking. Lakoff uses a recognition of differences between one's own values and those of another to define "egocentric empathy," in which one projects one's own values on another, and "absolute empathy" as feeling what another feels (115). Lakoff adds a third category, which fits well in political rhetoric, that of "absolute empathy plus moral instruction," in which the empathizer attempts to understand another's values in the process of empathy while also attempting to persuade another to adopt the empathizer's values (116). This "absolute empathy plus moral instruction" aligns well with the type of empathy that Obama advocates in The Audacity of Hope, except that Obama sees the moral instruction of empathy as a two-way street. Indeed, he expects the social ramifications of empathy to be even greater for the empathizer. "I believe a stronger sense of empathy would tilt the balance of our current politics in favor of those people who are struggling in this society," he writes (67-68).

Empathy is thus a means to personal and social transformation. Obama writes of empathy as an obligation, so that "I am obligated to try to see the world through George Bush's eyes, no matter how much I may disagree with him" (Audacity 68). Obama continues, "That's what empathy does-it calls us all to task, the conservative and the liberal, the powerful and the powerless, the oppressed and the oppressor. We are all shaken out of our complacency. We are all forced beyond our limited vision" (68). He recounts winning arguments with his grandfather on the basis of logic but being unsatisfied with the winning once he began to empathize with his grandfather and to better appreciate his grandfather's feelings and experiences. Failing to empathize, Obama 
discovers, "was in some way diminishing myself" (67). He begins to apply his mother's principle of asking himself how what he is doing would make somebody else feel. This, Obama writes, became "a guidepost for my politics" (67). Here Obama is arguing for empathy as a means of emotional discovery and understanding. It is a maturing process. It is also a personal and civic force that he believes should be applied across political and economic spectrums. Obama places a heavy and idealistic expectation on empathy as necessarily leading to social transformation. There are similarities here to how champions of narrative empathy have based their hope on the reading of fiction as leading to greater altruism, as discussed by Keen, and this further correlates to the general social and cultural valuation of empathy as always positive and always leading to better results. Empathy must move beyond mutual understanding, Obama writes, because "like any value, empathy must be acted upon" (68). Obama diagnoses a lack of empathy as a significant shortcoming of the nation, because he would expect greater empathy to lead to greater social justice and transformation. "As a country, we seem to be suffering from an empathy deficit," he writes (67). Exactly how we address that deficit and how doing so leads to positive change is not elaborated in The Audacity of Hope beyond the prescription that we should likewise follow that simple principle of Obama's mother in asking ourselves "How would that make you feel?" All of this amounts to a promotion of empathy as a value. But in his discussion of empathy-in relation to the Golden Rule, as more than sympathy, and as a moral guide-Obama does demonstrate a deeper consideration and appreciation of empathy than tends to commonly circulate. It seems to be more than a buzzword for him. 
Obama's valuation of empathy places him well within the liberal camp of American politics, because within that context empathy is often considered a liberal value. Lakoff writes of the difference in values as paralleling the stereotypical differences in parenting models between the nurturing mother and the strict father. For Lakoff, these are two different moral systems, each characterizing distinct worldviews. Lakoff's liberal categories of moral action includes "empathetic behavior and promoting fairness," "helping those who cannot help themselves," and "promoting fulfillment in life" (167). His conservative categories include "promoting self-discipline, responsibility, and selfreliance," "upholding the morality of reward and punishment," "protecting moral people from external evils," and "upholding the moral order" (166-167). In light of these categories, the importance of reading a self-other overlap-or debunking the autonomy myth, as Mark Bracher describes it-is all the more critical for the adoption of positions that run counter to more conservative ideas of individual reliance and responsibility. Obama's emphasis on empathy may clearly be read as signaling liberal moral action. It is even more telling that Obama credits his relationship with his mother and her teachings as imparting his empathic awareness. Early awareness of empathy tends to be strongly associated with the relationship between child and mother.

Obama burnishes his credentials as an empathizer in many ways. Typical are the now familiar ways in which he, as well as other candidates, tells the personal stories of others as a demonstration of one's own empathy. But Obama's efforts to present himself as an empathizer are notable also for how he stresses the idea of empathy in his speeches and writing, so that he may be seen as an empathizer who values empathy as a concept as well as a guide to moral action. The Audacity of Hope is a prime example. So is his 
speech "The Great Need of the Hour," in which Obama picks up and elaborates on what he considers to be the nation's "empathy deficit." Obama delivered the speech January 21, 2008, as a candidate at Ebenezer Baptist Church in Atlanta for the Martin Luther King, Jr., holiday. "I'm taking about an inability to recognize ourselves in one another; to understand that we are our brother's keeper; we are our sister's keeper; that, in the words of Dr. King, we are all tied together in a single garment of destiny," Obama says. The great need referenced in the title of the speech is empathy. Obama's notion of empathy is one of self-other overlap so that we might recognize ourselves in one another and see our futures as interdependent. He continues to list proof of our empathy deficit, such as the conditions of inner city schools and the growing disparity in income. As fits a speech made from a church pulpit, Obama exhorts his audience to engage in "a broadening of our hearts," adding, "It's not easy to stand in somebody else's shoes. It's not easy to see past our differences." Obama is not arguing for a critical form of empathy such as I will define it but for an empathy that attempts to look past differences. This is an empathy well suited to political agendas and action as it is focused on outcomes and the building of communities more so than personal identification as commonly used in identity politics. A respect for difference and the role of difference is important both in a call for empathy and in foregrounding the limitations of empathy. But the empathy that Obama is arguing for here has stronger elements of compassion and common cause in political coalition building.

Obama's thematic focus on empathy gains poignancy when at the end of "The Great Need of the Hour" he turns to personal stories. This personal story differs from most employed in political speeches because Obama is not telling the story in support of 
a particular political agenda or piece of legislation. He is telling the story in support of the power of empathy itself. Empathy is his agenda in this speech. Of course, by extension, this is also a story in support of his campaign and its focus on empathy. The story is in support of empathy and is an example of empathy on multiple levels, the first being the empathy displayed in the story, and the second being Obama's empathy in relating to the characters in the story. Stories have power, Obama says, and his campaign and presidency have both shown the potential he sees in rhetoric as leading to action. "The stories that give me such hope don't happen in the spotlight," he says ("The Great Need"). "They don't happen on the presidential stage. They happen in the quiet corners of our lives. They happen in the moments we least expect." Obama goes on to tell the story of a 23-year-old white campaign worker named Ashley Baia in Florence, South Carolina, who has been organizing a predominantly black population. At a neighborhood meeting Baia tells the story of her mother getting cancer and losing her healthcare. "She told everyone at the roundtable that the reason she joined our campaign was so that she could help the millions of other children in the country who want and need to help their parents too," Obama says, in order to highlight the empathy at work. The story continues as Baia asks the other people at the table to say why they are there. As Obama tells it, And finally they come to this elderly black man who's been sitting there quietly the entire time. And Ashley asks him why he's there. And he does not bring up a specific issue. He does not say healthcare or the economy. He does not say education or the war. He does not say that he was there because of Barack Obama. He simply says to everyone in the room, "I am here because of Ashley." By itself, that single moment of recognition between that young white girl and that old black man is not enough. It is not enough to give healthcare to the sick or jobs to the jobless, or education to our children. But it is where we begin. 
Here Obama is establishing empathy as the starting point for political action. He is relating a personal story, itself one about the power of empathy, in support for empathy itself. He is also performing simultaneously as an empathizer and as a champion of empathy, so that if one agrees with him on the power of empathy one also would be inclined to support his candidacy. It begins with recognition, he says, or identification, of seeing oneself in another. Obama's promotion of the theme of empathy as well as his efforts to be seen as an empathizer are mutually supportive.

Empathy motivates political action but also transcends politics, at least as Obama defines empathy. If we take the story as Obama tells it, the elderly man is not at the political meeting for political purposes so much as he is there because of the that "single moment of recognition between that young white girl and that old black man." This is a touching story and in many ways an idealistic one. It is also a favorite of Obama; he tells the story again in his most celebrated speech, the on race. The story is also important because it says something about how empathy works as a theme and as a demonstration of political rhetoric. It attends to an empathy that begins with personal recognition, relies upon the telling of personal stories, seeks common cause and wellbeing, and leads to political action. These are a few of the reasons why empathy in the form of personal stories and anecdotes has become such a familiar device in modern political discourse and presidential politics.

\section{Empathy and the Personal as Political Allegory}

The role of personal stories in rhetorics of empathy is difficult to understate. Under most definitions, and certainly as an affective reaction, empathy depends upon a 
connection to the personal. One of the differences between liberal and conservative rhetorics of empathy is found in how personal stories and policies are connected to empathy. Woodward locates this distinction in how liberals and conservatives employ "compassion":

In the liberal narrative of compassion, the word "compassion" is used primarily as a noun or a predicate adjective in relation to people. A person feels compassion or is compassionate. Compassion is a feeling, and it is embodied. In the conservative narrative, in contrast, compassion is deployed predominantly as an adjective, one that characterizes an ideological stance, policy, or program... Detached from people, compassion is attached to policies and practices. (125)

The use of "compassion" to describe policies and practices is tenuous, as compassion and empathy both are so closely connected with personal and human responses to the situations, plights, and experiences of another. What exactly does it mean for a policy to be compassionate, and how is that possible? Both compassion and empathy as they have been defined here cannot help but lose some of their significance the more that they are decoupled from the personal. Woodward uses as an example the common practice of presidents referring to a member of the audience during their State of the Union addresses. She recounts George W. Bush's reference during his 2001 address to a couple from Pennsylvania and the money that they would save under his tax plan. The reference focuses more on dollar figures than lives. "Compassion is here referred to through the implied relay to economic conservatism, which is in fact what compassionate conservatism is," Woodward writes (126). She continues,

The feeling of compassion is not evoked. We are not told a story, which implies a past. Indeed there is no real story here; instead we have an information-story in which we are presented with the possibility of a bright economic future and the principle that people are to be rewarded for identifying financial goals and working hard to achieve them. (126) 
As Woodward notes, the feeling of compassion or empathy is invoked in part through the telling of a story. Her analysis of liberal and conservative uses of "compassion" underscores two important observations about empathy in political rhetoric. The first is the contemporary emphasis on emotion, and empathy and compassion in particular, within political speech. The second is the employ of personal stories in order to evoke a feeling so that compassion may be more than an adjective for a policy.

I am certain that one could find conservative examples that use personal stories and empathy to evoke empathy; the suffering of crime victims in support of tougher penal codes immediately comes to mind. But I doubt one could find a current politician of national prominence more adept than Obama at employing rhetorics of empathy. He does so in stressing empathy as a theme, as discussed earlier. More notably, however, he also employs personal stories to evoke empathic feelings and judgments in connection to another's experiences or situation. This is a feeling of empathy in relation to people, as Woodward describes, rather than as an adjective for policies. It also aligns with Lakoff's argument that liberals tend to prioritize empathy as a moral metric in demonstrating concern for social welfare. The policy pursuit in which Obama has so far demonstrated the greatest use of rhetorics of empathy is his campaign for healthcare reform.

In a speech that may be best recalled for Rep. Joe Wilson's outburst "You lie!" Obama addressed a joint session of Congress in September of 2009 to urge the passage of healthcare reform. Empathy, he said, is part of our national character. He referenced the recent death of Sen. Ted Kennedy in arguing for a post-partisan embrace of empathy. Kennedy's passion for healthcare reform originated not in ideology but in his experience of having two children sick with cancer, Obama said, reinforcing the connection between 
empathy and experience, foremost, and with policy as secondary in following that experience. It starts with a feeling, Obama continues:

That large-heartedness - that concern and regard for the plight of othersis not a partisan feeling. It's not a Republican or a Democratic feeling. It, too, is part of the American character-our ability to stand in other people's shoes; a recognition that we are all in this together, and when fortune turns against one of us, others are there to lend a helping hand...("Joint Session")

Obama's appeal here is to empathy as a theme and as a value. He provides a definition of empathy as best reached through experience and the work of the imagination in the ability to stand in the shoes of others. There are echoes here of his mother's moral guide. As he describes it in this speech, empathy includes recognition of community, common cause, and of the role of fortune in determining one's station in life. This can be especially useful in discussions of healthcare whenever illness is seen as happenstance, although illness can also be interpreted by some as a consequence of personal responsibility or moral failings. Obama is appealing to an understanding of illness that does not assign it to character flaws the same way that people might try to assign poverty, for example, to laziness. As Obama says earlier in the speech, recounting the numbers of Americans who lose or go without healthcare, "In other words, it can happen to anyone." Here he is reinforcing the sense of shared vulnerability that is essential for empathy. (I will expand upon this and other conditions for empathy in the next chapter.)

Obama's appeals to empathy are more implicit in the speech when he relates the situations of anonymous Americans and their struggles with healthcare. These stories are ways of making more concrete the lesson that the loss of healthcare "can happen to anyone" and that "it happens every day" ("Joint Session"). Obama relates stories that seem to correspond to specific situations and individuals, saying: 
One man from Illinois lost his coverage in the middle of chemotherapy because his insurer found that he hadn't reported gallstones that he didn't even know about. They delayed his treatment, and he died because of it. Another woman from Texas was about to get a double mastectomy when her insurance company canceled her policy because she forgot to declare a case of acne. By the time she had her insurance reinstated, her breast cancer had more than doubled in size. That is heart-breaking, it is wrong, and no one should be treated that way in the United States of America.

These are not fully-fleshed stories, but the details are enough to provide the scaffolding of empathy. Indeed, Keen has found that only the most basic of details are necessary for a reader to empathize with a literary character; or, we can say by extension, for an audience member to empathize with a personal story in a speech. Too many details can even impair empathy, Keen suggests, because they get in the way of the reader's empathic imagination filling in the gaps in ways that allow greater identification. (Keen's work on narrative empathy and details is discussed further in my chapter on the paradoxes of empathy.) It is telling then that Obama chooses stories that include both a man and a woman. He may do so in order that the men and women in his audience have characters with whom they may best empathize. The naming of states is also an interesting feature as it provides just enough detail to make the stories ring true while also allowing plenty of space for the empathic imagination to work, reinforcing the idea that illness and loss of healthcare can happen to anyone in any state. These are indeed heartbreaking and upsetting stories that Obama relates. Their sadness further appeals to the audience's sense of compassion, justice, and their identities as citizens of the United States of America, where this kind of thing should not happen. A shared sense of outrage at these stories requires a political response. If the audience empathizes with the people in the stories and thinks these situations unjust, and if they think these situations should not be happening 
in the United States of America, then they should agree with Obama's agenda of healthcare reform.

Stories enable empathy because they allow people an approximate access to the experiences and situations of others. They work like bridges of and for experiences, however flawed that bridge may be. The use of personal stories as allegory is most notable in Obama's speech on healthcare reform in Strongsville, Ohio, in March of 2010. In order to understand how Obama uses stories as sites for and demonstrations of empathy in support of his reforms, it is useful first to review the rhetorical work of allegory. Shuman writes that the telling of stories asserts a truth claim both in the absolute sense that the story actually happened and in the metaphorical sense that the story is allegorically true, meaning that it is "true in the larger sense of conveying a true understanding of human experiences" (4). As discussed in the opening chapter, she defines empathy as "the act of understanding others across time, space, or any difference in experience," adding that "empathy holds out a great, perhaps the greatest, promise of storytelling" while also holding a destabilizing element due to the inherent liabilities of empathy (4). Empathy in allegory is always open to critiques of overgeneralization and entitlement claims, which are much of Shuman's focus. As allegory attains meaning beyond the absolute truth in a particular instance and context it must be translated and retold. That retelling of allegory always involves claims, implicit or explicit, as to who is entitled to tell and interpret the story. As Shuman observes, allegory must always be involved in the messy process of translation and re-appropriation. And this is the case with all personal stories, especially those told in a political context, because "there is no way around allegory, no way to make an account exist only for itself and not become an 
allegorical statement about something else" (69). Shuman defines allegory as "a form of narrative that travels beyond its owners; moreover, it is intended to travel" "across contexts and across experiences" (71). She notes that allegory is one of the key ways in which people empathize with others. It is not surprising then that allegory also figures prominently in political rhetoric as it is a means for understanding and feeling with the experiences of others, particularly in a specific political context.

The story of Canfield's involvement in Obama's healthcare speech and his push for healthcare reform begins with a letter that Canfield wrote Obama at the end of 2009 . Canfield describes herself as a 50-year-old self-employed cancer survivor who, after a 40 percent rise in her premiums, can no longer afford health insurance. She allows her coverage to lapse. Canfield describes her struggle to maintain insurance and her fear of losing the house that her parents built as a result of the financial pressure and risk. "I need your Health reform bill to help me," she writes Obama. "Please stay focused in your reform attempts as I and many others are in desperate need of your help.” Obama's response at the time is surprisingly brief and unfeeling, as he thanks Canfield for her letter, adding, "It's because of folks like you that we are still fighting to get health care done!" ("Response to Natoma Canfield").

This initial letter exchange is important not for the sentiment, or lack thereof, but because it signals Obama's entitlement to tell Canfield's story. Canfield has already announced herself as in support of Obama's agenda and, in even writing the President, may be seen as offering her story in allegorical support of the necessity of reform. She offers her story as a site for Obama's empathy and in service of his agenda. Indeed, Obama's brief response further emphasizes the connection between Canfield's story and 
Obama's healthcare plan. This offering of Canfield's story allows Obama to avoid criticisms of entitlement, the most powerful of which could come from Canfield or her family, to tell her story for his purposes. Instead Obama is introduced at the speech by Canfield's sister, signaling the family's endorsement of Obama's telling of Canfield's story. Canfield was unable to attend the speech herself because she was back in the hospital, and this time without health insurance. Empathy is easily critiqued, as Shuman argues, because empathy with the plight of another, even if supposed in another's interests, is a weak claim of entitlement to another's story and experiences. Further, "Empathy is almost always open to critique as serving the interests of the empathizer rather than the empathized" (18). As I will show with consideration of critiques of Obama's speech, in the process of becoming allegory Canfield's story is reinterpreted and retold in counternarrative to that of Obama and even in counternarrative to Canfield herself. That retelling as counternarrative is open to stronger criticisms of entitlement because it is against Canfield's own interpretation of her experiences.

The importance of empathy in Obama's speech is clear from the beginning. Although his is clearly a political speech and purpose, Obama does not credit politics per se as the reason for his visit to Ohio. Sure, politics are the reason, but Obama directly credits Canfield and her letter. Her begins by noting the difficulty of sharing a personal story, which is also a way of thanking Canfield for telling hers and allowing him to retell it. Obama then thanks Canfield's sister, Connie, adding, "And I want everybody to understand that Connie and her sister are the reason that I'm here today" ("Strongsville"). He is there because of their story and their situation. In other words, he is there because he empathizes with their plight. In crediting his visit to Canfield and her sister, Obama 
underscores the role of the personal as an impetus for the political, even at the presidential level, or so he says. Empathy is vital in recognizing that personal, feeling with it, and being moved toward a political response. Obama emphasizes that point, moving from the personal to the political, when he soon says again, referencing Canfield's story:

So you want to know why I'm here, Ohio? I'm here because of Natoma. I'm here because of the countless others who have been forced to face the most terrifying challenges in their lives with the added burden of medical bills they can't pay. I don't think that's right. Neither do you. That's why we need health insurance right now. Health insurance reform right now.

In the phrase "I'm here because of Natoma" there is a subtle reiteration of the story Obama told in Ebenezer Baptist Church and in his speech on race, the story of the elderly black man who says at the meeting "I am here because of Ashley." Obama offered that story as an example of the power of empathy and of how a moment of recognition between two very different individuals can lead to caring, political action, and change. It starts with the moment, Obama said before, and he credits a similar reason for his visit to Ohio. He then makes "I am here because of..." a refrain, starting with his mother's story and her death of cancer, continuing to the millions of people denied coverage, the expense of health insurance for small business, the seniors who can't afford their prescription, all those who are seeing their premiums go up, and, finally, because this is not the America he believes in. The progression in this introduction and Obama's refrain parallels that of empathy in going from the specific and personal to the general and the political. He starts with his own experiences with his mother. In this way empathy is inductive. Shuman argues that this is a crucial move for allegory to attain wider significance and to transvalue experience, writing, "This move, from the particular person 
to anybody, is the crucial move that allegory strives to make" (74). Obama begins with

Canfield's story and moves to unnamed others and then to the whole of the nation and its character, again underscoring health insurance reform as a moral issue that starts with significance at the personal. Notice also that in mentioning his mother's story Obama is demonstrating his own empathy and offering his personal and family allegory. His mother's story allows him some claim to understanding the experiences of those whose physical suffering is compounded by current healthcare and insurance policies, and he is offering his mother's story as a site for the empathy of others so that they might better understand his relation to the issue.

Throughout his speech Obama attempts to engage his audience's empathy. In doing so, he works to define healthcare reform as a moral issue with personal and human consequences. He tells of reading Canfield's letter to insurance company executives. "Now, I understand Natoma was pretty surprised when she found out that I had read it to these CEOs," Obama says. "But I thought it was important for them to understand the human dimensions of this problem" (“Strongsville”). I find Obama's phrasing of the "human dimension" of the problem instructive, because that human dimension is reached through a personal story about suffering. Empathy and the personal as a window to the human dimension of a problem, and thus to the moral dimension, is the focus of Vetlesen's moral philosophy on "empathy as being the basic mode of access to the domain of humanity's emotional experience" (210). As Vetlesen summarizes his thesis:

The aim of my discussion has been to develop a threefold thesis about (1) the way emotions in general and the faculty of empathy in particular are crucial in making us perceive a situation as one where a cosubject's weal and woe is at stake; (2) how, in the case of, as well as because of, my missing the human dimension of a situation, I also miss-remain blind to, indifferent to, unaffected by-its moral dimension; and (3) how this 
failure on the level of "seeing," or perception, undermines by ability to pass sound moral judgment about the situation in question. (210, my emphasis)

Morality for Vetlesen occurs at the level of "seeing" or perception, which makes it open to rhetoric in the ways in which perception is guided by rhetoric which can direct attention. By reading Canfield's letter to the insurance executives, Obama is attempting to direct them in seeing the human and moral concerns of the situation. So long as healthcare reform is a business decision—or a policy uncoupled from the personal—it can "remain blind to, indifferent to, unaffected by" the human lives and suffering that are implicated by the decisions made. Obama's attention to the "human dimension," like Vetlesen's use of the same phrase, is telling because it indicates that Obama shares Vetlesen's notion that perception of the personal allows for an altered understanding of an issue and contributes to moral judgment. By perceiving the human dimension one might empathize with the affected lives. This allows empathic access to the moral dimension. The same appreciation of empathy as informing moral judgment is on display in Obama's comments upon empathy as a vital quality for Supreme Court nominees:

I will seek someone who understands that justice isn't about some abstract legal theory or footnote in a case book; it is also about how our laws affect the daily realities of people's lives...I view that quality of empathy, of understanding and identifying with people's hopes and struggles, as an essential ingredient for arriving at just decisions and outcomes. ("Press Briefing," my emphasis)

Empathy is thus a means of perceiving the human dimension or daily realities of a situation and of arriving, through that perception, at moral judgment. In reading the letter to the executives Obama is attempting to instruct them in an empathic understanding of the effects on one life and, by extension, all the lives at issue in healthcare reform. Obama has a strong faith in the power of this kind of understanding in empathy and 
personal stories to influence the moral considerations of one's decisions. However, while the human dimension may be a valuable means of accessing the moral dimension, it does not follow that an understanding of the human dimension will necessarily lead to a greater appreciation of moral considerations, only that by cutting off the human dimension one limits access to the moral.

Just as he tells of attempting to lead the insurance executives through empathy, so does Obama attempt some of the same with his wider audience. He asks them to identify through their empathic imagination with Canfield and others who are at risk because of the current healthcare situation. "I want you to think about Natoma. When you hear people saying that this isn't the 'right time,' you think about what she's going through," he says ("Strongsville"). "I want you to think about Natoma and the millions of people across this country who are looking for some help, and looking for some relief." This is an engagement of the empathic imagination like that discussed by Hoffman. Otherfocused role-taking is at work when Obama asks the audience to think about what Canfield is going through and to then relate that to the broader issue of national healthcare. He is attempting to move them via empathic imagination from empathy to altruistic action along the lines of his plan for reform. Obama shifts to self-focused roletaking when he asks his audience to imagine themselves in a situation similar to Canfield or any of the other people at risk of losing their health insurance. He leads the audience through a series of such exercises in empathic imagination when he asks:

So let's just think about-think about if you lost your job right now. How many people here might have had a preexisting condition that would mean it'd be very hard to get health insurance on the individual market? Think about if you wanted to change jobs. Think about if you wanted to start your own business but you suddenly had to give up your health insurance 
on your job. Think about what happens if a child of yours, heaven forbid, got diagnosed with something that made it hard for them to insure.

The rhetorical strategy employed here may be successful in getting the audience to feel with those who are at risk of losing their health insurance, to the degree that members of the audience are able to imagine themselves in the situations that Obama presents. As Hoffman, Batson, and others find, there is power in perspective-taking through the empathic imagination. Empathizing with the plight of others adds affective and moral considerations to situations that otherwise may be understood and interpreted through other means. In a political speech, however, the overriding question is not if the audience can empathize with a situation but if in empathizing the audience can be led to adopt a political agenda or to pursue a course of political action. These are the larger moves that Obama is attempting when he ends the imaginative exercises by saying, "So the bottom line is this: The status quo on health care is simply unsustainable" as a segue to his call for reform.

The move to embrace a political position and political reform depends in part upon an empathic connection between self and other. This is the idea of self-other overlap that Bracher relies upon in his teaching and his attention to cognitive schema, and it relates to Burke's notion of consubstantiality. Both of those ideas will be further discussed in subsequent chapters. As an introduction or review here, self-other overlap is the idea of seeing oneself as connected to the self of another through shared vulnerabilities and shared significance in one another's lives. This recognition is emphasized by Obama in his role-taking exercises built upon the assumption of a shared vulnerability to illness and the loss of healthcare. This shared vulnerability is also at least a partial a negation of personal responsibility for one's health and health insurance 
situation, a negation that also supports compassion and empathy. Obama makes this shared vulnerability explicit when he says, in the midst of these role-taking exercises, "Part of what makes this issue difficult is most of us do have health insurance, we still do. And so-and so we kind of feel like, well, I don't know, it's kind of working for me; I'm not worrying too much. But what we have to understand is that what's happened to Natoma, there but for the grace of God go any of us" ("Strongsville"). One's own relative comfort or perceived invulnerability to losing health care is an impediment to empathy because it acts against recognition of a self-other overlap and the perception of shared vulnerabilities. It further distances one's own situation and experiences from another, making empathic identification all the more difficult. Here Obama is working against that comfort and distance by arguing for a recognition that the loss of health insurance, and even the loss of good health, is not solely a question of personal responsibility and good decisions. The events that contribute to the loss of health care are not always deserved but the result of circumstances and good or poor fortune beyond one's own control, because "there but for the grace of God go any one of us." This statement appears on its face to be mainly an alarm about potential risks, but it is just as importantly and more subtly part of a rhetorical strategy of moving others to empathy.

To take this further, recognition of the self-other overlap is akin to the participatory position called for by Vetlesen. He argues that by accessing the "human dimension" of an issue one's own self is called upon as a participant with moral concerns at stake. To recognize a self-other overlap is to move however slightly from the position of observer of the lives of others to one who sees the lives of others as having some moral significance to one's own life. Likewise, for Burke, a move toward identification is a 
move toward consubstantiality because in identifying one's ways, interests, and experiences with another, one is "substantially one" with a distinct other individual (21). Consubstantiality is a means for Burke based upon shared interests; it is an "actingtogether," which points to the power of the empathic imagination to lead to political action. This identification is the essence of persuasion in Burke's formulation. For a similar and more modern conception, we can also look to Keen's analysis of the empathic imagination as employed by writers in narrative fiction. Keen is useful for proposing different authorial strategies in the use of empathy. She describes "broadcast strategic empathy" as that which "calls upon every reader to feel with members of a group, by emphasizing our common human experiences, feelings, hopes, and vulnerabilities" ("Strategic Empathizing" 488). This is another rhetorical strategy of pushing the selfother overlap. Obama employs "broadcast strategic empathy" in attempting to reach as wide of an audience as possible. Obama is attempting to get his audience to empathize with that group which has lost or is in jeopardy of losing health insurance. Part of his strategy to do so is by arguing, as Keen says, that they should feel with this group because they are not so different and may very well belong to that group themselves.

At the conclusion of the speech Obama reverses order and returns from the general and the political back to the personal. "You know, in the end, this debate is about far more than politics," he says ("Strongsville"). "It's about the millions of lives that would be touched and, in some cases, saved by making health insurance more secure and more affordable. It's about a woman who's lying in a hospital bed who just wants to be able to pay for the care she needs." In this conclusion Obama again turns attention to Canfield's story, although she is not named. He makes one more move for the audience's 
empathy as a way of asserting the morality of his argument, through the imagination of the personal. By imagining Canfield sitting in her hospital bed and worrying about how she is going to pay for her treatment, the audience has greater access to the human and moral forces at work in the issue. In appealing to their audience's empathy Obama is arguing that health care reform is about people and real lives rather than just policy and political points. He presents himself again as a great empathizer who pursues policies because of that empathy. Obama is of course speaking to a friendly audience in Strongsville, one inclined to agree with him. But he is also speaking to a much wider national audience through the media. Those are the ones he is most concerned with persuading. If we are to measure the success of Obama's healthcare speeches by the political outcomes, then they mark perhaps the greatest achievement of his presidency thus far. He signed healthcare reform into law, however removed that final bill is from the ideals of many of his supporters. His use of rhetorics of empathy-in performing empathy, appealing to the empathy of his audience, and employing personal stories as allegory to move others to empathy in support of political action-no doubt contributed to his legislative success.

Before leaving Obama's speeches in support of healthcare reform, allow me to note one additional rhetorical lesson. This is in opposition to Obama's use of the personal as allegory and site for empathy. As Shuman reminds us, the promise of allegory and empathy is that they allow for the transvaluing of an individual's story so that it attains some greater significance and is able to perform rhetorical and social work. The risk, however, is that once the personal becomes allegory, the individual who otherwise owns those experiences begins to lose control of the story. The story and its interpretation go 
public. Stories travel, Shuman observes. "Access to meaning is controlled by access to stories," she writes (6). "But stories very rarely stay with their owners. In fact, what might be the most compelling feature of storytelling is the possibility that its power to transfer and transform will change the meaning of experience." Here is where a rhetorical critique of empathy is so important for analyzing how stories are used, who is empathizing with whom, and, most importantly, to what ends. Canfield loses some control of her story as political allegory when Obama decides to reference her in his speech. Political opponents of Obama's healthcare reform are able to reinterpret Canfield's story as an allegory not in support of Obama's agenda but in opposition. They are able to reinterpret Canfield's experiences, claiming an entitlement to do so even though Canfield had asserted her own interpretation in her letter to Obama. For example, blogger Clifton B, writing at his blog Another Black Conservative, responds to Obama's speech with a post titled "Tragedy Pimpin': Natoma Canfield Turns Out to be a Prop." He accuses Obama of "pimpin' someone's personal tragedy as a reason to support ObamaCare." He goes on to post a news report that finds Canfield may qualify for Medicaid or charitable assistance. This, Clifton B argues, shows that "Natoma isn't the hard luck story she pretends to be." He concludes by objecting to the use of allegory in appeals to empathy or other emotions, writing, "Personally I am sick to death with politicians on both sides of the aisle who make these emotional pleas for various types of legislation." In his response Clifton B is arguing for a counternarrative to that offered by Canfield and Obama. His narrative is one in which Canfield is a political prop who is "pimped" in support of a policy. His larger argument is against the use of allegory and emotional appeals in general within political debate because he believes individual cases 
are best addressed individually and should not inform legislation. In that sense Clifton B is arguing against Vetlesen's thesis perception of the personal and the "human dimension" of a situation allows access to the moral. Either that, or Clifton B does not think morality has political standing. It is admittedly hard to understand how political activity or legislation could be divided from people's experiences. It is easier to understand how Clifton B might be tired of political appeals to the emotions, but his efforts would seem better spent looking at the qualities of those appeals rather than arguing in general against the personal and the emotional in political discourse.

The counternarrative that Clifton B offers, that Canfield as a political prop and in not such a bad situation, is a pretty thin counternarrative. To be fair, he may not have meant it quite as such. Shuman writes of counternarratives as potential critiques to master narratives. By empathizing with the counternarrative we might begin to question and challenge dominant stories. In Shuman's words,

Counternarrative depends on the possibility of critique of the master narrative, and thus, to some extent, on empathy with the counternarrative. It is in this sense that subversive stories and the critique of empathy are implicitly linked. Empathy is one of the failed promises of narrative, but in that failure, it provides the possibility of critique and counternarrative, providing whatever redemptive, emancipatory, or liberatory possibilities narrative holds. (19)

Clifton B does not offer a counternarrative in this sense because there is no story or person with whom to empathize in his response. He may be offering a counter-account or a counter-interpretation but a weak counternarrative. The same goes for the conservative blogger writing under the name Confederate Yankee at the blog of the same name. In a post titled "Dear Mr. President: Thank You for Creating Natoma Canfield's Problems," Confederate Yankee finds that Obama tries to use Canfield's "heart-wrenching anecdote 
to justify the government seizing control of $20 \%$ of the nation's economy." He argues that Canfield's situation is the result of liberal policies that "are directly responsible for making health insurance so expensive by creating barriers to competition and driving prices up." Obama's speech is actually a failure of empathy, Confederate Yankee contends, because Obama sees Canfield not as a person but as a means to his political ends:

When Barack Obama uses Natoma Canfield as a prop today, he will see her as justification for intrusion, not as a person. To him, and those like him, Canfield represents a dim and anonymous Public That Must Be Taken Care Of instead of individuals with dreams and aspirations. In his perfect future world, she and we will be numbers in the system to be costjustified and managed from cradle to grave.

This is a somewhat difficult argument to understand. Confederate Yankee objects to government and politicians valuing and attempting to enact an ethic of care. This objection makes sense given the different moral worldviews Lakoff proposes for liberals and conservatives. Furthermore, Confederate Yankee seems, like Clifton B, to object to the role of the personal within political discourse. The personal is always contextual and can be a trigger for empathy; these appear to be rhetorical liabilities in a worldview that subscribes to Lakoff's morality of the "Strict Father" rather than the "Nuturant Parent" (Moral Politics 162). Yankee argues against Obama's entitlement to tell Canfield's story because, he writes, Obama does not see her as a person. Interestingly, Confederate Yankee asserts the importance of viewing Canfield as a person even as he discounts her story except as proof of disastrous liberal policies that stymie the healthcare market. Confederate Yankee offers instead alternative characters with whom to empathize. They are those employed directly or indirectly by the healthcare industry, and they are "your friends and neighbors, sons and daughters." Confederate Yankee implies that Obama's 
healthcare reform would threaten their livelihood. In a sense, he is arguing both that Obama has failed to empathize with Canfield and that audiences are at risk of empathizing with the wrong people, given the policies being promoted. Audiences should be empathizing with the employees of the healthcare industry. Perhaps had he told a personal story of one of the healthcare employees as an allegory for suffering under healthcare reform, Confederate Yankee may have had a stronger argument as a counternarrative.

These responses to Obama's speech in Strongsville reassert Woodward's argument that conservatives and liberals have conflicting definitions and uses of empathy in political rhetoric. While liberals tend to employ empathy primarily as a noun and as a feeling attached to people, conservatives are more likely to employ empathy as an adjective attached to policies. This is evident as both Clifton B and Confederate Yankee argue against Obama's telling of Canfield's story, claiming that is a way to obscure the truth, distract from policies, or otherwise engage in emotional manipulation. Part of the conservative argument may also concern who deserves empathy. Liberals, who are more likely to emphasize the role of social factors upon one's position in life, may be quicker to empathize with those they see as victims of social forces, such as poverty and racism. Conservatives tend to focus more upon an idea of individual autonomy that would limit empathy for victims of social forces and instead emphasize empathy for victims of those forces that act against their autonomy, such as government policy or personal violence. In this reading, the differences between liberal and conservative rhetorics of empathy are as much about who deserves empathy as they are about what empathy is and its place within political discourse. Perhaps because they argue against the allegorical and the emotional, 
Clifton B and Confederate Yankee are unable to offer counternarratives as sites of empathy for the purposes of their critiques. Indeed, it is Obama's telling of Canfield's story that can best be understood as a counternarrative in the ways that Shuman defines it. By telling Canfield's story, Obama is offering a counternarrative to that which asserts that the United States has the best healthcare system in the world and that the only people who suffer for a lack of healthcare are those who are lazy or make poor decisions. By empathizing with Canfield's story, the audience critiques these widely held beliefs. This may be counted among the "liberatory possibilities" that Shuman finds in storytelling and empathy. Lost in here, however, is Canfield's own control of her story. Her story becomes a site of political contestation as she is forced to listen from her hospital bed to its telling, retelling, and contested interpretations of her experiences.

\section{A Nation Empathizing With Its Multiple Selves}

Obama delivered his landmark speech on race in March of 2008 while his presidential campaign was confronted with a number of problems. Spurred by the conservative media, people were questioning Obama's patriotism, his thoughts on race, his religious affiliation, and his allegiance to his pastor, Jeremiah Wright, in light of inflammatory sound bites that had surfaced from his sermons. Obama's speech, "A More Perfect Union," was soon celebrated as Obama's finest and as holding historical significance. The speech is notable for many reasons, not least of which is Obama's use of empathy as a theme and as a means of persuasion. The importance of empathy in "A More Perfect Union" is commented upon by Lakoff in an analysis of the speech about a week after its delivery. Yes, it is a speech about race, Lakoff writes, and as such it is "the 
most important statement about race in recent history" ("What Made Obama's Speech

Great"). But what many commenters miss, he argues, is the importance of empathy and American character and identity in the speech. Empathy and identity here reinforce one another, so that it is through allegory and empathy that Obama is able to make his argument about empathy and American identity. "It is the mark of a great speech, not just to mention its themes but to exemplify those themes," Lakoff writes, continuing:

Empathy, union and common responsibility are the ideas behind the speech...and as the speech shows, they are behind the idea of America itself. The speech works via empathy, via the emotional structure built into the speech and into our national ideals. The speech works because, almost line by line, it evokes those foundational ideals - the ideals we have and feel, but that have been far too long hidden behind political cynicism, political fear, and the concern for advantage.

Lakoff offers a partisan but astute analysis of Obama's speech. This is one of his key insights, that Obama's speech is about more than race and that it works "via empathy," by evoking empathy and arguing for the importance of empathy as an American value. I extend Lakoff's analysis by attending to how Obama employs empathy in the speech, specifically through his telling of personal stories, those of others and his own. His employment of personal allegory differs from that in his healthcare speeches because the story that he is offering is his own, and he is offering it as an allegory of American history and identity. Because of the acclaimed nature of the speech, as well as Obama's novel use of personal allegory, "A More Perfect Union" deserves individual consideration for its use of rhetorics of empathy.

Stories are a valuable and central concept in "A More Perfect Union." Obama recognizes the power of stories as supporting empathy across differences of circumstance 
and experience. For Obama, stories are a way of bringing people together for common cause. Obama marks the importance of stories in his own political philosophy, saying:

I believe deeply that we cannot solve the challenges of our time unless we solve them together-unless we perfect our union by understanding that we may have different stories, but we hold common hopes; that we may not look the same and we may not have come from the same place, but we all want to move in the same direction-towards a better future for our children and our grandchildren. ("A More Perfect Union")

Obama is speaking in the spirit of a former community organizer. He acknowledges difference but has hopes for common cause within and among those differences. Stories, as Obama discusses them here, are not reasons for division but opportunities for understanding and sharing common hopes. There is an empathy at work here of the kind that Burke proposes as consubstantiality, an identification toward common interests and purposes. The common purpose in Obama's formulation is a better future for future generations.

Obama considers stories rhetorical means of bringing people together to form communities. Stories contribute to community character and identity and purpose. Stories serve as sites and repositories of feeling and memory. They can lead to political action. The importance of stories in these regards is made clear when Obama tells of his experience of first attending a service at Wright's church. In his speech he quotes from the account he wrote in his book Dreams from My Father:

I imagined the stories of ordinary black people merging with the stories of David and Goliath, Moses and Pharaoh, the Christians in the lion's den, Ezekiel's field of dry bones. Those stories - of survival, and freedom, and hope-became our story, my story; the blood that had spilled was our blood, the tears our tears; until this black church, on this bright day, seemed once more a vessel carrying the story of a people into future generations and into a larger world. Our trials and triumphs became at once unique and universal, black and more than black; in chronicling our journey, the stories and songs gave us a means to reclaim memories that 
we didn't need to feel shame about...memories that all people might study and cherish-and with which we could start to rebuild. ("A More Perfect Union")

Obama is describing the process, feeling, and power of empathizing with another's story. Stories merge; as Shuman says, they travel. In empathizing with the people in the stories, the members of the congregation are able to share those stories. As Obama says, those stories become their stories, the blood shed their own, "the tears our tears." The description works like a definition of narrative empathy as those hearing the stories begin to feel with the subjects of the stories and their experiences. It is worth remembering, too, that empathy is based upon imagined experiences, the kind of truth that is most vitally emotional if not historical. The congregants share these stories despite vast differences in circumstance and experiences. This is always the case with empathy and allegory, with the greater the distance and differences the further the empathic stretch. Obama recognizes the persistence and importance of difference in empathy when he discusses the coexistence of the distinct in the universal. The congregants' "trials and triumphs became at once unique and universal," he says, adding the further possibility that "all people might study and cherish" these unique and universal stories and songs that are "black and more than black." The power of stories for Obama, as described here, is based upon empathic values. Stories are significant, persuasive, and meaningful to the extent that people can identify and feel with them, even while maintaining the distinct in the universal. In empathy, stories are similar but different, "unique and universal," in the ways that they are "black and more than black."

The speech works, as Lakoff says, because Obama attempts to move his audience to empathize with personal stories, just as he and his fellow congregants were moved to 
empathize with the stories in the church service. But rather than attempting to move his audience to support a political agenda, as he did in the healthcare speeches, here Obama is attempting to define himself and his candidacy through rhetorics of empathy in which his story is the American story. He is not telling Canfield's story here; he is telling his own. And he is telling his story not just so that people might empathize with him, but so that they might see him as an empathizer and as a means to empathy. In a way, they are moved not to empathize with his story directly but to empathize through his story with their fellow citizens by his story's capacity for allegory. The object of their empathy is not Obama so much as it American identities_-unique and universal-accessed through Obama's own story and the others he tells. Empathy becomes a way for Obama's audience to better understand their own national identities through his personal story.

Empathy is more than a theme for Obama; it is a rhetorical strategy. Obama offers two critical stories as sites for empathy, those of black America and of white America. These stories are personified by Wright and Obama's maternal grandparents. They are also personified in Obama himself, to which I will return in a moment. Obama tells Wright's story through the lens of American racial history. Wright as he has been represented in the news and in video clips, Obama says, "isn't all I know of the man." He describes Wright's personal history and his good-and empathic-work through the church. "He contains within him the contradictions - the good and the bad-of the community that he has served diligently for so many years," Obama says. He then goes on to tell of the legacy of slavery and Jim Crow, of "a lack of economic opportunity among black men, and the shame and frustration that came from not being able to provide for one's family." Throughout this Obama demonstrates his empathy for Wright and 
invites his audience to that empathy as well. "This is the reality in which Reverend Wright and other African-Americans of his generation grew up," Obama says. In order to empathize with Wright we must understand his history, circumstances, and the emotions and reactions that result. Obama does some of the same rhetorical work in describing the circumstances and feelings of white Americans. "Most working- and middle-class white Americans don't feel that they have been particularly privileged by their race," he says. Obama tells of the factors and situations that contribute to "black anger" and "white resentments." He is attending to history and circumstance so that the audience can focus blame not upon individuals but upon social conditions, which is an important political move because social conditions can be changed.

Obama also attends throughout these narratives of white and black America to feelings. That attention to circumstance and feeling is vital if his audience is to feel with others and to enter moral considerations. By doing this, by telling these stories, Obama is offering individual and communal allegories as ways of understanding one another and making sense of one another's feelings through empathy. He is employing allegory in the way that Shuman describes it, as "a primary trope for translating experience," and, by extension, coming to some new understanding (71). Without equating their experienceskeeping the unique in the universal, as Obama says—both black and white America have suffered negatively due to America's racial history, he argues. In understanding one another's experiences and feelings and pain, we might escape our own pain. This is what Shuman refers to as one of the promises of empathy, that of "transcendence through compassion toward others" (8). In order to facilitate that empathic transcendence, Obama can also be seen as employing what Keen calls "ambassadorial strategic empathy." 
Keen's term, as with much of her work, is in the service of narrative fiction, but it useful in a rhetorical context because it helps describe the ways that Obama is attempting to move his audience. Ambassadorial strategic empathy is an attempt to bridge the gap between audiences. As Keen describes it, "Ambassadorial strategic empathy addresses chosen others with the aim of cultivating their empathy for the in-group, often to a specific end. Appeals for justice, recognition, and assistance often take this form" ("Strategic Empathizing" 483).

Viewed in light of Keen's concept of ambassadorial strategic empathy, Obama may be understood as speaking to white America as an ambassador of black America. This certainly fits his with his emphasis on the history and circumstances of black anger and with the circumstance of having to address Wright's sermons. But his position is not so unidirectional. Obama's ambassadorial rhetoric of empathy works both ways, for white and black America, as he demonstrates his empathy and identification with each. This mutual empathy achieves its most powerful moment in the speech when Obama compares his relationship with Wright to his relationship with his maternal grandmother. These relationships serve as allegories for Obama's multi-racial identifications, and for those of the nation. Explaining why he maintains his relationship with Wright, Obama says,

I can no more disown him than I can disown the black community. I can no more disown him than I can my white grandmother-a woman who helped raise me, a woman who sacrificed again and again for me, a woman who loves me as much as she loves anything in this world, but a woman who once confessed her fear of black men who passed by her on the street, and who on more than one occasion has uttered racial or ethnic stereotypes that made me cringe. ("A More Perfect Union") 
This passage is charged with feeling. Obama is describing people with contradictions, but he loves and empathizes with them despite those contradictions. He describes an experience with his grandmother with which many white Americans can empathize, the feeling of hearing a loved one express those "racial or ethnic stereotypes that made me cringe." Obama is working rhetorics of empathy here as an ambassador for white and black America, as an empathic ambassador among our American selves.

The overriding and more important story of "A More Perfect Union" is Obama's own story as an allegory for the American story. Obama says of his grandmother and of Wright, "These people are a part of me. And they are a part of America, this country that I love." That is, both Obama personally and America nationally are comprised in part by the white and black allegories of Wright and Obama's grandmother. Obama signals the allegorical significance early in his speech when he speaks of his faith in the American people, a faith that "comes from my own American story." He goes on to tell of his black Kenyan father and white mother from Kansas; his grandmother and his grandfather, a veteran of World War II; his experiences in America and abroad, in some of the world's best schools and some of the poorest; his wife's family history which includes slaves and slave-owners; and his relatives "of every race and every hue, scattered across three continents." In telling his story he is also telling the story of America, one that extends into the wider world. Obama makes this all very clear. "For as long as I live, I will never forget that in no other country on Earth is my story even possible," he says. "It's a story that hasn't made me the most conventional candidate. But it is a story that has seared into my genetic makeup the idea that this nation is more than the sum of its parts-that out of many, we are truly one." As he is standing there speaking, with American flags behind 
him, Obama is offering himself and his presence as evidence that out of many stories there is also one.

Obama's story and identity thus become an allegory for American identity. $\mathrm{He}$ offers his own story as a site and means of empathy, and he performs empathy for those many stories that make up and parallel his own. As Lakoff writes in his analysis, highlighting Obama's move to identify his story with the American story,

It is a common metaphor that an institution is seen as a person, with the special case that a nation is understood in terms of its leader. In this speech, Obama becomes contemporary America... How could he be anything but patriotic when he is America? And how can we, identifying with him, be anything but patriotic when we are America? ("What Made Obama's Speech Great")

Offering one's own story as an allegory for the national story is especially powerful rhetorically when one is campaigning to be the leader of that nation. People want to be able to empathize with, to identify with, their leaders. They also want leaders who they think can identify with them. Just as allegory depends upon narrative, and identity itself likewise is a function of narrative, Shuman reminds us that "the concept of self is itself allegorical" (58). In offering his identity as national identity, Obama is arguing for a national identity modeled after his own identity. Commenting upon the speech, Marilyn Cooper finds that Obama "shaped a narrative that aligned his personal identity and disposition with strongly held cultural narratives of American optimism, belief in the inevitability of progress and exceptionalism, and with a common understanding of Martin Luther King as a moderate conciliator and national healer" (434). The rhetorics of empathy at work here merge the personal with the national. Obama performs as one who empathizes with the nation, and he tells his story as a site for the empathy of his audience as Americans. In doing this, Obama is able to dodge some of the criticisms of empathy 
even while he makes empathy and a signature feature of the speech. There are no critiques of entitlement, no accusations of using others as political props, because Obama is telling his own story. With some rhetorical finesse, he is also telling the nation's story in that telling. But he does so by collapsing the difference through his story and that of America. He also does so by employing rhetorics of empathy that argue for the value of stories, that showcase his own empathy, and that conflate empathizing with Obama as empathizing with one's own American identity, and vice versa. Obama is telling his own story but not so that his audience might empathize with him exclusively. He is not telling it so that his audience might empathize through him with the nation as he presents it and, by extension, with themselves.

Obama concludes his speech by telling again the story that he told in Ebenezer Baptist Church, that of the young white campaign worker and the elderly black man who have come together through empathy, not through the political but through the mutual and the personal. Lakoff describes the story as "pure empathy" ("What Made Obama's Speech Great"). It also signifies Obama's commitment to a liberal moral worldview that prioritizes empathy. The story reinforces Obama's significant valuing of empathy. Obama relates empathy to democracy. He is not alone in doing so. As Lakoff writes, summarizing the rhetoric that he thinks the public has been waiting to hear from a presidential candidate such as Obama, "At the heart of our democracy is empathy-madereal, a political arrangement through which we care for one another, protect one another, create joint prosperity and help one another lead fulfilling lives." Obama returns again and again to the idea of empathy as a democratic one that holds a nation together by enabling mutual understanding. Recall that Hoffman likewise refers to empathy as "the 
glue that makes social life possible" (3). For Obama, empathy is where we start. It is a process in working toward an ever-more-perfect democracy.

A useful way to think about empathy rhetorically is in terms of subjects and objects of empathy, in who gets to empathize with whom, and the interests and purposes that empathizing serves in a given context. Obama's speeches and writing demonstrate the political and social currency of empathy as a concept and value. They show how presenting oneself as an empathizer-as the subject of empathy — has become a standard political practice for presidential candidates. In this way empathy is almost reciprocal. The public seems to better empathize with those they consider as best empathizing with them, all of which shortens the distance between candidate and people. Obama does more than circulate the idea of empathy. He actively promotes it as a value, as rhetorical means, and as a critical mode of judgment. Obama's speeches, especially those on healthcare, demonstrate how rhetorics of empathy perform allegorical work so that in identifying with another's story we are able to access the "human dimension" of a situation in order to make moral judgments better informed by consequences at the level of human experience. In those speeches, broadcast to a nation, Obama is not trying to get the audience to empathize with him but with a third party by telling their story. The strategy is that by empathizing with this story his audience will be moved to support the associated political agenda. This is a common strategy with rhetorics of empathy. We see it in marketing and in appeals to charity on another's behalf. Its social context and rhetorical function are made clear in these political speeches. And in his speech "A More Perfect Union," we see how Obama is able to use rhetorics and allegories of empathy to change not only how he is seen as a candidate but how Americans identify with 
themselves as Americans through the stories that we share. Here rhetorics of empathy also tell us much about Obama and his popularity as a candidate, as one who empathizes, moves us to empathy, and who offers his own story as empathic means to understanding who we are as a nation.

In one of his earlier speeches as President, in April of 2009 at the Holocaust Days Remembrance Ceremony, Obama reiterates the importance of empathy. We have an obligation to empathize, he says, to not "wrap ourselves in the false comfort that others' sufferings are not our own." We instead should "make a habit of empathy; to recognize ourselves in each other," he says. At least rhetorically, Obama commits himself to this habit. In his speeches he provides performances, examples, means, and allegorical opportunities for empathy. The way we work toward perfecting our union is through empathizing, Obama argues. And the way we do that is by telling our stories, one another's stories, and the nation's stories as exercises in empathy.

\section{"I Feel Your Pain": Political Expectations and the Limits of Rhetorics of Empathy}

In discussing empathy as theme and rhetorical means in the speeches of Obama, it is important to keep that rhetorical awareness forefront. Rhetorics of empathy are rhetorical performances of and via empathy to a particular ends. Without that rhetorical awareness, performances of empathy can begin to be directly equated with empathy. The popularity of rhetorics of empathy in political discourse has made a rhetorical awareness all the more important and, at times, more obvious. It has exposed some of the risks and limitations of rhetorics of empathy, such as those employed by Obama. Namely, empathy 
makes demands on speakers as well as an audience, and it can suggest promises or propose commitments that are difficult to keep.

Clinton offers a telling example of some of the success and liabilities of rhetorics of empathy, particularly with his "I feel your pain" comment. Clinton is commonly associated with rhetorics of empathy in general. His ability to respond empathically and personally to a presidential debate question about how his life has been affected by the national debt is a strong performance of rhetorics of empathy, and it doubtlessly contributed to his electoral success (Woodward 109). But he did not say in that debate, "I feel your pain.” That statement comes out of an exchange with AIDS activist Bob Rafsky, who interrupts Clinton during a campaign fundraiser speech. As recorded in The New York Times, Rafsky asks Clinton, "This is the center of the AIDS epidemic, what are you going to do? Are you going to start a war on AIDS? ...We're dying in this state" ("The 1992 Campaign"). Clinton attempts to respond with empathy, saying, "I know how it hurts. I've got friends who've died of AIDS." Rafsky retorts, "Bill, we're not dying of AIDS as much as we are from 11 years of Government neglect." Clinton and Rafsky shout over and interrupt one another, until Clinton begins talking about the importance of mutual civility and respect. He demands some empathy from Rafsky, saying, "I have treated you and all the people who've interrupted my rally with a hell of a lot more respect than you've treated me, and it's time you started thinking about that." It is at this point that Clinton adds his famous, "I feel your pain, I feel your pain" statement before again demanding some empathy from those who remark upon but know nothing of him and his life. He ends by stating his commitment to fight AIDS. 
This episode is telling because while "I feel your pain" is commonly considered shorthand for rhetorics of empathy, the actual exchange also demonstrates the rhetorical nature and limits of that strategic empathy. When he first says that he knows how it hurts, Clinton is attempting to mollify Rafsky through a performance of empathy. Clinton could even be accused here of attempting to avoid responsibility for the issue and to avoid taking a policy position. Sometimes performing a position of empathy is much easier than taking a stand on political policy. But Rafsky will not be mollified, and he turns his question from one of empathy to one of governmental action, or inaction as it were. When Clinton says, "I feel your pain," he says it out of frustration and anger that Rafsky is not feeling more of Clinton's pain. "I feel your pain" is a statement of empathy in an attempt not to really feel another's pain—and one might question how much Clinton can feel the pain of a man dying of AIDS—but an attempt to quiet dissent and regain control. To be fair, it is also an acknowledgement of another's emotional state and that there are people and lives at stake when talking about political policy. But rhetorics of empathy, such as performed here, can simultaneously work as a way to dodge responsibility for those policies and the commitments that genuine empathy makes upon people and politicians. The exchange was useful nevertheless in making AIDS more of a campaign issue. Following Rafsky's disruption, Clinton met with New York City AIDS activists to draft an AIDS agenda for his administration. Rafsky died the next year.

Empathy is seen as demanding something personally of a president, and so Clinton met personally with AIDS activists. Dickerson labels what he calls "the empathy trap": "The problem with empathy, however, is not just that there's never enough of it to go around. It's that by offering it, presidents raise unrealistic expectations of a different 
sort." Understanding or feeling with another is perceived to be a starting point, so that empathy alone is not enough. Dickerson is focused on the personal expectations of a president who empathizes with an individual, such as at a debate or campaign function, to take personal action based upon that empathy. As Dickerson describes it, "The risk of empathy is that it pushes a president into role he's not really suited to play: job counselor, psychotherapist, loan officer." This is an expectation borne out of a president's personal interaction with people. It is not that serious of a risk, because a public cannot expect a president to personally intercede on the behalf of everybody who speaks with him. The larger social and political significance of this empathy risk, I think, is that it speaks to a public expectation that a president who empathizes must act upon that empathy for political change.

Questions about the commitments supposed in a rhetorics of empathy have also followed Obama. Liberals who do not think Obama has made good on the implied promises of his rhetorics of empathy have been among his toughest critics. A notable example is Cornel West, who was a prominent supporter and campaigner for Obama. In an interview with Chris Hedges for the website Truthdig, West talks of feeling deceived and betrayed by Obama, particularly in Obama's economic policies and appointments. "All this populist language is just a façade," West says, calling Obama "a black mascot of Wall Street oligarchs and a black puppet of corporate plutocrats. And now he has become head of the American killing machine and is proud of it" (qtd. in Hedges). These are criticisms and accusations concerning Obama's allegiances and the authenticity of his empathy with "the weak and the vulnerable." West then goes further in taking on Obama's personal history and identity as American allegory. "He's always had to fear 
being a white man with black skin. All he has known culturally is white. He is just as human as I am, but that is his cultural formation," West says. Obama's international and multiracial background in this telling thus is not the foundation for a greater capacity of empathy with whites and blacks, making the American story his own. Instead, Wests says of Obama, "He has a certain rootlessness, a deracination. It is understandable." Notice that West couches his criticisms in his own performance of empathy in understanding Obama's situation and that Obama is just as human as West is or as any of us. To be fair to West, the primary focus of his criticism is on Obama's economic policies, an area where many liberals have been disappointed. But by targeting Obama's allegiances and his personal history and identity, West is going after Obama's perceived strengths, as they were on display in "A More Perfect Union." West is questioning the empathic connection between Obama and the wider American public. He is questioning the legitimacy of Obama's story as American allegory and as a means to empathy, and he questioning Obama's black identity. He asserts that Obama's language is a "façade." West's argument is that Obama's performance of empathy with the economically stricken is merely a performance, one that masks his greater comfort with the upper-class establishment. The proof, West contends, is not in the empathy but in the policies. His criticism is harsh. It is valuable here because it demonstrates how rhetorics of empathy may be questioned along lines of identity and policy. Interestingly, identity as a site of critique, but with different intentions, is also found in those who question the legitimacy of Obama's birth certificate and his status as an American citizen. These "birther" claims are critiques of the authentic "Americanness" of Obama's story and identity. These may also be failures of empathy. An inability to empathize with or through Obama as 
American allegory is thus reinterpreted not as a failure of empathic identification but as a sign of the illegitimacy Obama's identity itself as American allegory. West's criticisms also demonstrate that, as intimated in Dickerson's "empathy trap," rhetorics of empathy create expectations of promises and commitments. Just as the empathy-altruism hypothesis is a point of contention within theories of empathy, so is the idea that a politician who performs empathy would necessarily push more caring policies. A performance of rhetorics of empathy always operates on multiple levels, one of which may be arguing that the rhetor is an empathic person, another of which may be signaling political allegiance to a specific moral code. Policy does not have to follow empathy. Character and allegiances-which are another name for empathic identification or consubstantiality-can be questioned.

One demand that rhetorics of empathy do make upon politicians is simply the work of caring. Empathy is emotional labor. That is true for anyone, yet imagine the demands upon and potential for exhaustion of a president's capacity for empathy. Still, political advisors and the public ask for more empathy from their leaders. Going into the 2010 midterm election, former political aids of Clinton wanted to see more emotional connection from Obama. "If only Mr. Obama could more effectively demonstrate empathy, they argued, he might be able to convince the supporters he thrilled in 2008 that he's still on their side," the aids told John Harwood of The New York Times. The celebration of empathy in politics, its promotion and criticisms, and the demand for greater and more authentic empathy all demonstrate the importance of rhetorics of empathy in contemporary political discourse. The hope of many in the audience is that a performance of empathy is a sign of something more about a candidate's character and 
policies, his or her attention to the human and thus the moral dimension of issues. It is a hope that, as Obama says, change starts with empathy in a moment of recognition. This lends rhetorics of empathy value and significance. A rhetorical awareness adds to that value in opening rhetorics of empathy to critique toward not merely cynicism but accountability. 


\section{CHAPTER III}

\section{“SHOULD YOU ENCOUNTER": CONTESTED APPEALS AND THE CONDITIONS OF EMPATHY}

Late in the summer of 2010, freelance writer Rodger Jacobs was running out of time and options. He had moved from Los Angeles to Las Vegas to care for his ailing mother, who had since died. He and his girlfriend, Lela Michael, were about to be evicted from their rented home. He did not know where they would go or how they would manage. To express his frustration, Jacobs wrote a letter to the editors of the Las Vegas Sun newspaper. The editors replied by contracting Jacobs to write a first-person series of articles titled "The New Homeless: My Story." As the series developed in three parts over three months, Jacobs chronicles his experiences and those of Michael as they walk the fine social and economic lines dividing those who sleep under roofs and those who sleep on the streets.

The series immediately caught my attention for how rhetorics of empathy are employed and negotiated, both in Jacobs's personal account and in the often contentious comments of the readers. Jacobs's articles attracted nearly 750 comments in total and even received some national attention, mostly in blogs concerned with labor and social issues and in media sites concerned with Los Angeles, Jacobs's old home. Much of the debate found in the comments-and those comments include responses by Jacobs, 
Michael, and the Las Vegas Sun editor of the series-centers upon whether Jacobs and Michael are deserving of the compassion or empathy that they solicit. The rhetorical conditions of empathy are at issue here, and increasingly so as the series develops. What began as articles about Jacobs's difficult situation become more and more concerned with what Jacobs describes as a painful and upsetting public reaction to his posts. The first article in the series is simply titled "I Am Frightened" and serves to introduce Jacobs and explain how he came to be on the verge of homelessness as he prepares to be evicted from his home. The second, published a month later, is titled "Hostile Toward Homelessness" and updates Jacobs's situation as he is now living with Michael in a Budget Suites of America extended stay hotel. But much of the second article is concerned with the reader reaction to his first post. That trend continues with the third article, titled "Homelessness and the Indignity of Hurtful Speech." In that third and final piece, published more than two months after the second, Jacobs takes on his critics and tells of his plans to move back to Los Angeles, saying goodbye to a community that he feels has turned its back on him. Each article is accompanied by a video, which does much in adding to Jacobs's demonstration of his situation and his pain, undeniable in the video, as he appeals for empathy.

In this chapter I use the series as a point of analysis to argue further that rhetorics of empathy are a vital and underexplored component to much social and political debate. I analyze the series and comments in order to show how the conditions of empathy are rhetorically constructed and how they function as invitations or, more forcefully, calls to empathy, which may be subject to rejection upon those same contested rhetorical conditions. I build my analysis upon the psychological, philosophical, and literary 
conditions of empathy and compassion, such as proposed by Nussbaum. Much of the debate in the articles and the comments center upon appraisals of the quality and severity of another's suffering, whether that suffering is deserved as a consequence of another's actions or is undeserved, and recognition of a "self-other overlap" in which one views the experiences and possibilities and fate of another as having significance and correspondence with oneself. I demonstrate the ways in which the social and personal arguments within and surrounding the series also address these rhetorical conditions for empathy. Jacobs writes to evoke empathy in his audience. As I further demonstrate, those who deny Jacobs and Michael empathy do so on upon the same conditions in which Jacobs bases his appeal. His critics argue, for example, that Jacobs does not deserve empathy because he is responsible for his situation. The failings are not social or economic, they argue, so much as personal. Such arguments may be motivated in part because of the demands that empathy also makes upon those who would accept and extend it. To answer Jacobs's evocation of empathy affirmatively would force the readers to see differently not only Jacobs but also their community and perhaps themselves. Such a change in perception may also lead to a change in action, so that one is moved to work to change the conditions that led to Jacobs's situation or to help Jacobs directly or those like him. In the end I argue that rhetorics of empathy provide an important means for understanding how social issues are personally perceived, argued, judged, and acted upon. Those judgments are important because they may ultimately lead to social action, which begins with rhetorics of empathy.

My analysis of Jacobs's articles and their response builds upon that of the previous chapter. As in the speeches of Obama, Jacobs's rhetorical strategy is largely 
based upon empathy. But while Obama was promoting empathy as a value, performing himself as an empathizer, or attempting to move his audience to support his candidacy or his political agenda through rhetorics of empathy, Jacobs's agenda is less explicit. There is a link next to the articles so that those wanting to donate money to Jacobs can do so. But the articles do not read as solicitations. Jacobs seems to be seeking more than anything else simply empathy itself. Or you could call it understanding or validation, sympathy or compassion. He initially wrote the editors of the Las Vegas Sun for the same reasons, not so that they would give him money but so that they might hear him out and empathize. He also wanted them to recognize that stories of economic hardship are not abstract issues but are quite real for those people who are suffering them. Whereas Obama is trying to move his audience to empathize with somebody else in support of an agenda, Jacobs is trying to move his audience to empathize with him. The series that Jacobs writes and the resulting comments do much to showcase the conditions of empathy at work, as they function rhetorically in most rhetorical appeals to empathy. Jacobs is able to respond to his critics in posts and in subsequent articles and in comments - and they likewise are able to respond to him and to one another-in ways that showcase the contested conditions of rhetorics of empathy and how move to empathy may be rejected.

There is much at stake in Jacobs's accounts both of life on the edge of homelessness and of the stinging reaction as well as the generous assistance he received from his readers. First, there is everything at stake in his own life and that of Michael. Then there are questions about the type of people we are as community members and as readers and writers of the series. There are also questions about social policies, personal 
and social responsibilities, and the relationship of circumstance and accountability. Finally there is the question about how all of these are negotiated in the pages of the Las Vegas Sun in a city reeling in a recessionary tailspin. At the time of the series, Las Vegas, once among the nation's greatest growing economies, was the national leader in foreclosures and unemployment. These questions are all raised and debated through Jacobs's experience and the resulting negotiation of rhetorics of empathy, its employment and its rejection.

\section{The Conditions of Empathy}

Empathy is commonly understood as an unconscious process. By that I mean that people generally do not think of themselves as deciding to empathize or to not empathize in their daily encounters with others. Take motor mimicry as one example of empathy in action; we do not consciously decide to make facial expressions mirroring those of conversation partners or the characters we see in films. We just seemingly do so. This natural understanding of empathy as a human function — which should not come at the expense of the important cultural, rhetorical, and social functions and expressions of empathy-makes the analysis of empathy more difficult. How do we analyze the cultural and rhetorical functions at work in something that appears to occur naturally? This difficulty is reflected in the lack of rhetorical theory addressing empathy. As noted in the opening chapter, rhetorical theory on the emotions and identification is useful in understanding rhetorics of empathy but do not account for how empathy functions socially in contributing to moral judgments and actions. Fortunately, there are other related areas to look for approaches to understanding empathy that may be useful for 
rhetorical analysis. Before delving into a rhetorical analysis of Jacobs's series, it is useful to outline the conditions at work in his appeals to empathy.

In my analysis in this chapter I rely heavily upon the cognitive requirements of compassion as proposed by Nussbaum because they provide a framework for how empathy may be read and determined. Although Nussbaum is not a rhetorician, she does work in the pragmatic and Aristotelian traditions with a strong focus on the civic function of the humanities. Let me acknowledge at the forefront in using Nussbaum's conditions that compassion and empathy, although strongly correlated, are not the same. There are problems with importing Nussbaum's cognitive elements of compassion to serve as a theoretical foundation for the rhetorical conditions for empathy. I will return to these concerns throughout my analysis, but I wanted to recognize them early in defining my approach. In order to understand the rhetorical work of Jacobs's series and the conditions of the readers' response, I combine Nussbaum's requirements for compassion with the psychological concept of "self-other overlap" and the work of social psychologist Adam Galinsky. I further add to Nussbaum's Aristotelian theories of suffering and pity through Vetlesen's argument for the importance of perception of the human reality of a situation. As discussed in the previous chapter, this perception contributes to moral judgment and action and is a significant part of Jacobs's strategy in moving his readers to empathize with him. I take this perception to be rhetorical in the ways that it depends upon a demonstration of and attention to the personal. I begin with an overview of the relevant conditions for empathy before going into a close reading of Jacobs's series, the exchange in the readers' comments, and a consideration of what is at stake with such rhetorics of empathy. 
In establishing her cognitive requirements of compassion, Nussbaum draws upon a long philosophical and rhetorical tradition—from Aristotle through the Stoics, Rousseau, Schopenhauer, Adam Smith, Spinoza, Kant, and Nietzsche. She also turns to contemporary psychological research in order to arrive at three common elements of the cognitive structure of compassion. As Nussbaum describes them, those conditions are: (1) "the belief or appraisal that the suffering is serious rather than trivial," (2) "the belief that the person does not deserve the suffering," and (3) "the belief that the possibilities of the person who experiences [or witnesses] the suffering are similar to those of the sufferer" (Upheavals 306). Nussbaum questions the necessity of that third condition, which is derived from Aristotelian philosophy, while adding to it her idea of "eudaimonistic judgment," in which "the person must consider the suffering of another as a significant part of his or her own scheme of goals and ends. In effect, she must make herself vulnerable in the person of another" (319). In my analysis I conflate a shared vulnerability of suffering and eudaimonistic judgment with the related and broader condition of a "self-other overlap." Together these include shared possibilities, shared vulnerabilities, recognition of a common humanity, and shared significance in one another's lives.

Nussbaum's conditions will become clearer in direct analysis of Jacobs's series and the responses. As a general overview of those conditions, let us start with the appraisal of another's suffering as significant. Empathy is not limited to suffering, although it is commonly experienced in concert with the perception of the pain of another. The more significant the perceived suffering the stronger the empathic response tends to be. We do not generally empathize too strongly with someone who suffers from 
a stubbed toe, for example, or frets over a lost dollar, or mourns the death of a fish. We do not empathize much in these situations because we appraise the suffering as trivial. However, personal details and context are important here, because if that stubbed toe is suffered by a professional dancer, then we may appraise that suffering as more significant due to its consequences and empathize all the more.

In order to perceive another's suffering or any emotional experience we need to pay attention to the personal. Empathy is a way of understanding others through habits and means of perception. Traditionally, these are others who we may see face to face. But as we have begun to relate to ever more distant others, we have sometimes lost sight of their faces. Some modern communication technologies have re-established face-toface communication over great distances. Still, when attempting to move others through rhetorics of empathy, there is a need for personal details so that the other might find a presence in the attention and concern of an observer. The personal humanizes. Vetlesen highlights the importance of the personal, or of the "human dimension" of an issue, when he writes of perception and empathy. Such perception is a rhetorical move. In Vetlesen's words, "missing the human dimension of the situation, I also, and for that very reason, miss its moral dimension" (179). It used to be, Vetlesen writes, that "under conditions of physical proximity, where the full exposure of changing looks is allowed for, to matter to one another, to be engaged in the What next? is the primordial form of relating to each other" (202). We no longer operate exclusively under those conditions. In order to enable empathy, rhetorically or otherwise, we need ways to again matter to one another and to alter the perception of proximity. The way to do is to personalize a situation, to better allow access to that human dimension. (We should be careful, however, not to 
personalize it too much.) Suffering is always more immediate and more likely to be perceived when it is attached to a face, a name, a person. This is one reason why the video components of Jacobs's series are so effective. It is one thing to read of his psoriasis. The reader had to take Jacobs's textual description for what it is. But it is another thing to see in the video Jacobs's cracked and peeling hands. He shows his hands directly in response to reader comments that his psoriasis is not that bad and is the equivalent of a hangnail.

Nussbaum's second condition is that of not assigning responsibility or fault. This condition also raises questions about the distinction between empathy and compassion. We may not empathize so strongly with somebody who antagonizes a dog and is bitten because we understand the bite to be partially the fault of the antagonistic victim. We do empathize with the victim who is not at fault or whose fault is limited. This is another reason why donation campaigns featuring suffering children can be so effective at engaging empathy, because we do not blame children for their poor health, poverty, or other social conditions the same way that some people may blame their parents or other adults. We therefore appraise the responsibility of children in a way that increases our compassion for them. The appraisal of fault also points to the importance of context and history. Those who understand one's life conditions to be largely a result of social and historical forces not under one's control may more readily empathize with people who are victims of those same forces. Those who view one's life conditions to be largely a result of one's own decisions may be more likely to assign responsibility and resist empathizing with the victims of social conditions. As will be clear in Jacobs's series, the 
idea of responsibility is highly contested. His complicity in his situation is offered as a reason to deny him empathy.

The third condition, that of recognizing a self-other overlap, can be traced back to the Aristotelian idea that empathy requires a belief that we and our loved ones have similar vulnerabilities and possibilities for suffering as does the victim with whom we would empathize. Aristotle supports this understanding in his discussion of pity, his closest comparable term to empathy. It is worth recalling here Aristotle's definition of pity, as discussed in the first chapter. Aristotle writes in Rhetoric, "Speaking generally, anything causes us to feel fear that when it happens to, or threatens, others causes us to feel pity" (63-64). This speaks to the earlier condition that we need to appraise the other's suffering as significant and legitimate. Moreover, Aristotle is making a contemporary argument that in order to understand the suffering or emotional conditions of others we need to be able to relate them to our own capacities and experiences. The significance of difference is implied. We have difficulty empathizing with those who seem less like us, who seem to have wholly different vulnerabilities and experiences. Although it is critical that we recognize differences, the totalization of those differences can severely impair empathy. This is evident, for example, in conflict when enemies are dehumanized so that they no longer share the same humanity and possibilities for suffering that others do, thereby inhibiting empathy and enabling the worst of warfare. At that point enemies may be excluded even from pity. There are examples throughout modern warfare of such rhetorical moves to eliminate enemies or other victims from human consideration and pity. Aristotle adds to his consideration of pity,

Pity may be defined as a feeling of pain at an apparent evil, destructive or painful, which befalls one who does not deserve it, and which we might 
expect to befall ourselves or some friend of ours, and moreover to befall us soon. For if we are to feel pity we must obviously be capable of supposing that some evil may happen to us or some friend of ours, and moreover some such evil as is stated in our definition or is more or less of that kind...And, generally, we feel pity whenever we are in the condition of remembering that similar misfortunes have happened to us or ours, or expecting them to happen in the future. (Rhetoric 69-70)

The Aristotelian influence in Nussbaum's conditions of compassion is evident here as Aristotle underscores the argument that the assignment of personal responsibility inhibits pity. This is a social determination. More importantly for the condition of self-other overlap, here Aristotle is arguing that we need to understand ourselves as having or as capable of having vulnerabilities similar to those of another. If we do not, we will have trouble feeling compassion or even empathy. Finally, Aristotle comments upon the importance of personal experience in recognizing a self-other overlap. He also realizes that we recognize that overlap not only through personal experiences and capacities but also through those of family and friends. As Hoffman has argued, this one way to turn the familiarity bias-the bias that we most readily empathize with those most like us-into an instrument of empathy rather than an impediment by imagining those close to us in the situation of a victim.

The self-other overlap also refers to Nussbaum's assertion that empathy requires “eudaimonistic judgment." In basic terms, this is the requirement that one believes the other person matters, that the other has bearing on one's own life, and that the other is to be included within one's circle of human concern. Eudaimonistic judgment can be based upon an understanding that one and another are members of the same communities. We may be not so quick to empathize with a depersonalized other in some distant country if we do not think that person's life has any significance to our own. We may, however, 
empathize if we view ourselves and that other as part of a common global community. We may empathize even more so if we personalize that other so that his or her life acquires some presence or significance within our own, better creating the conditions for eudaimonistic judgment. The idea of a shared humanity - that there are some similarities in the human experience and that human concerns might transcend culture and geography-is part of the self-other overlap condition in the ways that it supplies shared vulnerabilities and possibilities. A shared humanity also establishes a common human community so that one believes that another's suffering is also one's own concern. We see this shared humanity most readily applied in the context of human rights. I should note quickly, however, that I do not intend the idea of a shared humanity to somehow negate very important cultural differences. These are not all-encompassing commonalities. I mean to recognize those differences even while affirming that critical differences do not entirely negate the most basic similarities in human experience or concern for others.

Finally, the self-other overlap includes rhetorical ideas of identification, such as argued by Burke. In viewing myself as sharing a humanity and concern with another and as having similar vulnerabilities and possibilities for suffering, I also should be able to at least partially identify with the other. The self-other overlap enables identification, just as identification can be understood as helping constitute the self-other overlap. The conditions are mutually reinforcing. This critical condition of recognizing a self-other overlap also underscores one of the liabilities of empathy. We most readily empathize with those whom we have the most in common, those with whom our perceived self- 
other overlap is greatest. This contributes to the familiarity biases that work against the extension of empathy to those with whom we do not so readily identify.

In drawing upon Nussbaum's cognitive elements of compassion I may have given the impression that compassion and empathy are interchangeable. They are not, although they do have much in common. In particular, the conditions for empathy and compassion are similar because empathy is often a component of compassion. Nussbaum recognizes as much when she writes, "If empathy is not clearly necessary for compassion, it is a prominent route to it" (Upheavals 332). The conditions for compassion may thus be seen as conditions for empathy since empathy is a "prominent route" to compassion. Speakers or writers who would attempt to move another to an empathic position would do so with many of the same rhetorical strategies. And those working to deny another empathy, or to argue against the extension of empathy to those others, would do so on the same basis. This is not to ignore the important distinctions between empathy and compassion as positions. Compassion is always for another's suffering, while empathy frequently applies to suffering but can also be an experience of another's boredom or joy. Empathy leads to and influences moral judgment, but empathy does not depend upon a congruence of judgment as compassion does because in order to feel compassion we must take up a moral position parallel that of the other. On the other hand, we may be able, for example, to empathize with the plight of the guilty prisoner sitting in solitary confinement even while we do not feel compassion for him or her because of the crimes committed. We do not need to feel the prisoner is morally in the right in order to feel empathy with him or her. Admittedly, this distinction between empathy and compassion does somewhat trouble the rhetorical conditions considered above. But I do not think that the distinction 
limits the validity of using the conditions for compassion as tools for a rhetorical analysis of the conditions of empathy.

The rhetorical conditions of empathy are those positions and arguments that would support empathy. They are (1) an appraisal of another's emotional state, particularly suffering, as significant. This may be accomplished through the personal display of pain and emotions or by otherwise putting a face to and describing the human dimension of a situation. (2) An assessment of the victim as not at fault for his or her situation. And, (3), recognition of a self-other overlap through a shared humanity and shared emotional possibilities and vulnerabilities. As I will demonstrate, these conditions matter because of the moral and personal demands that empathy places on us. We can accept, deny, or ignore these as we relate to one another. These rhetorical conditions of empathy are at play in many of the debates over social policies, the plight of others, and how we might and should respond. They contribute to our personal and social identities as individuals and communities. They are instrumental in how we read and perceive, judge, and respond to one another, all of which include rhetorical actions. With this overview of the conditions of empathy in mind, let us now return to Jacobs, his life among the newly or nearly homeless, and the responses of his readers in the pages of the Las Vegas Sun.

\section{The Display and Appraisal of Suffering}

We can suffer in many ways, including, but not limited to, the physical, psychological, emotional, existential, spiritual, as well as empathically in witness to another's suffering. These ways of suffering frequently overlap, so that physical suffering 
takes a psychological toll, or continued anxiety might manifest itself physically. Jacobs's display of suffering in the series may be collected in two broad categories, the physical and the psychological or emotional.

Jacobs suffers from numerous physical afflictions. He catalogues these in his first piece, "I Am Frightened":

I have been afflicted with severe psoriasis and advanced psoriatic arthropathy (arthritis) for eight years; several months of the year I must use an electric wheelchair just to get from one room to another due to severe plaque psoriasis on my feet. I am also plagued by hypertension, gout, GERD, perennial allergies, the early stages of COPD and bipolar disorder. Lela is 52 years old and not in the best physical condition herself.

It is an overwhelming list. Some of the terms are not explained-GERD and COPD—so that the reader is left only with the impression that, yes, this man suffers from numerous medical concerns and must be in pain. There is also risk to such an extensive list, however. It can overwhelm a reader's sympathies. Those who attempt to empathize with these conditions may be at risk of empathy fatigue or what Hoffman calls "empathic over-arousal," defined as "an involuntary process that occurs when an observer's empathic distress becomes so painful and intolerable that it is transformed into an intense feeling of personal distress, which may move the person out of the empathic mode entirely" (198). Furthermore, the specifics Jacobs's experiences, of what it means to have gout and arthritis, are not detailed, so that the actual suffering is lost within the catalogue. The most affective part of this list is when Jacobs describes his inability to walk from one room to another. That is something readers can understand as a personal detail to which they can relate. 
Many of the initial reader comments on Jacobs's physical suffering focus upon his smoking habit, evident in the video that accompanies the article. Typical is a comment by TomD1228: "Stop smoking. My god you have health issues as it is" ("Frightened" post 72). Some readers blamed Jacobs's health issues and even his current situation on his smoking. Smoking for these commenters became a way to take attention away from Jacobs's physical suffering and to assign Jacobs greater responsibility for that suffering. As for Jacobs's other health concerns, commenters questioned their legitimacy and their severity. Samjung23 writes, "I doubt you have all those medical problems. It's either that, or you need to man up and get over it" (post 97). Adds rphamblin, "It sounds like you're a hypochondriac" (post 231). Jacobs, his girlfriend, and even the Las Vegas Sun editor of the series soon become involved with the comments. The health comment that seems to have most annoyed Jacobs is one by Vicarious, who mocks the supposed severity of Jacobs's condition. Vicarious writes, "This guy gets his meds and his state aid because of Psoriasis? Hey dude go to CVS they have a whole row of creams for that and your jock itch. Umm I have a hangnail can I get full medical, dental and vision? Because it f-ing hurts" (post 323). Jacobs later reads this comment on camera and displays his hands in order to show the severity of his psoriasis. But the move by Vicarious is a common one. Readers attempt to undercut Jacobs's appeal for empathy by arguing that the conditions for that empathy—in particular the severity of Jacobs's suffering—are not met.

Jacobs responds by telling Vicarious to "get an education" and then goes into a prolonged explanation of his psoriasis condition ("Frightened" post 331). In most of his comments Jacobs is rather patient with his responses, but he ends this post by writing, "I do not know which is more staggering: your ignorance and arrogance or your willigness 
to share it with the world under the cloak of anonymity, of course, because cowards like you will never use their actual names and stand accountable for their words and deeds" (post 331). This is an important note. The Las Vegas Sun website at the time asked that people comment through registered accounts but allowed them to register those accounts under whatever display name they chose. The Las Vegas Sun did so in the thought that forcing commenters to register would create more of an online community and lead to better quality comments. Still, while they are commenting through registered accounts, the true identity of the commenters can remain anonymous behind user names to those reading the comments. This anonymity seems to further increase the distance between Jacobs and his readers. With greater distance, the move to empathy is weaker. The moral obligation that Vetlesen attributes to empathy as a demand placed upon the viewer appears to be diminished when the viewer can act as an anonymous participant. There is an interesting connection here between empathy and accountability, one that anonymity seems to negate. The anonymous function of the comments is apparent in many of the commenters' names. (For those who did have their supposedly real name in parenthesis after their username in the comments section, I included only their username in citations for consistency and because I would not be able to verify their real names in any case.) Jacobs continues to respond to Vicarious's comment and others like it in his second piece for the Las Vegas Sun, writing,

One of the comments in the original Sun article, comparing my condition to "a hangnail," represents common public ignorance about psoriasis and its arthritic byproduct. Psoriasis is not a skin disorder, it is an immune system disorder with serious side effects. I am plagued by tendinitis, enthesitis (pain and swelling where tendons and ligaments attach to the bone) and I am exhibiting symptoms of severe joint degeneration in my hands and feet. I live with pain 24/7. ("Hostile") 
Jacobs's strategy is to correct Vicarious on his understanding of the facts of the affliction and to mock his ignorance of the disease. On video Jacobs is dismayed at the commenters' lack of knowledge about psoriasis. In terms of rhetorics of empathy, this effort to educate his readers about psoriasis is of dubious effect because it is not the definition of psoriasis that is being debated but its contribution to Jacobs's suffering and his current situation. Jacobs would perhaps do better to focus upon what it is like to endure his conditions rather than upon providing a clinical definition. The most powerful rhetorical moment is not his definition of psoriasis but when he shows his hands on video. I do not think such a display only works on video; Jacobs could have similarly described his hands in his articles so that people might better understand his condition and empathize with him. His final statement in the above quote, that he lives continually in pain every day, is more striking in this regard for its elicitation of empathy in foregrounding Jacobs's experiences with his ailments.

The variety of reader comments on Jacobs's condition include those who diminish the degree of his suffering and those who blame Jacobs for his pain, due to his smoking and what they consider other poor life and health decisions. There are those who allege that Jacobs is exaggerating or lying. For example, some dismiss Jacobs's physical pain and tell him to get a job at McDonald's. Jacobs's response:

And for those of you suggesting that I find another line of work, I invite you to go back and look at Katie's video again; do you see the state of my arthritic hands? The dry, peeling skin that has to be moisturized every half hour? I've said it before in previous comments and I'll say it again: What part of "disabled" do some of you people not understand? ("Frightened" post 133).

The frustration and pain are evident in this response. It has a different tone and effect than did the initial article in articulating Jacobs's condition. Jacobs is asking readers to 
watch the accompanying video so that his psoriasis and his pain in particular are not simply abstract concepts to them. Seeing the condition allows one to better empathize, although Jacobs suggests here that they turn to the video not just as a means of enabling empathy but as documentary proof of the seriousness of what he describes. The video representation and the textual description of the significance and consequences of his condition support each other in adding to Jacobs's appeal.

But not all readers are so critical in their responses. There are those who respond favorably to Jacobs's appeal to empathy. One reader, under the username quatorze, responds by writing, “GOOD LORD PEOPLE! Didn't you read this paragraph? [continues to list Jacobs's ailments] Not everyone has your good fortune. They are unfortunate. Show some compassion and empathy" ("Frightened" post 53). However, such empathic responses are greatly outnumbered by those denying empathy. This may be due in part to a greater drive to comment when readers find themselves in opposition to the Jacobs's appeal rather than moved to agreement. Comment sections often function as spaces for voicing dissent. The empathic comments in regard to Jacobs's condition generally reaffirm the severity of his suffering and point back to the details of his conditions, such as the psoriasis that would limit his ability to work in a fast food restaurant.

A third and much less common type of response to Jacobs's description of his suffering is that of sharing an account of one's own suffering. An invitation to empathize in these instances is met with a demonstration of empathy and invitation to others to empathize in return. Telling stories of one's own suffering may be a way to demonstrate empathy. That is, unless those stories start to distract too much from the focus on Jacobs. 
Readers who have suffered may read Jacobs's article, empathize with it, and feel that the context of the article, their empathy, and what they would expect to be Jacobs's empathy for their situation as well all contribute to offer a safe place for them to tell their stories for the purposes of empathy. For example, there is the comment of thirtyish, who writes, "While I have not walked in your particular shoes, I do walk in comfortable flats, because I have rheumatoid arthritis. As you know, RA is very similar to your PA, and many of the medications are the same. I used to take Enbrel and Methotrexate. Used to. Before I was laid off 15 months ago" ("Frightened" post 388). Jacobs responds with empathy, writing, “Thirtyish, I literally feel your pain” (post 389). Sharing understanding, experiences, and an account of one's own suffering is another way in which people empathize. A risk in such moves toward empathy is what Hoffman calls "egoistic drift." As he defines it, "egoistic drift" occurs when one's self-focused empathy becomes empathizing with oneself at the expense of the other, so that the other's experiences and feelings are supplanted by one's own empathically-initiated recollections. But comments about arthritis and the resulting "I literally feel your pain" do not approach egoistic drift.

There were fewer responses to Jacobs's descriptions of his psychological and emotional suffering. This is likely in part because Jacobs does not spend as much time elaborating upon these ways of suffering, and it may be in part because psychological and emotional suffering is sometimes more difficult to describe, understand, and relate to when it does not include a commonly accepted cultural context or form, such as in the death of a loved one. The emotional distress of losing one's home and having one's sense of identity threatened in a poor job market is not so easily translated. Still, Jacobs does attempt to make this suffering clear. The title to his first piece in the Las Vegas Sun is 
simply "I Am Frightened," a way of clearly stating his psychological state. Elaborating, Jacobs writes, "I am overwhelmed with fear, anxiety and uncertainty; God knows I've made some hard left turns on the road of life in the past, but at 51 and in ailing health, it is with a dreadful sense of angst and hopelessness that I greet this new personal catastrophe." Reading this it is not exactly clear how his fear and anxiety manifests itself in Jacobs's life, but it is clear that Jacobs is in considerable distress.

The rhetorical qualities of the comments upon the series add to Jacobs's distress. He writes toward evoking some empathy, validation, and support. He wants a supportive connection with his audience. This is part of what he aims to gain in the series. Instead he receives much more blame and criticism or, in a milder form, suggestions on what he should do to improve his life. Jacobs writes in the second piece, "Hostile Toward Homelessness," that when the first article was published he spent much of his day "defending myself against allegations" that were made in the comments. Such a defense is emotional work. In this third piece, "Homelessness and the Indignity of Hurtful Speech," Jacobs writes that the pain he felt in reading the comments has been enduring. He first thanks those who have shown him and Michael sympathy and support, then adding, "but any warmth of kindness was lost to judgmental creatures wrapped in their conservative ideology and intoxicated by their own venomous rhetoric." The change in tone here is striking. Whereas the first series invited the reader to walk in Jacobs's shoes and understand his pain, his anxiety, and his situation, by this third installment the responses and the continued stresses of Jacobs's situation have worn him down. There is a risk in appealing to empathy for oneself because it makes one more vulnerable to the rejection of that empathy from others. Jacobs's frustration and pain at the responses is 
clear as he describes the commenters as "judgmental creatures" deploying their "venomous rhetoric." What Jacobs had intended as an invitation to empathy was met by severe criticism, which Jacobs perceives as a personal attack, and it hurts.

There are at least three lessons we can take from the display of suffering in the series and the ways in which that display attempts to evoke empathy, which frequently is argued against. The first is that statements of suffering are at their most powerful when they combine description or facts with personal details. This is evident in Jacobs's responses as well as in the comments of those who affirmed the significance of his suffering. Those who do reaffirm the significance of Jacobs's suffering frequently reiterate details and portions of Jacobs's own account of his conditions, as these are clearly what they find to be most persuasive. When stated simply as an abstraction on suffering, however, the immediacy and rhetorical effect of the display is much diminished. There is not face to put to the situation or the pain in those abstract instances. The appraisal of suffering that Nussbaum calls for is purely an abstract issue when the suffering is presented in clinical rather than personal terms. Without a face-or a video of psoriatic hands- the argument turns to definitions and allegations. Second, statements of suffering are rhetorically powerful because they are difficult to de-legitimatize. For instance, TomD 1228 writes, "The only sympathy I have is for his health issues...and even there he still smokes the damn cancer sticks against doctors advice" ("Frightened" post 172). That is, even while TomD 1228 blames Jacobs, he still cannot deny Jacobs's suffering. The display of pain thus is the only condition of empathy that Jacobs meets in TomD 1228's consideration. Once presented with Jacobs's hands, there is no counter argument available other than to attack the veracity of the image or to present different 
hands. This is one reason why the video components of the series are so important and moving.

Those trying to undermine the significance of Jacobs's suffering do so by moving to one of the other conditions of empathy, such as by questioning his victimhood and asserting that Jacobs is responsible for his own suffering. They may argue against the self-other overlap by contending that they could never be in a situation like that of Jacobs because they are a different person in kind and character. Or they simply accuse Jacobs of lying. These recourses indicate that when applicable, statements of suffering may be the most powerful of the rhetorical appeals to the conditions of empathy. That power mostly applies, however, when-and this is a third lesson-the suffering is more physical than psychological. There was little empathy expressed for Jacobs's psychological and emotional state. I expect this is because psychological and emotional suffering are more difficult to portray and because they still are not granted the same degree of cultural legitimacy as physical suffering. Furthermore, psychological and emotional suffering is often considered to be under more of the sufferer's control, which raises questions about responsibility and victimhood.

\section{Questions of Responsibility and Victimhood}

Responsibility is a contested idea within theories of empathy. We may empathize with those who are victims of circumstance, but may we also empathize with those who are responsible for their suffering? The simple answer is yes, because empathy is a broad enough of a reaction to apply to suffering as well as joy, to apply to the responsible party as well as the victim. Empathy for a victim is more powerful, however, as it moves 
toward compassion and sympathy, which do include judgments on the victim's responsibility. Empathy is how we arrive at those positions. Although victimhood is more a question for compassion than it is for empathy_because we can empathize even with the prisoner in solitary confinement while understanding that the prisoner is clearly guilty—responsibility is relevant as a condition for empathy because in attempting to forestall compassion one is also attempting to forestall empathy.

Jacobs portrays himself as a victim as a way of eliciting empathy. He is a victim of the economy, of unscrupulous lenders and landlords, and of fate. He explains in the first of his series that he and his girlfriend moved to Las Vegas in order to care for his ill mother, who has since passed away. In that way he is also a victim of his good intentions. In "I Am Frightened" Jacobs describes himself and his girlfriend as "brutalized by the economy" and in debt to a "merciless payday lender." Then there is the "draconian" property management company, the state bureaucracy he has to contend with, and even the "cockroaches and black widow spiders" that Jacobs and Michael have to pay to exterminate. In the second article, "Hostile Toward Homelessness," Jacobs further presents himself as a victim of a generally hateful readership and a largely indifferent community. Jacobs tells of the day the first article is published. He spends much of that day responding to allegations of "sloth," "arrogance," "weak moral and ethical judgment," "alcoholism," and more. In the third and final article, "Homelessness and the Indignity of Hurtful Speech," Jacobs again likens the economy to a malevolent force as the "Great Recession swept in and devastated home values, savings and retirement accounts, jobs, futures, dreams, security." Worse for Jacobs than the economic pain or that in his joints is the hurtful speech generated by the series. Here Jacobs again presents 
himself as a victim of his readership, one that that he had attempted to bring to a position of empathy. He writes of the "mean-spirited remarks that have fueled my decision to leave town." Jacobs thanks those community members who offered assistance and donations, but the suffering that he describes is sufficient to overshadow the kindness of the community and to compel him to leave. Words hurt, emotionally and psychologically, and Jacobs presents himself as suffering under an unfair attack from the very readership he was attempting to empathically engage. He clearly is troubled by the response to his article and feels the pain from that response as significantly as he would any other. In Jacobs's telling, the series makes him twice the victim, first from the economy and second from the critical and mean-spirited comments of the readers.

Many of the commenters withhold empathy and compassion by arguing that Jacobs is responsible for his situation. Furthermore, they are upset that Jacobs does not assume more of that responsibility within the series. It is true that Jacobs is reluctant to admit to any mistakes on his behalf. Whether this is because he does not think he made any mistakes, or because he thinks that admitting mistakes would undercut his authorial position and his appeals to empathy is unclear. He may simply be a person reluctant to admit mistakes. Without such admissions, Jacobs is forced to endure comments such as these from Area51, who writes, "Rodger basically does not want to take responsibility for his actions" and "Oh please. The 'they are picking one me' attitude is wearing thin" ("Hostile" posts 124, 172). Area51 sees Jacobs as appealing for status as a victim who would deny his own responsibility. In a more detailed comment, Thia writes,

Tell me sir have you learned and grown as a person from this hardship? Tell me what do you intend to do differently so you do not end up in this position again? What offends so many sir, is that you are not in as bad of a place as you believe yourself to be in. What offends so many sir is that 
even with all the kindness you have received you write in a manner that see's only what you do not have and did not get. What offends so many sir it that you write in a manner that says I am a victim pity me, and takes no responsibility for your own choices. Not once have I read that you admit you regret anything. Not once have I read that you in anyway are humbled or grateful. You write sir like the kindness and generosity of others is your right and due you. (post 106)

Thia not only denies an extension of empathy to Jacobs but is offended by the ways in which he portrays himself as a victim of circumstances. To be fair to Jacobs, he does acknowledge in the article the kindness of those who offered assistance, although that assistance is overshadowed by what he characterizes as hateful responses. Much of Thia's comment argues conditions of responsibility and victimhood. People demonstrate responsibility by taking experiences as opportunities for learning and growth, promising to change, acknowledging their errors, and demonstrating work toward improvement. Thia does not see enough of this in Jacobs's article to warrant an extension of empathy toward him. She picks up on an idea frequently stated in the comments that Jacobs acts as though something is owed to him. This is one of the places where politics becomes involved in the responses. Who is granted and who is denied victim status is politically and culturally defined. Those who recognize the determinant power of social forces upon another's station in life would be more willing to see somebody on the verge of homelessness as a victim of the economy. Conversely, those who do not see such social forces as having a determinant power on one's station in life would be more likely to attribute Jacobs's situation to a personal failing, such as pride or laziness. Those same readers may be likely to allow greater empathy for somebody who is a victim of violent crime, for example, because such victimhood has greater legitimacy for some when it can be attributed to a direct and personal assailant. (There is also comfort in this, because a 
personal assailant can be caught and prosecuted.) To say that one deserves help or redress may be read as an appeal to victimhood, which can evoke arguments demanding greater responsibility.

Those commenters who extend empathy to Jacobs do so by focusing on the role of unexpected events in an individual's life. They also point out that everybody makes mistakes, which is a way of asserting the self-other overlap and of de-emphasizing the significance of mistakes that so many of us have in common. They extend empathy in arguing that it is not their place to judge Jacobs's decisions but only to empathize with him or anybody else stuck in a bad situation. For example, in response to Jacobs's article, "Homelessness and the Indignity of Hurtful Speech," The_Next_Opinion writes, “As for the people saying that bad decisions contributed to this situation- you are absolutely correct. Unfortunately, I've never met a person who made perfect decisions every time. If you meet him, give him my number" (post 103). The move here is not to absolve Jacobs of his responsibility for his situation but to argue that in this case responsibility is not so much of an issue because some mistakes are to be expected. This may be likened to a determinist argument, one in which we are all at the mercy of fate. Similarly arguing for the importance of circumstances beyond Jacobs's control, OpinionVegas adds,

As I read this unfortunate story, I couldn't help but think about what our society has become? It seems that many among us have forgotten the importance of helping people less fortunate than ouselves and have developed a sense of denial in concluding that other people's dire straits are always because of things that they did or did not do with their lives and that they could exert control over all of life's variables-that simply is not possible. Have those unforgiving souls actually forgotten that many things in life-good or bad-are undeniably influenced by circumstances totally beyond one's control? People have many different levels of support systems available to them (i.e. family, friends, savings, education, qualifications, etc...) so when unfortunate situations arise for many, you 
can't simply judge them by what you would do from your sterile and inexperienced (hopefully) perspective. (post 15)

Opinion Vegas views Jacobs's situation as “unfortunate" and admonishes others for being too quick to judge Jacobs rather than to offer help to somebody less fortunate.

OpinionVegas attributes this rush to judgment as born of "a sense of denial" because people want to view others as responsible for their own fate so that they will not have to fear the likelihood a similar misfortune visiting their own lives. This is, again, a reference to the self-other overlap, to which we will turn shortly. The conditions of life, OpinionVegas writes, are largely beyond our control.

Responsibility is a recurring theme throughout the series and the reader comments. For those denying empathy, Jacobs is not a victim. He is instead largely responsible for the situation in which he has placed himself. These commenters do not empathize because assigning responsibility allows them to focus upon the decisions that Jacobs made, and to fixate upon his failure to acknowledge his complicity in this situation, rather than to consider those circumstances that are beyond Jacobs's control and the ways in which he is now suffering. The first lesson here for those who would appeal to empathy is that the appearance of portraying oneself as a victim in order to appeal for empathy is particularly off-putting for some readers. The appeal to empathy based upon one's own status as a victim foregrounds the rhetorical nature of the request, makes it more obviously self-interested and thus more suspect, and as a result may be met with stronger denial. There is also something in the American ideal or myth of personal autonomy that makes asking for personal assistance culturally unacceptable. The catch, however, is that a successful appeal to victim status enables empathy and compassion, so there also is risk in not making the appeal. An appeal based upon the victim status of 
somebody else may be more accepted, because it is not culturally objectionable to appeal for help for another. Perhaps this is why charity advertisements, such as those portraying poor and suffering children, tend to not have the children themselves making the appeals but have some intermediary speaking for them. In that way it is not the quietly suffering children who are asking for help but another asking for help on their behalf.

We also see in the debate over assessing responsibility and victimhood the importance of focusing upon the role of outside events and circumstances in a person's life. This is a way to push back against the myth of personal autonomy, which is at the basis of much political ideology. The more than one can focus upon the importance of context and circumstance, rather than upon individual decisions, in determining the course of a life, the more one will be read as entitled to empathy on that account. Such an appeal and reading requires greater attention to social and historical circumstances. An attention to social forces is particularly important in considering issues of poverty and opportunity. Finally, I do think that some admission of responsibility would have strengthened Jacobs's position as a caveat to those seeking recognition or personal errors. By denying any responsibility Jacobs creates an opportunity for critics who fixate upon the point of responsibility. Some recognition would improve Jacobs's ethos in their eyes as he is the one appealing on his own behalf. But this is a difficult balance, because the degree to which one assumes responsibility may also begin to limit empathy. By acknowledging some responsibility, even while focusing on his good intentions and the capriciousness of life, Jacobs might have strengthened his appeal so that more reluctant readers would be willing to read his position as a victim as an honest one rather than as a suspicious request for pity. 


\section{Recognizing a Self-Other Overlap}

The third rhetorical condition for empathy, the self-other overlap, requires that one views another's life as having some significance or consequence to one's own. This generally occurs when one views oneself and another as members of the same community, even if that community is so extensive as to include all of humanity. In her interviews with altruists, Monroe finds that such a perspective of human community is a defining condition for altruistic behavior. In Monroe's words,

Altruists have a particular perspective in which all mankind is connected through a common humanity, in which each individual is linked to all others and to a world in which all living beings are entitled to a certain humane treatment merely by virtue of being alive. It is not any mystical blending of the self with another; rather, it is a very simply but deeply felt recognition that we all share certain characteristics and are entitled to certain rights, merely by virtue of our common humanity. It constitutes a powerful statement about what it means to be a human being. (206)

Monroe is describing a perspective on the self-other overlap. She argues that such a perspective can be arrived at through habits and through processes of socialization, although at it then becomes more unconscious and less connected with a consideration of moral principles. The rhetorical function of such a perspective would be of greater importance at levels of socialization and perception rather than arrived at through argumentation. As a condition for empathy, a self-other overlap first needs to be perceived.

The self-other overlap denotes concern. We see it applied within discussions of human rights and the responsibilities that people have to one another to reduce human suffering. The self-other overlap also requires a belief in some commonalities as to how we experience the human condition. Cultural, historical, social, and personal interpretations and expressions of human experiences differ widely; but to recognize a 
self-other overlap we need to have some critical confidence that there is something common or shared within our experiences of what it means to be human. This is necessary in order to begin to relate one's experiences to those of another, so that if I see somebody in physical pain I may empathize by thinking of how I feel when I experience pain. Finally, as it was proposed and developed by Aristotle and other ancient philosophers, the self-other overlap as a condition for empathy is built upon the idea that what happens to somebody else could happen to me. There is a shared vulnerability. It asks that we see ourselves as also on unsteady footing due to the precarious nature of life, even if this shared vulnerability is simply a common recognition of the inevitability of death. To take a less dramatic example, if the prospect of being unemployed is not even a remote possibility in my life, then I may find it more difficult to empathize with somebody who has recently lost his or her job. This recognition of a self-other overlap is a critical condition for rhetorics of empathy in part because it so strongly resonates with the other conditions of suffering and responsibility.

Jacobs makes a few explicit appeals to the self-other overlap. Some of those appeals center upon ethos, so that in describing himself and Michael as good, hardworking, community-minded people, Jacobs is also making a case for their similarity to an imagined newspaper audience of similarly decent people. For example, in "I am Frightened" Jacobs writes of himself and Michael, "We have been hardworking people all of our lives, honest and forthright, passionate lovers of art and culture, but soon we may need to learn how to read books and study art under the glare of a streetlamp while the thought of a warm, safe place to sleep and three square meals a day fades into memory." Jacobs is describing himself and his girlfriend in terms that many of his 
readers likely would to apply to themselves. He is saying, in essence, We are like you. Jacobs adds, then, that although they are upstanding people they are in a desperate situation, thereby implying that his readers could just as easily find themselves in a similar situation. If we are like you, then you are also like us, or so goes the implication. By making this argument Jacobs is reinforcing the self-other overlap and appealing to his readers' empathy because their experiences and vulnerabilities are similar. If not for circumstances, some of the readers might be in a situation very much like that of Jacobs and Michael. Indeed, the entire premise of the series of articles is that the experiences of "The New Homeless" are common in Las Vegas and that Jacobs and Michael are representative, in their particular way, of many people facing uncertain prospects.

Jacobs is also fond of appealing to the self-other overlap at the end of his articles, doing so in the first and second pieces. This appeal, however, is different from the one based upon similarity of character and vulnerabilities of fate. At the end of the pieces Jacobs appeals to the self-other overlap by trying to demonstrate how his life intersects with that of his readers. We are part of the same community, he is arguing. This essentially is an argument that readers should not ignore Jacobs and Michael because their lives hold significance to the lives of others and deserve concern as community members. For example, Jacobs ends his first article with a scenario in which his path literally crosses that of his readers:

And so, in your travels across the Las Vegas Valley, should you encounter a weary-looking man resting against a streetlight, one hand on a wooden cane, the other clutching a dog-eared paperback of a Georges Simenon Inspector Maigret novel—my escapist lit choice of the moment - you will be gazing into the face of one of the new homeless. Give a friendly toot of the horn as you drive by and consider stopping and dropping a fiver or a ten spot into a hand that is mangled and scabbed-over by psoriasis...don't worry, it's not contagious. ("Frightened") 
Jacobs is attempting to do much in this passage. By providing details as though he is a character in a scene, he is attempting to engage the readers' imagination as if they are encountering him on the street. He is standing beside himself in the passage, so that he becomes both the speaker and a character in this account. In this way he attempts a bit of sleight of hand in offering himself as an object of empathy, much as the host in those charity commercials might stand beside and introduce a person who suffers. Jacobs writes of readers "gazing into the face of one of the new homeless," which could stand for the rhetorical effort of the series as a whole. He is attempting to personalize the plight of the near and new homeless, and by doing so he offers readers an empathic means of understanding the plight of the new homeless in Las Vegas. His request is friendly and personal so that readers might "give a friendly toot," and he is reassuring them that they need not worry about catching his psoriasis. The overall attempt here is not only to put a friendly face on homelessness but to show that he and his readers are part of the same community and pass on the same streets. The phrase that resonates strongest with me is Jacobs's "should you encounter," as it may be read both as a hypothetical and as a question of obligation. Empathy, and the self-other overlap in particular, is all about ethical obligation and encounters, rhetorical and on the streets we travel. "Should you encounter" is experienced as a statement of possibility and as a question of the readers' dispositions. That is, do they look Jacobs in the face and allow themselves the risk and obligations of such an encounter, or do they pass on by.

By the second article, however, Jacobs is starting to doubt the invitation to this rhetorical and physical encounter, even as he still appeals to the self-other overlap. At the end of "Hostile Toward Homelessness" he notes the size and commonalities of the near 
homeless community at the extended say motel where he is living. He writes, "My path converges with the path of the schoolchildren, backpacks and textbooks in tow, their voices loud and cheerful as they scatter across the sprawling grounds of the Budget Suites. So many families live here, so many people struggling as I am, and I cannot help but feel that we are invisible to the community at large." Jacobs is describing how his situation is not unique. Many people in the community are caught in similar circumstances of homelessness. He is demonstrating the self-other overlap in the temporary housing that he and his neighbors-many of them likely the former neighbors of his readers - are forced to accept as they attempt to continue somewhat normal lives. These are people "struggling as I am," Jacobs writes. But while they are also part of the larger community, their collective presence is largely "invisible." Jacobs is asserting that their lives retain significance to the larger community-that they are there on the street, seeing their children off to school, living at the motel, all as members of that community and of larger communities-even if those larger communities would choose to ignore them.

The self-other overlap as Jacobs presents it cannot be denied, only ignored. It is a condition that is difficult to deny. Most of those denials in the reader comments are evident in arguments that the community does not owe Jacobs anything. Implied in such a denial is that not even mutual consideration or respect is owed but must be earned. Typical is the response of BrianK, who writes, "I also have a problem with anyone who thinks society owes them something" ("Hostile" post 69). Such responses and moves toward rejection have to argue for an understanding of community that is without obligations to one another. It is an argument for the autonomous individual, one that 
corresponds to arguments of responsibility that would also deny appeals to empathy. Part of the difficulty in denying the self-other overlap is that even in reading the series and commenting upon the articles a reader is admitting, to however minimal a degree, that Jacobs's life has some significance to the reader's own simply in the fact of reading and responding. It is difficult to argue that one does not care about another's situation when one is spending time reading about and then writing in response to that situation. Of course, there also are those who are oblivious to Jacobs's situation. They do not read the articles and do not encounter him as they go about their lives and therefore cannot acknowledge the self-other overlap and extend their empathy. But that is a failure to encounter an opportunity for the extension of empathy more so than the rejection of empathy that would be occasioned by such an encounter.

Much more common in the comments is an affirmation of the self-other overlap. This occurs sometimes in the form of quotes and clichés, such as when tonyasal4369 contributes, "There But for the Grace of God go I" ("Hostile" post 263). Here the selfother overlap is succinctly stated in the idea that were fates different, anybody could find him or herself in a situation like that of Jacobs. There are those who comment that Jacobs is not so unlike many others in the decisions that he has made. Askmrmark responds to criticism of Jacobs and Michael going to eat at a Denny's by writing, "Give them a break folks, You would do the exact same thing when you get in this position" ("Hostile" post 186). He is arguing for the self-other overlap on the grounds that others could find themselves in Jacobs's situation and, that if they did, they would make some similar decisions. 
Finally, some commenters support the self-other overlap by writing that they understand Jacobs's situation because they have had similar experiences, further underscoring the argument that Jacobs's situation is not unique. They use their positions as community members, as readers of the series, and as commenters to argue that other readers should see Jacobs's as not so dissimilar from themselves. The self-other overlap in these cases includes a strong experiential correlation between Jacobs and some readers. For example, Kausinkonfusion writes,

You two do not deserve the ridicule that was bestowed upon you in your 1 st article (or the articles to come), and I told you face-to-face, I am in similar shoes as you both, and in life you can not possibly always have the "right" choice to be made, therefore we all have made due with our choices, and they are proving to be quite difficult to handle as of late. ("Hostile" post 65)

Kausinkonfusion is extending her empathy on support of the self-other overlap because she has had similar experiences to those of Jacobs. This makes it easier for her to argue that Jacobs is more like the readers than they may recognize and, further, to argue as a consequence that he is deserving of empathy, not ridicule. She is also making an argument on the grounds of responsibility, but that argument is as much about the difficulty for anybody to make the "right" choices as it is a denial of Jacobs's responsibility for his situation. The self-other overlap here is both a result of empathy and a condition for further empathizing. Kausinkonfusion empathizes with Jacobs through their common experiences, and this informs her understanding that she and Jacobs have similar possibilities and similar vulnerabilities. She also works to advance empathy because in recognizing these similarities in the self-other overlap, Kausinkonfusion argues that Jacobs deserves greater empathy due to those similarities. 
The self-other overlap proves itself to be the strongest of the conditions of empathy in part because it is the most difficult to deny. It is a nuanced condition that may be implicit in many forms of an argument: in recognizing one's place in a community, arguing for similar possibilities and vulnerabilities to suffering, and in making the case for the significance of one's own life in relation to the lives and concerns and even the identities of others as members of overlapping communities. Furthermore, the self-other overlap works as a reinforcement for other conditions of empathy by making stronger connections between reader and writer in descriptions of suffering—due to shared vulnerabilities and experiences—and in supporting through shared possibilities the understanding that circumstances and situations frequently undermine strong assignments of personal responsibility for one's station in life. The self-other overlap sets itself apart from the other conditions through its work to support and enable rhetorics of empathy as well as the other conditions for rhetorics of empathy, so that the self-other overlap takes a place foremost among those conditions.

\section{Empathy as Subject of Debate}

Jacobs begins "I am Frightened" with an explicit invitation to empathize. "I invite you to talk a mile in my shoes for a few brief moments," he writes. Indeed, the idea of being in another's shoes recurs throughout the articles and comments. By attempting to employ rhetorics of empathy — with mixed results—-throughout the series, Jacobs follows up on this invitation. He includes personal details to describe his situation and his suffering. He works to put a face on the condition of the new homeless. As he writes at the conclusion of his first article, readers may find themselves "gazing into the face of 
one of the new homeless" ("Frightened"). This was the intention of the series. An editor's note to open the series explains that Jacobs is asked "to tell his story, in his own words." These invitations to empathy are recognized by much of the readership of the series, although clearly not all accept them.

Empathy and the related terms of sympathy and compassion themselves become subject to debate within the articles and the comments. After a barrage of negative comments, Jacobs attempts to demonstrate in the second article how he thinks empathy should be performed. He mentions a beautician at Wal-Mart who cuts his hair and who herself was recently homeless. He adds, "I did not ask what mistakes" she made that put her in that perilous position ("Hostile"). In the next paragraph he discusses giving away some of his and Michael's items on Craigslist. He observes a young woman who takes their dining set and he considers the conditions in which she might be in need, quickly noting, "but it's not my place, or anyone else's, to render such judgments." These may be read as retorts to the commenters on the first article and are to be understood as demonstrations of how Jacobs thinks people should empathize. Empathy, as he presents it, is not about assigning responsibility to the mistakes of others, nor is it about judging another's life choices and situation. Instead empathy is about recognizing the suffering of others and, in response, extending empathy and possibly assistance in order to address that suffering. (As mentioned earlier, empathy need not correlate only to suffering. But for the purposes of Jacobs's series, and many of the common social demonstrations of empathy, that tends to be its focus.)

The commenters on the articles argue over similar points of empathy. I have already addressed considerations of responsibility in extending empathy. Of additional 
note is how the commenters explicitly recognize invitations to and demonstrations of empathy and then affirm or reject those. In this regard the responses tend to extend empathy, reject it, or comment upon the rejection of that empathy by others. "I am empathetic to your plight and the fear you feel...Vegas can be a very hard place to live when you are 'down in life,"” writes Cuts240 ("Hostile" post 11). Along the same lines, but drawing upon personal experiences, sn 1254jk writes, "I was in similar situation two years ago, I do get work while I was in Vegas, but not enough. So I walk out of my home and head back to California. I do sympathize with the Jacobs on their hardship, because I was in same predicament where they are now" ("Hostile" post 94). In contrast, typical of those rejecting empathy are comments such as these by CliffHarrison, who writes, "I've completely lost what little compassion I once had for this couple," and runmad, who adds, "I have zero sympathy for this couple" ("Homelessness" posts 2, 3). Their rejections of empathy are based upon recognition of Jacobs's appeals to empathy within the articles. They see those appeals, feel the rhetorical imperative to respond, and do so by explicitly denying an extension of empathy.

These denials of empathy themselves become a topic of discussion, especially as Jacobs's articles begin to be as much concerned with the tone of the response as with the situation he and Michael are in. While not so much making an argument for empathy, or reinforcing the rhetorical conditions of empathy, some commenters are dismayed at the lack of empathy shown by their fellow readers. LT2LV writes after the second article, "The hatred and lack of compassion in so many of these posts is appalling and heartbreaking" ("Hostile" post 86). More forceful is Nick_Danger, who writes, "People read the articles. Your comments are what he is writing about. Hate and a lack of 
understanding for the less fortunate... So ease up, show some compassion and learn from a man who is willing to share his pain. Thank you Sun for allowing this man to educate us ("Homelessness" post 5). Louise adds in a later comment, "The backlash connected to this story is crazy. This man's story is personal, and if people don't want to read it they shouldn't. But to belittle him because his story isn't pathetic enough in their eyes is sad and indicative of people who lack true compassion" ("Homelessness" post 26). Nick_Danger and Louise are locating the lack of expressed empathy as a character fault on the part of the commenters. They are admonishing them as fellow community members. The debate over whether to extend or deny empathy thus becomes a debate over the type of community people belong to and who they are as individuals. Both Nick_Danger and Louise also turn attention back to the rhetorical nature of the exchanges, with Nick_Danger reminding the commenters that their comments do have effects on Jacobs and that Jacobs is "willing to share his pain"; Louise likewise reminds them that Jacobs's story is a personal one, grounded in his experiences, and not deserving of their criticism even as it makes appeals to their empathy.

Then there are those comments that mix some extension and denial of empathy or that express empathy as a way to move further into egoistic drift. Such moves demonstrate ways of affirming the value of empathy, and of affirming one's own value as an empathic person, but then denying that empathy to Jacobs. That denial may be in the form of offering one's own story as a way to validate one's judgment of Jacobs. Such an argument is, in effect, I understand your experience, and because I understand your experience I can critique it. This is a way to assert one's own empathy but not allow that empathy to approach compassion. An expression of empathy or of identification then 
becomes a way to deny further compassion to another. (In denying an appeal to compassion, one is also making moves toward empathy more difficult as they rely upon similar rhetorical means.) For example, Thia writes,

I have empathy for you Mr. Jacobs, I know what daily pain is like, I know what it is like to be angry and defiant. I know what it is like to have your body fail you. The thing is no one owes us anything. You sir are asking for charity and compassion as if it is your right as if your plight is everyone's concern and problem. The truth is it is not their problem; the truth is many who are working make it on less money than you have. ("Hostile" post 106)

Thia bases her empathy upon her personal experience in situations similar to those facing Jacobs. She uses her expression of empathy as a way to undercut Jacobs's authority on knowing his own plight. In effect, Thia is presenting herself as an alternative face of suffering in arguing against Jacobs's appeals to empathy. Similar moves are made by other commenters who relate stories of being homeless and how they then drew upon their own resources to get themselves out of their situations. It should be noted, however, that even among their fellow commenters some of these up-by-my-own-homelessbootstraps stories are in doubt. Arguing against appeals to empathy in this mode may be an attractive rhetorical option for commenters wishing to deny Jacobs empathy because it allows one to offer counter testimony, thereby meeting Jacobs on similar rhetorical footing. It also allows one to assert one's own position as an empathic individual. That last point is important because empathy holds strong status as an unquestioned positive social value. Those denying empathy do not want to deny empathy on the basis of the value of empathy but because they see another as not entitled to it. In other words, they do not want to argue against empathy itself; they just want to argue against Jacobs as deserving empathy. 
Attention to Jacobs's appeals for empathy, and especially the rejection of those appeals by commenters, is taken up in a few small media outlets beyond Las Vegas. The media commentary on the articles and the reader response was consistently one of dismay at the lack of empathy displayed. The articles found a wider audience and social significance given the state of the economy when they were published and the persistent fears of a breakdown in community. For example, Choire Sicha writes in The Awl,

The constant reminder of the American lack of empathy is astounding. It's everywhere...And so it was with great wariness that I approached the comments section at the end of this first-person story by a man in Nevada who, driven into destitution by disability, family medical bills, the current lack of work and shady landlords, will find himself homeless at midnight tomorrow. These comments: well, they did disappoint. They went from awful to judgmental to trashing to witch hunt.

More distressful for Sicha, then, is not the economic plight and social policy failures that Jacobs faces but the nature of the comments and what those comments say about the American public. She attributes this to a lack of empathy in America. This lack of empathy is becoming a common concern—although of questionable proof-among commentators who hold a strong community focus. Similarly, it is the quality of the comments that concern Susan Bruce at the AFL-CIO's Working America blog. She writes after the first article, "The lack of compassion is troubling — but the level of anger is even more disconcerting. I suspect that the anger some people have for the homeless is fueled by their own fears that they are only a paycheck or two away from being homeless themselves." There are echoes of Aristotle's theories of pity in this argument. Again, it is not Jacobs's situation so much as the response that it generates that is more troubling to these commentators. The cumulative comments begin to eclipse the articles themselves as the most significant rhetorical events within the series. It is in the comments even more 
so than the articles that rhetorics of empathy are negotiated and debated, although the initial appeals to the conditions of empathy are made in the articles.

The appeals to empathy and their acceptance and rejection as played out in the comments and resulting media analysis demonstrate the conditions and terms of debate in rhetorics of empathy. Empathy itself is presented as an individual and social value that is unopposed in its goodness. But when subject to rhetorical appeals, the conditions of empathy may be debated and empathy itself withheld based upon the effectiveness and evaluation of the appeals. None of the commenters chose to present themselves as fundamentally opposed to empathy as a value. Those who upbraided their fellow commenters for failing to empathize did so as a judgment of character, calling them mean or heartless. All of this speaks to the force of rhetorical appeals for empathy, as the social significance and value of empathy itself is not subject to debate. Instead the debate centers upon the rhetorical nature of the appeals and the personal qualities of the readers. These include personal stories and details, experiences, and personal and communal identities and obligations. They are demonstrated in the ways one might read, judge, understand, and act upon the experiences of another. Some readers donated money to help Jacobs or to help affiliated charities. Some did not. The appeals are such that Vegas01 responds, criticizing any taxpayer funds that may have supported Jacobs, "If the purpose of these articles was to get the reader to show compassion and donate money, they failed" ("Homelessness" post 56). Social debates over rhetorics of empathy are built upon the implicit demands that empathy makes upon us. They matter not least of all because there are personal and social consequences at stake. 


\section{At Stake in Rhetorical Conditions of Empathy}

Bruce's fear at the Working American blog that commenters are angry and resistant to empathizing with Jacobs because they are afraid to acknowledge their own perilous positions points to the demands that appeals to empathy make upon us. Perilous positions can hinder empathy because, as Hoffman writes, people are less likely to empathize when they are themselves in uncomfortable or unstable positions. Still, simply calling the commenters angry does not get to the deeper difficulties demonstrated within these rhetorics of empathy and their implications. Those difficulties include the demands that rhetorics of empathy make upon us. Rhetorics of empathy are inextricably tied up with questions of personal and social identification in productive as well as limiting ways. Rhetorics of empathy matter because they occupy a central position in debates over ways of understanding ourselves and our relations and responsibilities to one another.

As ethical considerations - and ones that have been shown to contribute to prosocial action-rhetorics of empathy hold personal and social consequences. They make demands based upon our inclusion in human communities. Contrary to many of the commenters on the articles, we are owed something by others, even if that something is only common human regard. Vetlesen makes this argument when he writes of the connection between the human and the moral,

The link is such that the perceived human reality of a situation involving the weal and woe of others addresses me, calls upon me, lays a moral obligation on me because I am, see myself as, and wish to be able to continue to see myself as a human being. But it must be emphasized that this link is recognized by the subject only if he or she adopts a participatory, rather than an objectifying and detached, attitude toward others. (10) 
To recognize and accept rhetorical appeals to empathy is thus to view oneself as part of that human community, so that one might succeed or fail in keeping the terms of membership in that community, the first expectation of which is regard other people as people. These consequences are evident in Jacobs's series. Some of those who empathize with Jacobs are compelled to offer support, assistance, validation, and empathy. Once one empathizes, it is more difficult to simply continue to the next article and leave Jacobs and others like him to their fates. Empathy denied, on the other hand, makes no additional demands of the reader or witness. This obligation is further distanced through the medium of the articles as a substitute for the face-to-face and the largely anonymous commenting system on the Las Vegas Sun's website.

Perhaps more significantly, to be moved to empathy entails consequences for how one views oneself and others and the relationships between. Readers who recognize a self-other overlap and empathize with Jacobs would see themselves as potentially homeless. They would necessarily see something of themselves in Jacobs and something of Jacobs in themselves. This is more than simply a fear of acknowledging that they could themselves be in a situation similar to that of Jacobs. To recognize the qualities of another in oneself is to open up one's own identity to revision. As Bracher has argued in Radical Pedagogy, identity is among the most fiercely guarded of personal concepts. To open up one's identity to questioning and perhaps revision is a frightening prospect, especially for those who are not so secure in their conceptions of self. For such people appeals to empathy from and with another who is too dissimilar from themselves could simply be too risky an opening to those questions of identification. 
The debate in the comments surrounding the very idea of empathy point to the work that is needed in better understanding rhetorics of empathy and their functions, contexts, and consequences. Empathy itself is an unopposed positive term in the comments. Even those who would deny empathy to Jacobs do so not because empathy as an idea is rejected but because they argue against the rhetorical conditions through which Jacobs might successfully make his appeals to empathy. Empathy itself is then able to escape critique. It may slide into egoistic drift, or empathy may be positioned contra empathy - as in "I can critique you because I know how it is to be you." But this is all done uncritically. Such discussions of empathy demonstrate the importance of a critical empathy that is always questioning the limits of empathy, always foregrounding the differences in positions between those who get to empathize and those who get to be empathized with, always raising questions about the means and consequences of rhetorics of empathy. A critical empathy reminds us that rhetorics of empathy are performed and resisted for purposes, personal, social, cultural, and political. Additionally, it forces an awareness that even as we move others and are ourselves moved toward empathy, that empathy depends upon personal differences which can never be erased or transcended. Critical empathy views empathy as always a situational approximation.

Finally, rhetorics of empathy matter because they are at the heart of so much social debate. In this chapter I have demonstrated further some of the ways rhetorics of empathy are enacted and debated. This is a valuable lens for viewing interpersonal and social discourse because it moves beyond the fact and counter-fact modes of argument that are historically given exaggerated consideration. Instead through rhetorics of empathy we see non-rational and affective arguments at work. In the case of Jacobs's 
articles, we see appeals to readers to empathize with the author, and we get to see the responses to and consequences of those appeals. By better understanding how these rhetorics of empathy are employed and resisted we can better understand the dynamics at play, the stakes of the arguments, and the relative effectiveness of rhetorical strategies based upon these arguments. Furthermore, as Lynch argues, the very liabilities of rhetorics of empathy are also what lend them usefulness in rhetorical theory and analysis. Rhetorics of empathy foreground questions of the relationships between self and other, imbalances in power positions, and how we assess states of emotion, responsibility, moral judgment, and obligations. I will expand upon this value of a critical rhetorics of empathy in the final chapter.

The debates over empathy within Jacobs's series in the Las Vegas Sun are at their core debates over ways reading and interpreting Jacobs, his experiences and situation, and rhetorics of empathy in general. They are debates over who gets to tell and assess Jacobs's story. The extension and denial of empathy can thus be understood as following from how one presents one's own story, or puts a face on it; how others evaluate the importance of situation relative individual responsibility; and how we understand our own possibilities, vulnerabilities, and experiences in the situations of others in a given context. These depend in part upon habits of reading and writing, which is where composition and pedagogy enter consideration. In the next chapter I turn my attention there. I specifically focus upon how empathy has been considered in the writing classroom and how rhetorics of empathy might inform the ways in which we teach reading and writing. 


\section{CHAPTER IV \\ WRITING PEDAGOGIES OF EMPATHY: A TAXONOMY AND PROPOSALS}

"Who could be against teaching empathy?" asks Michael Petrilli, vice president for an education policy group, in an April 2009 story by Winnie Hu in The New York Times. The story follows the growing trend of teaching empathy in schools, which is part of a larger movement toward character education. Teaching empathy in particular is supposed to help students stop bullying, be better citizens, and reduce misbehavior and fighting. Although he is commenting upon trends in primary and secondary schools, Petrilli recognizes the general allure of teaching empathy. Indeed, who can be against teaching empathy? For teachers of rhetoric and writing, the more important questions, which I address in this chapter, include: what does it mean to teach empathy, particularly in a college writing classroom? What constitutes pedagogies of empathy? What are the possibilities, risks, and strategies of such pedagogies? I propose pedagogies of empathy within rhetoric and composition that can be largely grouped into two emphases, empathy as rhetoric and empathy as disposition. These pedagogies of empathy overlap-as rhetoric is always also about character, and disposition is always also about rhetorical positioning and performance-but the broad categorization is a useful way of considering the various purposes and strategies of pedagogies of empathy. 
I begin by developing a taxonomy of pedagogies of empathy. I include in this taxonomy pedagogies of empathy as moral virtue, as teacher positioning, and as part of literary studies, which consider empathy as a means of entering the imaginative perspectives of fictional characters. Literary empathy is relevant for teachers of rhetoric and composition because of the ways in which students may read characters, fictional and nonfictional. However, theories of literary empathy do not fully allow for the real-world human dimensions and implications of the character or people that we read and write about. Furthermore, theories of literary empathy do not foreground questions of pedagogy such as those considering how students might empathically position themselves in their writing, the demands such a positioning makes upon writers, how they might best cultivate empathic habits, and what it means to teach empathy as not just an imaginative move but also as a rhetorical one. I build upon this taxonomy to propose those pedagogies most relevant to rhetoric and composition, pedagogies of empathy as rhetoric and as disposition. The difference between the two is of rhetorical awareness and technique as distinct from the methodological cultivation of ways of reading the world, of encountering and reading others, of considering other perspectives, and of enacting and embodying these rhetorical practices. In proposing these pedagogies I draw upon contemporary theories of empathy in psychology, moral philosophy, and cognitive literary studies to outline specific strategies for pedagogies of empathy. I conclude with a consideration of the risky but necessary work of educating the emotions.

Teaching empathy is important work and an area in which the humanities should play a vital role. The importance of teaching empathy is something that the larger academic and public communities are starting to consider. For example, in Not for Profit: 
Why Democracy Needs the Humanities, Nussbaum underscores the importance of pedagogies of empathy, particularly in the humanities, within an increasingly interconnected world that puts pressure upon human bonds and understanding. The challenges Nussbaum identifies require the cultivation of abilities that we otherwise are losing as society increasingly views education as a personal rather than a social investment, and one for personal rather than social gain. Nussbaum writes, "These abilities are associated with the humanities and the arts: the ability to think critically; the ability to transcend local loyalties and to approach world problems as a "citizen of the world'; and, finally, the ability to imagine sympathetically the predicament of another person" (7). Empathy is central to the pedagogy Nussbaum wishes to recover and reinvigorate. At its best, empathy is critical thinking. Empathy supplies the bridge that enables people to transcend local loyalties to become citizens of the world. And a sympathetic imagining of another person's predicament-perceiving what philosopher Vetlesen calls the "human dimension" of an issue-is the very essence of empathy. The charge of Nussbaum, one that I assume here, is that the humanities must do more to recapture these pedagogical values and purposes. Those of us working in rhetoric and writing classrooms are especially well positioned to further develop and put into practice such pedagogies of empathy.

\section{Empathy as Moral Virtue}

Perhaps the most popular pedagogies of empathy at the moment are those that treat empathy as a moral virtue. These pedagogies provide lessons in civility and personal comportment and exercises in thinking about how one's actions might affect others. They 
are a form of character education and frequently involve anti-bullying lessons. At their best such pedagogies ask students to imagine themselves in the positions of others, although this role-taking can be problematic if not paired with critical reflection upon the limitations and biases always entailed in role-taking. Nevertheless, pedagogies of empathy as moral virtue can provide a useful way of pushing students to consider and treat one another as individuals with distinct interior and emotional lives. So, as Annie Gevertz, 12, says when she considers gossiping about other students, "Sometimes, I think about how it would feel if it were said about me, and I'll keep it to myself instead of sharing" (Hu). This is the result of a basic lesson in empathy. The purpose is to teach students to be less harmful to one another, not simply by banning bullying but by pushing students to identify with the feelings of the potentially bullied. This pedagogy may be described as rhetorical in the sense that through the use of empathic perspectives Annie is considering the effects of her words in terms of audience, emotional impact, and ethics. Annie is able to determine that were she the other person, the words she might have said would be painful.

Empathizing with another who one has hurt or could hurt-as Annie empathized-may be considered a form of victim empathy. One puts oneself in the place of the potential victim. The media too frequently is full of reports of the mournful consequences of bullying, especially online where the damage can be done without any physical confrontation and where the terrible consequences can be much more severe than expected. On the extreme end of the spectrum are victims of not just rhetorical, emotional, and psychological abuse but of physical and sexual abuse. Potter writes about rehabilitative pedagogies of empathy in her chapter "Can Sex Offenders Learn Victim 
Empathy in Prison?" (Her answer is "yes," with reservations.) As with the pedagogy of potential bullies, to purpose of teaching victim empathy to sex offenders is to change a person's understanding of his or her behavior and how it affects others. This is different from a pedagogy of empathy as rhetoric or empathy as disposition because it is not focused upon how we read and write-not even upon how we read and write about others in the world—but, like Annie's schoolyard pedagogy, it is focused upon how we consider real others and the consequences of our actions upon them. With this focus, teaching victim empathy is teaching empathy as moral virtue or character education because its primary purpose is to make people more considerate of others and then to treat others with greater compassion.

Potter's study is helpful for a deeper understanding of how empathy may be taught as moral virtue, particularly to an adult population that has a history of abusing others. Potter studied a sex offender treatment program at the Kentucky State Reformatory for Men. She attended the "victim personalization" section of the program. She describes it as "an eight-week psychoeducatoinal therapy session for sex offenders designed to cultivate empathy in the inmates, first for their victims, and second for more generalized others whom they might target as victims in the future" ("Can Sex Offenders Learn" 57). The underlying assumption here is that by empathizing with their victims and seeing them as real people instead of as abstractions or objects, the sex offenders will realize the consequences of their crimes and feel shame and guilt at the harm they have done. The program is interesting for the ways that offenders are instructed to personalize and take the perspectives of their victims. It is a comprehensive pedagogy, involving sensory, physical, imaginative, and rhetorical means of engaging empathy. Exercises 
include writing from the perspective of victims, writing from the perspective of the victims' families, and sitting for a mock rape exam in order to physically embody the role of a victim. Potter describes the exercises as targeting a full range of perspective-taking possibilities and as pushing against a flat narration of characters and events. As Potter writes,

The inmate has to develop the ability to give a full account of the victim's sensory experiences, physical space, emotional reactions, state of mind, interests, goals, friendships, and so on. Since to take the perspective of another requires that one be able to gasp more than a thin description of action, the inmate has to develop a repertoire of sensory and emotional language and experience that allow for a broader scope than the inmate's history and worldview might initially allow. (58)

Notice that part of the goal of the program is to help the inmate develop emotional language and a set of experiences that allow greater access to positions of empathy. These are important qualities of a pedagogy of empathy. Emotional language provides one greater access to a reflective and critical empathy. A wider set of experiences is important because a limited worldview, including limited experiences, also limits one's ability to entertain the perspectives of others. The most striking quality of this pedagogy is how deeply it includes perspective-taking - a central element of moves to empathyand how widely it targets personalization through the cognitive, the emotional, and the bodily. Because empathy is more than cognitive positioning, such a pedagogy is well suited to tap into a fuller empathic spectrum. It is one thing to say, for example, "Imagine how your victim feels." It is quite another to ask somebody to imagine the victim's life plans and friendships and family and experiences, and then, sitting for a mock rape exam, to imagine what the victim felt sitting in a similar position, as this program does. This pedagogical move corresponds to assertions within composition that the power of the 
affective and the physical have been ignored or misunderstood within the discipline. For example, Micciche, responding to an article by Jennifer Edbauer, writes, "Like Edbauer, I worry that, as a field, we're sometimes reluctant to consider innovative ideas-like those emerging from emotion and affect studies_as occasions for thinking about how we teach, perform, assess, and talk about writing" ("Trouble" 265). For Micciche and Edbauer, the issue is not bringing affect to writing but recognizing that affect is already a part of writing and the teaching of writing, just as it is already a part of how we might attempt to enter the perspectives of others.

Pedagogies of empathy such as those referenced in The New York Times and observed by Potter-pedagogies that broadly focus upon empathy as moral virtue and as a quality of character-have a deep history within pedagogy and the rhetorical tradition. Potter makes this connection when she writes, "The moral framework on which the sex offender treatment program relies resonates with the notion of virtue and character as central to morality. As I understand the program (and especially victim personalization), empathy is thought of as an Aristotelian virtue" ("Can Sex Offenders Learn" 59). I am likewise reminded of Isocrates's pedagogy, which combined rhetoric with ethics in the teaching of statesmen, and of Quintilian's famous definition of rhetoric as "the good man speaking well." Such ideas of rhetoric and rhetorical education combine language with action, ethics, and a person's character in relationships with others. These concerns remain critical to rhetoric and are essential to understanding and teaching rhetorics of empathy. Still, pedagogies of empathy as moral virtue are limited in their application to the writing classroom. We are not, after all, teaching schoolchildren to stop bullying one another or teaching incarcerated sex offenders to better empathize with their victims. 
Although they may recognize words as having effects and writing as one way to imagine the perspectives of another, pedagogies of empathy as moral virtue do not examine the best ways to employ empathy in the teaching of writing, or even writing in the teaching of empathy. They approach empathy somewhat as a disposition-as with any taxonomy, the distinctions here are not absolute-but pedagogies of empathy as moral virtue are more about what it means to empathize and how to do so in order to guide one's action rather than about cultivating habits in how we read and write and understand others. Perhaps most importantly, pedagogies of empathy as moral virtue also do not view empathy rhetorically as a way of purposely understanding, communicating with, and persuading others beyond the schoolchildren and sex offenders.

\section{The Empathic Teacher}

Another common pedagogy of empathy focuses upon the position of the teacher and the atmosphere of the classroom. Such a pedagogy is found in Mary Rose O'Reilly's A Peaceable Classroom and in her concern for creating a space of nonviolence, compassion, and social justice. In Notes on the Heart, Susan McLeod advises teachers to cultivate their own empathy for students as a way to understand and communicate the affective world of students. McLeod argues for the pedagogical value of the empathic teacher, writing, "It is empathy that we recognize in some of the best teachers in our discipline, teachers who work not only to understand their students but who also actively try to appreciate their perspective, who try to feel and think along with their students" (114). Perhaps the scholar who has done the most in arguing for the empathic teacher is Jeffery Berman in his Empathic Teaching: Education for Life. Berman relates English 
teachers to therapists and advocates a "relational model of education, where students and teachers interact intellectually and emotionally," what he goes on to call "a pedagogy of self-disclosure, where teachers and students share aspects of their lives with one another" (22). Likewise, Lad Tobin mulls questions of self-disclosure in telling of his involvement with a discussion group of composition teachers and personal counselors. Tobin argues that self-disclosure in the classroom should be evaluated and employed based upon its rhetorical effectiveness. Although Tobin does not specifically consider empathy as a teacher's position or as an explicit purpose in self-disclosure, he does echo O'Reilly's concern that a teacher be "personally present" (202). The role Tobin describes himself performing as a teacher is that of "someone who is infinitely curious but also emotionally consistent, open-minded but also tough-minded, approachable but also authoritative, compassionate but also critical" (201). These are many of the qualities of an empathic teacher.

There is much to value in the pedagogies of the empathic teacher or empathic classroom. To start, such pedagogies recognize that teaching is deeply personal and humane work that requires emotional investment. By playing the comparison between therapy and pedagogy, teachers such as Berman are also quick to note the important boundaries that must always be respected between teachers and students. But to be an empathic teacher and to occupy or perform that position in the classroom, even to create an empathic atmosphere, is a different pedagogical task than treating empathy as a rhetorical move or disposition. The difference is evident in how Berman defines the empathic purpose of his teaching: "The emphasis here is on how classroom selfdisclosure can lead to students' heightened awareness of themselves and their 
classmates...My teaching is based on empathy: trying to understand another person's feelings and thoughts without losing sight of the differences between self and other" (32). Berman's purpose, then, is to be empathic towards his students and to better enable them to empathize with their classmates and with him. Berman advocates that teachers make a difference in student lives by raising student confidence, helping students to personalize knowledge, being friendly and accessible, being willing to open up in class and acknowledge one's own experiences, and remaining a part of student lives beyond the classroom (13-14). Such a pedagogy may be worthwhile in outlining modes of empathic interaction between teachers and students. But this is different from focusing upon the more rhetorical and dispositional aspects of empathy or on how empathy engages writing beyond the personal. These are some of the more interesting possibilities for pedagogies informed by rhetorics of empathy. Tobin comes closer to rhetorical considerations of empathy when he writes of strategic self-disclosure. Still, strategic self-disclosure is not the same as strategic empathy, not in a teacher's role and not in the classroom or in writing.

\section{Reading Characters in Fiction and Nonfiction}

Some of the most intriguing work on empathy and reading and writing is occurring within literary studies, particularly in the burgeoning field of cognitive literary studies and in attention to the literary imagination. An individual's capacity to understand another person's position and to care about others as people and not just as bodies-a basic capacity of empathy —is supposed to be strengthened through that individual's engagement with the literary arts. Or, as Nussbaum writes, "It is an achievement to see a 
soul in that body, and this achievement is supported by poetry and the arts, which ask us to wonder about the inner world of that shape we see-and, too, to wonder about ourselves and our own depth" (Not for Profit 102). The literary arts and empathy thus become a way of reading others and ourselves. This is a common move by those advocating the cultivation of empathy through literary engagement. They hold that the ways in which we read and write about people in literature can transfer to the ways in which we understand others in the real world. Nussbaum argues that increasing these empathic and imaginative capabilities through engagement with the literary arts will further develop the empathic citizenry necessary for a healthy democracy. Similar concerns are evident in the push toward greater multiculturalism in reading works of fiction about people from diverse backgrounds and cultures.

Support for teaching literature as a means of cultivating empathy rests on some strong assumptions, as Keen points out in Empathy and the Novel. The strongest assumption is that of the empathy-altruism hypothesis. As discussed in the first chapter, the empathy-altruism hypothesis holds that greater empathy will lead to greater altruistic social action. For educators working in the humanities, the hypothesis is attractive because if reading narrative fiction cultivates empathy, and empathy leads to altruistic action, then reading narrative fiction may be considered one way of creating a more altruistic society. The attractiveness of this reasoning contributes to Keen's skepticism. She writes, "That the novel should be singled out as a technology most adept at invoking empathy and shaping moral behavior challenges what psychologists have been able to discover about empathy, but it endorses what many people believe about the transformative power of reading and of reading fiction in particular"' (35). If reading 
literary fiction can be said to contribute to a more altruistic society, then literary empathy becomes a reason to defend the humanities. There are important connections to explore between empathy and the reading of literature, but, as Keen cautions, those connections should be considered more closely before they are held as a reason—or especially as the reason-to read fiction.

Those who advocate reading literature as a way to teach empathy too often conflate reading and teaching, as though pedagogy is irrelevant once somebody opens a novel. There are, of course, many ways to read and to teach literature, and the reading of literature and the teaching of literature are very different things. Distinctions among ways of reading and teaching literary fiction are not always made by advocates of reading for empathy. Keen notes as much when she writes,

Too often the discussion of effects of novel reading combines the social and pedagogical outcomes of group discussion and classroom experiences. If the value of discussion and the contributions of teachers in the intellectual and moral growth of readers are to be understood, then these elements must not be hidden within accounts that claim to study "effects of reading" but actually conflate reading, discussion, role-taking activities, writing tasks, and teaching. (Empathy and the Novel xiv)

As Keen suggests, pedagogy and the activities surrounding reading are vitally important when considering the cultivation of empathy through engagement with literary texts. Unfortunately, Keen does not extend her focus to include pedagogy. She is more immediately concerned with the experiences of readers and the literary history and contestations of empathy.

That leaves to scholars such as Bracher the work of exploring literary pedagogy and the cultivation of empathy. Bracher has argued for the possibilities of literary education as transforming individuals and the ways in which they interact in society. $\mathrm{He}$ 
combines his psychoanalytical background with developments in cognitive studies to focus upon cognitive script formations-basically, the ways in which people learn habits of perception, interpretation, and response to certain stimuli, such as their environment and others—as a way of teaching literature for social justice. The idea is essentially that by instructing how people read others and the world in literature, and by distinguishing "faulty appraisals" or ways of reading from those that are less so, teachers of literature might also instruct people in how to read their world. The idea that there are faulty ways of reading others, in fiction and in the world, and that it is the teacher's job to address those "faulty appraisals," may make some teachers justifiably uncomfortable and concerned. I will return to those concerns later in this chapter. For now, it is helpful first to further investigate Bracher's pedagogy. Bracher notes that literature teachers have long been interested in teaching towards social justice, but that interest has been largely confined to various forms of cultural criticism and critiques of prevailing injustices. These approaches have not provided any evidence of delivering on their promises, Bracher argues, leaving literature teachers to look elsewhere "if we want our teaching of literature to advance social justice, rather than merely signaling our commitment to it" ("How to Teach" 363). The elsewhere Bracher looks to is an approach informed by psychology and the cognitive sciences in an effort to engage the reader's capacity for empathy. Bracher's pedagogy is focused upon appraisals of others. He acknowledges that there is much debate about the empathy-altruism hypothesis in relation to the development of sympathy for suffering characters through the reading of literature. But he argues that his pedagogy is different because:

I hold that the contribution of narrative empathy to social justice lies not in its production of sympathy for the suffering of fictional characters but 
rather in the fact that each experience of narrative empathy contributes incrementally to the development of more accurate and comprehensive information-processing scripts, which then subsequently generate not only feelings of sympathy but also ameliorative actions in response to real subalterns outside the text. (375-376)

This is an important distinction as it is not the reader's feelings for the fictional characters that work toward social justice so much as the reader's ways of reading those characters. This development is further accented by the pedagogical techniques Bracher advocates, techniques that direct student attention to how they read characters and how those ways of reading apply to others outside the text. The ways of reading Bracher emphasizes include greater attention to the importance of context in an individual's plight, attention to human suffering, to the common humanity characters and readers share, and recognition of the responsibilities characters have to one another and that readers have by extension to those in real life situations similar to the situations of the characters.

Pedagogies of empathy in literary studies provide a suitable starting point to pedagogies of empathy as rhetoric and as disposition. They demonstrate how psychology and the cognitive sciences can inform reading and writing pedagogies, and they provide another way to talk about teaching for social justice in terms of empathy development and the supposed connection of empathy to altruistic action. Pedagogies of empathy in literary studies also provide reasoned caution against rushing too quickly to embrace pedagogies of empathy as saving the humanities and society in general. Missing from pedagogies of empathy in literary studies, however, is a deeper engagement with pedagogy and with writing. As Keen shows, pedagogy is often conflated with reading, which demonstrates the need to more deeply consider the relationship between pedagogies and empathy development. Bracher does more of this than most. But his 
social justice pedagogy is also focused upon reading instead of writing. Student writingincluding and extending beyond the textual analysis and argumentation typically called for in literature classrooms-adds an important dimension to pedagogies that focus upon the cultivation of empathy. One of the principles of empathy is a relationship between self and other, a relationship that may be made more concrete, explicit, and may be critically examined through writing. Indeed, the relationship between writing and empathy is even stronger than that between reading and empathy, Keen finds, when she considers the authorial empathy of fiction writers, although the reasons for that relationship are not entirely clear. The strong connection of writing to empathic capabilities at least suggests that a pedagogy of empathy should be considered in the writing classroom.

Furthermore, in examining pedagogies of empathy in literary studies there is a critical distinction to be made in the perception of reality over that of fiction. The reader's relationship to a fictional character is not the same as the reader's relationship to a character read as a real person. The real person can make a moral demand upon the reader. This function of morality is built upon the human capacity for empathy and a responsibility to do something about the suffering of others when confronted with that suffering, even if the something one does is to look away. The sense of responsibility in reading about a real person is evident in many of the responses to Jacobs's series in the Las Vegas Sun, and it is the basis of Vetlesen's thesis, that in order to perceive the moral dimension of a situation one must perceive the human dimension. As Vetlesen writes, "The perceived human reality addresses me, calls on me, lays a moral obligation on me, since I am, and see myself as, a human being" (178). Vetlesen's argument that the human 
reality of a situation addresses the perceiver suggests that the perception of another understood to be a real person-or a textual representation of a real person-carries greater emotional and moral significance. I would not expect readers to have the same sense of perception and moral obligation toward fictional characters, even those whose suffering mirrors that of real world counterparts, as they would the perspectives and situations of people they read as real. The different perceptions and emotional reactions between reading fiction and nonfiction are further evident in controversies such as those surrounding James Frey's A Million Little Pieces after readers learned that Frey's seemingly autobiographical account of addiction and recovery was not true to history. The sense of betrayal on the part of the readers in learning that portions of the book were fictionalized may be understood as stemming from their emotional connection to Frey as a character, whom they initially read as Frey the real person.

We might similarly expect a stronger emotional response and sense of moral obligation in reading about nonfictional characters, such as in the texts common in rhetoric and composition courses. Indeed, a study by Batson et. al. found that when given a fictional or a nonfictional prompt in a situation in which students were to allocate funds to help different charities, empathic feelings were somewhat greater in response to the nonfictional prompt. Both the fictional and nonfictional prompts elicited greater empathy than did objective positioning. Many of the same elements of fiction that enable empathy—including point of view, narrative, and an attention to context—can be easily applied to nonfiction and personal writing. Furthermore, the psychological distancing that fiction allows is not so easily employed with nonfiction. The distance between reading Bracher's others in Uncle Tom's Cabin and reading of others in the real world is not so 
great when those textual others are read as real people rather than as fictional representations. Instead of making the leap from fictional characters to nonfictional characters, we in composition courses can start with the nonfictional. This can be the case in first-person writing in the composition classroom as well as in less personal analytical and research writing, which nevertheless frequently involve a human element and, in that, opportunities for empathy. The following pedagogies of empathy as rhetoric and as disposition, as I propose them, complement and extend the type of pedagogies advocated by Bracher and others in working to cultivate empathic habits through ways of reading and writing and in teaching students how to consider empathy a rhetorical strategy.

\section{Teaching Empathy as Rhetoric}

Empathy has long suffered a fate similar to the rest of the emotions in the teaching of rhetoric. Grouped under appeals to emotions, as pathos, the affective dimensions of rhetoric have been presented to students as something less than logic: less true, less dependable, and as a form of underhandedness or manipulation on the part of the rhetorician. Micciche has been forceful among those arguing for a reconsideration of the emotions in rhetoric and rhetorical education. "Without a framework for understanding emotion's legitimate role in the making of meaning and in the creation of value in our culture," she writes, "we impoverish our own and our students' understanding of how we come to orient ourselves to one another and to the worlds around us" (Doing Emotion 1). Rather than as additive, Micciche sees emotion as "integral to communication, persuasion, attachments of all sorts, and to notions of self 
and other" (24). Emotions are not a type of appeal, then, but always already part of rhetoric and, beyond that, part of how we understand ourselves and our world.

Among emotions, empathy occupies a distinct position at the juxtaposition of much that is at stake. Empathy is a meeting of self with other, at once personal and social. It pairs affect with cognition in productive ways as empathy is always a combination of cognitive and affective appraisals and reactions. As Lynch notes, empathy is an interesting rhetorical concept exactly because of the problems it foregrounds. Micciche makes a similar observation in singling out empathy as especially suitable for interrogating the interactions and indivisible qualities of emotion and reason. Rhetorics of emotion have been neglected in part because emotions are difficult, Micciche argues. They disrupt us, do not follow the rules of order we set, and they can be hard to identify and examine. Teaching rhetorics of empathy offers a suitable means of more closely examining the personal, social, and rhetorical functions of reason and emotions, particularly as they meet in empathy. There are two ways we might develop and employ a pedagogy of empathy as rhetoric. Those are (1) focusing upon empathy as a mode of belief, listening, analysis, and understanding; and (2) teaching difficult and critical empathy, which may be applied as a mode of critique. Both of these define empathy rhetorically and have application within writing classrooms.

Empathy is already a mode of belief and analysis. People use it every day in deciding what policies to support, what to buy, who to believe, and in making myriad judgments about themselves and other people and situations. What a pedagogy of empathy as rhetoric does is help make apparent-and therefore open to analysis, critique, and more purposeful use-the ways in which empathy is employed rhetorically. A 
pedagogy of empathy as rhetoric builds upon other rhetorical pedagogies in which arguments are made and analyzed. Rarely if ever, however, is empathy explicitly discussed within pedagogies of rhetoric as a rhetorical concern beyond the teacher's relationship with students. One of the few teachers and scholars to advocate for teaching empathy as rhetoric is Teich, who bases his argument in an appreciation of Rogerian rhetoric. Teich compares the study of empathy to that of formal logic commonly employed in courses on argument: "I believe that it is important specifically to study empathy—as important, say, as studying formal logic. Studying the empathic process provides supplementary and alternative understandings about discourse" (274). Teich outlines broad pedagogical concerns for empathy, including empathy as a hermeneutic and in the context of empathy's literary precursors, but he does not go so far as to suggest specific strategies for pedagogies of empathy.

Although they do not focus directly upon empathy, we can look to Rogerian rhetoric and Elbow's believing game to begin to develop specific pedagogies of empathy as rhetoric. Rogers identified empathic listening, or listening with understanding, as a potentially transformative means of communication. As discussed in the first chapter, to listen empathically, Rogers writes, "means to see the expressed idea and attitude from the other person's point of view, to sense how it feels to him, to achieve his frame of reference in regard to the ting he is talking about" ("Communication" 315). Continuing, Rogers writes,

It (listening empathically) is the most effective agent we know for altering the basic personality structure of an individual, and improving his relationships and his communications with others... We know from our research that such empathic understanding-understanding with a person, not about him-is such an effective approach that it can bring about major changes in personality. (316) 
Rogers's attention to changes in personality speaks to pedagogies of cultivating empathy as a disposition, which I consider next. The potential that Rogers sees in empathic listening demonstrates the power that such a rhetorical positioning can have in facilitating communication and as a means of connecting to another, showing goodwill, attempting to enter another's perspective, or, more problematically, feigning any of the above as a means of gaining a rhetorical advantage. Rogers's techniques are especially useful in talking about pedagogy because Rogers focuses so much on techniques, such as the suspension of judgment and the restatement of the other's position to the other's satisfaction. These hold important rhetorical implications for listeners and speakers in establishing ethos, values, agendas, relationships, and affecting results.

The Rogerian approach to rhetoric is echoed in Elbow's believing game and in Ratcliffe's concept of rhetorical listening. Ratcliffe argues for a rhetorical mode of invention and understanding — what she calls "standing under"—-that, like the Rogerian model, resists the immediate urge to make counterarguments and quick judgments. Ratcliffe argues for a wider type of listening, one almost as immersion, where the listener attempts to go beyond claims to approach context and values and perhaps common ground. In Ratcliffe's words, "If we recognize not just the claims but the historicallygrounded cultural logics enveloping other people's claims, we may still disagree with the claims, but we may better understand the personal and cultural assumptions (dare I say, values and beliefs) that guide other people's logics" (209). In positional terms, the difference here and in a Rogerian model is that of not standing across from somebody in opposition but instead standing beside that person in an attempt to look the same direction from a similar position, to appreciate the other's perspective. I also read in 
Ratcliffe's rhetorical listening some of Vetlesen's idea of "receptivity." As Vetlesen writes,

Fundamentally and most generally, human receptivity means an openness to the world and all that we encounter in it. Receptivity as I conceive of it signifies a "readiness to" - to attend to, to perceive, to judge, to act toward-whereby the what, the specificity, of that at which all of this is to be directed is not yet given but is rather what the subject, in his or her active readiness, is awaiting and what will set in motion the entire sequence of human response. (18)

In the work of Ratcliffe and Vetlesen, listening and receptivity are both states of openness that precede judgment or action. At least, that is the ideal. These are active states that require an attentiveness and a readiness in human response. These are rhetorical positions relative others and the world. They influence how one perceives, understands, and responds in words and actions.

Neither Ratcliffe nor Elbow means to argue for simple and noncritical acceptance. Empathy is a not a suspension of critical engagement, just a suspension of judgment toward rejection before understanding or belief. Likewise, Elbow's believing game can be seen as a method of analysis, as a different kind of critical thinking. Elbow famously compares his believing game to what he calls the doubting game, which is more prevalent in the academy and wider culture. Explaining the difference, Elbow writes,

instead of scrutinizing fashionable or widely accepted ideas for hidden flaws, the believing game asks us to scrutinize unfashionable or even repellent ideas for hidden virtues. Often we cannot see what's good in someone else's idea (or in our own!) till we work at believing it. When an idea goes against current assumptions and beliefs-or if it seems alien, dangerous, or poorly formulated—we often cannot see any merit in it. (2)

Elbow's believing game - which he prefers to calls methodological belief-relies upon experiences and emotions and inhabitance as well as propositions and formal logic to test an idea. In the ways that it relies upon these qualities it is a rhetoric of empathy. Elbow 
argues that the doubting game is very good at finding flaws but the believing game better suited to making decisions, to actually come to a position of belief or a change of mind, character, or action.

I do not mean here to conflate Rogerian rhetoric, rhetorical listening, and the believing game. Each has very important distinctions. Ratcliffe's rhetorical listening, for example, calls for more contextual awareness and less of a suspension of judgment than does Rogerian rhetoric or Elbow's believing game. Rogers is concerned with a therapeutic setting and application, not a rhetorical and pedagogical one. And Elbow directly distinguishes his approach from a Rogerian one when he writes that the believing game is not just withholding judgment and restating another's position but is instead actually trying to believe what the other person is saying, which is moving from a position of understanding to one of shared belief. I bring these approaches together because they share empathic qualities. These are some of the qualities that Teich recognizes when he writes about models of empathy, and here he is referring specifically to literary models, that "they emphasize the need for less destructive competition, less self-centeredness, less egoism, and more cooperation, more understanding, more reconciliation in personal relations and social actions" (292). This is a slightly romantic idea of empathy, one that does not fully consider culture, context, method, and difference. Nevertheless, such a conception shows how empathy might become a method, an approach, even a statement of values and a pedagogy.

As Rogers, Elbow, and others acknowledge, engaging a rhetoric of empathy is not easy and may be dangerous. A pedagogy of empathy as rhetoric would do well to account for and make use of this difficulty. It is fairly easy to empathize with a hungry child, for 
example. We want to identify with the child's hunger for what it says about us and that child. About us, the empathizer, identifying with the child's hunger reaffirms that we are caring people. It reaffirms our common humanity as people who depend upon others for nourishment and, specifically, who depend upon our family and friends and the larger community for support, particularly when we are young. Our empathizing with the hungry child reaffirms the child's common humanity, too, and it allows us to focus upon context. We rightly see the child as not being responsible for the situation in which that child was born or the political, environmental, and social factors that contributed to the child's hunger. This is an important but relatively easy empathy. By contrast, a difficult empathy is one in which we empathize with social outcasts and those who do violence to others, those we might consider monsters. To play on the title of one of Potter's articles, we might ask ourselves, Can we learn empathy for sex offenders? Difficult empathy requires empathizing with sexual offenders, murderers, and terrorists. Such empathy can be difficult but all the more necessary because of its difficulty. It is necessarily pedagogical, too, as a way of questioning the assumptions and boundaries of empathy. What does it say about us and about the murderer if we empathize with him? It says that we have a common humanity and are due some common basic consideration as human beings. Empathy in this situation gives special attention to historical and social context, asking what factors contribute to a person becoming a murderer. Empathy in this instance does not allow us the luxury of determining the murderer to be inhuman-inhumane, yes, but not other than human-which forces us in that empathy, that recognition of common humanity and historical context, to also see ourselves in the murderer and to see the murderer in ourselves. This is not empathy as noncritical acceptance but empathy as a 
means of understanding. It is difficult and even dangerous because in forcing this empathy we are taking the necessary risk of changing how read and write and view others as well as ourselves.

Missing from some of these rhetorical conceptions of empathy as a mode of listening or understanding or believing is a larger critique of empathy, which is all the more important when speaking of pedagogy. Critiques of empathy focus upon the impulse to empathize, upon easy and difficult empathies, upon power relations between the empathizer and the empathized, and upon irreducible differences, which are always a part of empathy. Empathy can serve a colonizing agenda when the empathizer starts to remake the empathized in his or her own image or begins to assume too much about what is known, because, after all, we can never have full access to another's point of view. It is worth repeating that empathy is always at best an approximation. It is this risk of colonization through empathy that concerns Kulbaga in her criticism of Azar Nafisi's Reading Lolita in Tehran. She argues that the novel enables a pleasurable or easy empathy that fits a "neoliberal feminist rhetoric of freedom and choice" without attention to critical reflection or political action. The women in the novel are too easily imagined and empathized with as Western readers would prefer them to be; that is, as upholding and desirous of Western values and ideals. As Kulbaga writes, "Rhetorically, the memoir asks for the same imaginative empathetic stance from its privileged American readers, who, as consumers of the narrative's familiar imperialist construction of the veiled woman awaiting Western empathy and rescue, are caught up in pleasurable pedagogies of identification and difference" (517). The rhetorical question critical empathic readers should be asking themselves, Kulbaga argues, is "empathy to what end?" (518). This 
question forces a critical empathy that recognizes empathy's rhetorical purposes. It is one that questions where empathy is easy and where it is difficult and what commitments such empathies allow. It asks for a constant awareness of the limits of empathy. To teach and employ a critical rhetoric of empathy is thus to be aware of the necessity of difference. It is to question power relations between those who empathize and who are subject to empathy and to always keep in mind the essential differences that keep empathy at best an approximation. These are precisely the types of rhetorical questions that students need to be asking. I expand upon critical empathy and its necessity in the next chapter.

A final benefit of teaching a critical or difficult empathy is that it provides the analytical and rhetorical tools to help students question and resist the empathic positions that others, including their teachers, might try to move them toward. Rhetorics of empathy can be manipulative. A pedagogy of empathy as rhetoric helps students understand, question, and evaluate the rhetorical uses and purposes of empathy. The following pedagogical strategies and techniques are not all entirely new. Not many teachers ask their students to explore the limits of empathy, those with whom it is easy and difficult to empathize with, and why. But a rhetorical analysis of advertisements, for example, is commonplace in writing classrooms. These strategies and techniques differ from the usual in their focus upon empathy as a rhetorical move and device. Together they offer a more comprehensive strategy for teaching empathy as rhetoric in writing courses. Thus employed in the classroom, a pedagogy of empathy as rhetoric might:

- Teach and incorporate techniques of Rogerian rhetoric, such as the restatement principle. In courses on argument and social issues I have had 
students practice identifying controversial issues with one another, locate their disagreements, and then attempt to restate one another's perspectives to one another's satisfaction. Paired with written reflection, such exercises can help students not only understand other perspectives but to actually occupy and give voice to those perspectives.

- Ask students to analyze or critique political speeches, advertisements, and charity pleas for the empathic positions they push students to occupy. Many advertisements do so through appeals to identity, desire, group membership, and sympathy. What feelings for self and other, and what relationships among those, do the advertisements ask? Such exercises could mirror traditional rhetorical analyses but include a focus upon emotions and identity positions as rhetorics of empathy.

- Examine and practice employing testimony and personal experiences in writing as a means of using rhetorics of empathy.

- Ask students to identify those they most easily empathize with and then those they have the greatest difficulty empathizing with. Students could question the avenues and barriers to empathy, including their affective responses. Why and how is it difficult to empathize with a supposed enemy or a violent criminal? How might we do so? What common humanity do we share? At the same time, for those the students most readily empathize with, what are the significant differences that are too easily overlooked? 
- Make greater use of narratives from other countries, cultures, and experiences as a way to challenge the limits of empathy and to expose students to other points of view that might not so readily engage their empathy.

- Ask students to play the believing game, to suspend their own impulse to counterargument and instead to enter a position of rhetorical listening and receptivity. What are the values in a particular way of seeing and feeling?

- Include more visual rhetoric and more attention to how rhetoric and empathy are registered in the in the body and particularly in the face, both those of the empathizer and of the empathized.

- Employ empathy as a means of invention by asking students to attempt to enter other perspectives and to write about issues from those perspectives and in those voices, all while acknowledging and critiquing their impulse to claim full knowledge of others, especially when those others are remade in their own image.

- In the experiencing of empathy as well its rhetorical analysis, have students always ask, empathy to what ends and in whose interests?

\section{Teaching Empathy as Disposition}

A pedagogy of empathy as disposition aims not to so much at a rhetorical awareness of empathy but to cultivate more empathic habits in students through the ways they read and write and interact with one another and their wider communities. Although Nussbaum and others have argued for the value of literary education, specifically narrative fiction, in developing empathy, I turn again here to the work of Bracher, who 
gets deeper into pedagogical strategies and techniques. As mentioned earlier, he advocates a literary pedagogy informed by psychology and the cognitive sciences. Bracher's focus is not just to change what students know but to change behaviors and the ways students think about and relate to others. Building upon the arguments of moral philosophers such as Nussbaum, Bracher explains,

the question of how the study of literature might contribute to the production of social justice is thus not a question of how it can inculcate new values, provide new knowledge, or develop new analytical skills but of how it might help people overcome their indifference to, and instead experience compassion for, the billions of people who live in misery on our planet. If literary study could systematically help students overcome their indifference to the suffering that surrounds them and experience compassion for the sufferers, it could make a significant contribution to social justice. ("Teaching" 471).

Bracher's push for social justice aligns with other efforts to broaden the people and populations for whom we feel empathy. Bracher asks that we examine the factors that lead to or limit compassion. He advocates a pedagogy that attempts to reform the cognitive schema that contribute to faulty appraisals of responsibility of the sufferers for their own suffering alongside a failure to account for other influences, such as social and environmental factors. A faulty schema, as Bracher describes it, is one that would read the poor as necessarily predominantly lazy people who simply need to work harder. It is a schema that results in a feeling not of sympathy or understanding but of resentment for the freeloaders who live off the rest of society. Such a schema generally does not recognize the factors that contribute to poverty; instead it blames the poor for being poor. Bracher's solution is a pedagogy in which: "Teaching our students to stop making faulty judgments of responsibility, which result in indifference, hostility, and harmful actions on their part, requires replacing their truncated, inadequate cognitive schemas of causality 
with more adequate causal schemas, schemas that take into account the full range of causes involved" (488). He argues that the appropriate corrections can be made by educating students about schemas, helping them identify faulty and harmful ones, and then pushing them to construct and practice more adequate schemas as replacements.

Let me acknowledge that all of this talk of schemas can begin to sound as though students are cognitive processing machines to be reprogrammed for more compassionate outputs. Bracher could do more to account for differences in personal experiences, emotional states, and values in students. He limits his pedagogy to the literary, leaving alone all of the political and cultural and nonfiction writing and discourses where these schemas are so often in play. Additionally, Bracher's attention is largely focused on reading, not writing. These omissions suggest some of the possibilities a pedagogy of empathy as disposition might pursue in a writing classroom and the ways in which such a pedagogy differs from and expands upon Bracher's work.

Bracher writes that in order to employ more effective pedagogies for social justice we need to better understand how compassion-or empathy-is developed. Here I turn to developmental psychologists such as Hoffman, who is particularly useful in putting forth a theory of empathy that can inform rhetorical and compositional pedagogies of empathy. I rely upon Hoffman and other developmental psychologists because these areas have not yet been fully considered within rhetoric and composition. Among other things, Hoffman considers the positions of role-taking in empathy, the ability to direct empathy by directing attention, and the limitations of empathy due to multiple biases and the shortcomings of experiences, all of which have valuable pedagogical implications. 
As discussed earlier, Hoffman identifies two types of role-taking: self-focused and other-focused. To review, in self-focused role-taking the observer imagines how he or she would feel were he or she in the place of the other. In other-focused role-taking, the observer pays attention to any available personal information about the otherincluding facial expressions and body positions, past experiences, personal history and qualities - and imagines more directly how the other feels. These are slight differences in role-taking positions but with significant effects. Hoffman cites studies that find selffocused role-taking is more affectively powerful for the observer than is other-focused role-taking, although both produce more intense feelings than do objective positioning (55). It follows for teaching writing then that asking students to identify through roletaking is likely to produce more intense feelings relative the issues and people they are writing about. Moreover, Batson et. al. find that "inducing empathy for a member of a stigmatized group can improve attitudes toward the group as a whole"; that "these feelings can be stimulated by taking the perspective of a person in need, imagining how that person is affected by his or her plight"; and, most significantly, that "inducing empathy may be a potent and valuable technique for creating more positive responses to the stigmatized of society" (1656). Their research supports the hypothesis that feeling empathy for a member of a stigmatized group can lead one to help that group at large and that such empathy may be best engaged through nonfictional perspective-taking. Their study was essentially a rhetorical one in which students read about another's perspective through other-focused role-taking and then determined how to allocate supposed relief funds. Extended to the writing classroom, where the emphasis could be on writing as well as reading, the study suggests that empathic ways of reading and writing might translate 
to more empathic ways of understanding the situations of others and more altruistic actions in response.

The relationship between self-focused and other-focused role-taking highlights the uneasy nature of empathy as an ongoing negotiation between self- and otheridentification. While self-focused role-taking is more powerful, it is also riskier as the observer can become so consumed with his or her own experiences and emotions that he or she then loses any significant identification with the other. For example, if a friend tells me that her grandfather died, and I empathize by thinking of my grandmother's death, I may then become so engrossed and affected by those memories that I fail to empathize with the other person's grief. Hoffman describes this loss of empathic connection as "egoistic drift." As Hoffman writes,

Egoistic drift points up empathy's fragility: It highlights the fact that although humans can empathize with the other they are not the other. My hypothesis is that self-focused role-taking arouses more intense empathic distress because it makes a direct connection between the victim's affective state and the observer's own nee system. But this very connection makes it vulnerable to egoistic drift. The result is that selffocused role-taking produces a more intense, but sometimes less stable empathic response than other-focused role-taking. (56-57)

Hoffman argues that regardless of the affective impetus, once the focus shifts from another's perspective to one's own feelings, the connection no longer counts as empathy. The tension and fragility of empathy as self- and as other-focused role-taking, as well as the potential power of empathic positions to influence how people understand others and act, underscore the necessity of a critical empathy in which rhetorics of empathy are themselves subject to analysis. I consider further in the next chapter the tensions at play in self- and other-focused role-taking and egoistic drift. 
Likewise, Hoffman's conception of empathic biases is important in recognizing the limits of empathy. In basic terms, we most readily empathize with those with whom we share the most in common. It is easiest for a middle-class suburban American student to empathize with other middle-class suburban American students. The same biases apply to geography, age, time, and all other factors that can distinguish one person from another. One way to address biases is to expand one's experiences and to become more familiar with a wider variety of people and perspectives. Nussbaum credits such increased familiarity with promoting social progress. An additional response to the familiarity bias is what Hoffman terms "multiple empathizing," which is a sort of empathy jujitsu in which the bias is turned against itself (297). Hoffman suggests that instead of asking a person to empathize with a stranger we might instead ask that person to empathize with a family member or close friend in a stranger's position. For example, instead of trying to imagine what it is like to be unemployed, a student might instead imagine how his or her father would feel were he suddenly unemployed. Such an exercise in multiple empathizing could also help the student avoid making what Bracher would identify as a faulty appraisal in blaming the father's unemployment upon his own laziness or other character deficiencies. Instead the student might focus more on social and economic conditions and personal history. As Hoffman writes, "Empathy's familiarity bias makes one less likely to empathize with a stranger; what better way to counter than tendency than to transform the stranger into a person one is close to" (297). These are primarily changes in phrasings, prompts, and rhetorical positions, but they can contribute to significant differences in interpretation and response. 
Vetlesen reminds us of the centrality of perception in accessing the human reality of situations and thereby enabling the empathic and the moral. "Perception" as Vetlesen defines it "means the ability to 'see' the human import, the human reality, of a situation" (174). Vetlesen further argues that one must take a participatory position of perception in relationship to another because "all-around adoption of an objective attitude would disavow my very humanity" (179). As discussed earlier, these are rhetorical positions. They are also pedagogical positions in the sense that they can be constructed, directed, examined, and purposefully employed. Empathy is often considered an automatic response to the observing or hearing of somebody else's situation. But Hoffman reminds us that attention itself is voluntary, and "it follows that socialization experiences that direct the child's attention to the inner states of others should contribute to empathy development" (289). Hoffman's attention here is on the development of empathy in children. Still, the voluntary functions of attention are important for educators; both as attention to the circumstances of others, as Bracher argues for, and attention to the inner states of others. Pedagogy is partially an exercise in directed attention. In Vetlesen's terms, attention may be understood as directed perception of the human and a participatory rather than objective positioning. Through directing student attention we might cultivate particular habits of attention and moral response, including those more conducive to empathic understanding, critique, and response.

So much of empathy is determined by how we read and write the world, is mediated by language and rhetoric, and is concerned with our relationships to one another. All of this informs how a pedagogy of empathy as disposition might be put to use in the writing classroom. As Bracher, Batson, Hoffman, and Vetlesen demonstrate, 
even subtle changes in the wording of an assignment and the rhetorical positioning and perspective-taking of students can have larger consequences in developing habits of empathy. These become ways of reading and writing and understanding others, with greater potential for altruistic stances and perhaps altruistic actions. More so than the pedagogical strategies proposed in teaching empathy as a rhetoric, these strategies make use of the cognitive and affective potentials of attempting to inhabit other perspectives through reading and writing and the reflection that reading and writing make possible. They also include a social justice agenda based upon the hypothesized likelihood that teaching toward greater empathy, not just as a cultural value but as a disposition informed by rhetorical practices, might contribute to the creation of a more just world. These are not all novel strategies or techniques but together offer a reinforced means of engaging and inducing empathic habits in and beyond the writing classroom. As with any pedagogy, the success of these strategies depends in part upon the experiences, relationships, and existing dispositions held by students, as individuals and as a class. Part of the work of a pedagogy of empathy is to prompt students to further investigate their experiences and relationships, how those are conditioned by their social positions and how they contribute to or limit the reading and writing of empathy. A pedagogy for the cultivation of empathy as a disposition in the writing classroom might:

- Ask students to assume role-taking positions in their writing, including selffocused and other-focused perspective-taking. They could compare the differences between such positions and the emotions that the perspectives elicit. They could attempt to write about issues from a variety of empathic perspectives and positions. 
- Examine the ways in which we read and write about others and make judgments about their characters, situations, and responsibilities. How do we represent others and the perspectives of others in our texts? How do we do so in the real world? What do those representations tell us about ourselves as well as about others?

- Emphasize the importance of context and as well as personal and social history in the paths that lives take, the options available to people, and the choices they make. With this emphasis, students may be less likely to blame victims for their suffering. They may be more likely to push back against myths of individual autonomy. What conditions contribute to making us who we are? What are our options and probabilities of becoming who we are within those conditions?

- Recognize difference - that we can never fully know another's positionswhile also recognizing a common humanity, even with those who seem to be beyond the limits of empathy.

- Ask students to be aware of their familiarity biases. Why are some people easier to empathize with than others? What assumptions to we make when we empathize based upon familiarities?

- At the same time, utilize techniques such as "multiple empathizing" to try to negotiate those biases. For example, instead of asking a student to write an essay about homelessness, we might ask instead that the student imagine his or her mother is homeless and to then write about how she could have come to be so, how homelessness affects her as well as others, and what might be done 
about it. Such an exercise pushes against a tendency to view homelessness, for example, as abstract rather than a human issue. Multiple emphasizing also can help shift the location of blame from the individual to the social.

- Push students to acknowledge what Vetlesen calls the "human reality" of a situation and how it addresses them directly and how they are also implicated in a situation. A writing prompt on world hunger, for example, would then address the student not as some distant and unaccountable observer but as a fellow human being who is also an actor and part of a world in which so many other people go hungry. A student in a revision session could be asked to examine the limits of her knowledge of hunger, what it feels like to go to sleep hungry, and to consider her social positions relative the hungry and within world food economies.

- Direct student attention to representations of others and readings of their inner states, such as situational details, physical and facial characterizations, and the social context and representations of emotions.

- Suggest that students expand their experiences and associations with people beyond their familiarity biases, perhaps starting with their classmates or through personal interviews or readings from more diverse perspectives.

\section{The Messy Work of Schooling the Emotions}

A recent study by Sara Konrath found empathy on the decline among college students since 1970 and especially since 2000 . This scared many people, although Konrath does not seem too concerned. She writes on her blog, "The good news is that 
empathy is not 'destroyed' or 'under siege'... Instead, empathy may be sick." Konrath's study points to the attention afforded empathy as well as the unique position of educators to do something about empathy among students and within the wider culture. As Bracher writes, commenting upon the influence of professors, "For while it is true that literary professionals are small in number and slight in status, the fact that we teach-and/or teach others to teach-a significant number of the world's elite suggests that our access to power is not as minimal as our numbers and social position might imply" ("Teaching" 463-464). Rhetoric and composition teachers may be even slighter in status than some academic and literary professionals. But by nature and position of the college composition course, rhetoric and composition teachers may also have a greater reach than most. With that reach, questions of what we teach, why we teach what we do, and the ethics of that teaching become all the more important.

Some rhetoricians and teachers will be uncomfortable with the moral component of pedagogies of empathy because of the moral certitude or rightness they implies. This is a common and perhaps unavoidable feature of pedagogies of empathy. It begins with definitions of empathy itself. Vetlesen ties empathy directly to morality. Potter also recognizes this relationship in her chapter on teaching victim empathy, writing,

Without empathy, the moral agent is unable fully to grasp the moral features of certain situations, because part of what makes those situations the kind they are is the other particular person. Empathy plays a central role in coming to understand the context and potential implications for others of our contemplated actions so that we can reason well toward right ends. ("Can Sex Offenders Learn" 61)

The last sentence of that section may be the most telling and the most uncomfortable in the context of teaching. Potter writes of reasoning "well" and of "right ends." This confidence in "right" ends will likely worry some, and indeed Potter continues to 
consider at length questions about coercion and authority and context. But some baseline certainty about morality—such that it is immoral to subject others to sexual abuse—is necessary if a pedagogy of empathy is to have any purpose. Although empathy can be put to dubious and ill-intended uses, the very teaching of empathy insists on some moral value in the consideration of others and their perspectives. Indeed, morality is partially grounded in the emotions, not just in reason and rationality. Micciche observes as much when she writes, "Ethical and rhetorical action is motivated by a sense of what is 'right' and 'good' in a given situation, a judgment that not only emerges from reasoned deliberation but also from experience and belief and feeling about what is right, what is just" ("Doing Emotion" 168-169). Bracher also takes up these arguments in his conclusion to "Teaching for Social Justice: Reeducating the Emotions Through Literary Study." There is no such thing as a value-neutral pedagogy, he reminds us, and teaching compassion or empathy as a value is hardly as disputed or contentious as some of the other teaching commonly conducted within the university.

Because of the affiliated social justice agenda, built upon the empathy-altruism hypothesis, pedagogies of empathy are subject to many of the same criticisms of critical pedagogies. Those include arguments that teaching for social justice makes students objects of the teacher's agenda and in this way is dehumanizing to students, or that such teachers are forcing students to adopt the teacher's own values and ideals. These are legitimate concerns. But I think there are some crucial differences between the pedagogies of empathy that I propose here and other critical pedagogies. For starters, the principle objectives are different because critical pedagogies, as I understand them, set student social liberation and political and social efficacy as primary purposes, which 
create all kinds of questions of authority. I do not see the same questions of authority within these pedagogies of empathy because they do not aspire to the same kind of political and social liberation. The focus of pedagogies of empathy is in the ways in which students understand and relate to others in the world. Questions of institutions and authority may follow from such pedagogies, but they are not the starting point. Bracher makes a similar argument in responding to critics from the other side, those who argue that his compassion-inducing pedagogy does not go far enough toward social justice by failing to focus on material, structural, and political changes. "Such changes are clearly essential," Bracher concedes, adding, "I am focusing on cognitive and emotional changes not because I see them as a substitute for material, structural, and political changes but rather because they are a prerequisite for such changes" ("Teaching" 505). He also argues that some appraisals are faulty if they do not consider all of the necessary and relevant facts, and that we would be doing a disservice to our students and others if we did not correct such faulty appraisals. This can lead to arguments over which facts are necessary and relevant and which are not, but we may be able to agree that empathy does require some attention at least to the human dimension of an issue as well as some context. In other words, not all facts are equally necessary and relevant, and not all appraisals equally valid, once we affirm some value to empathy. I expect most people would make that affirmation in most cases.

I view pedagogies of empathy as indicating but not necessarily leading to specific values and political positions. The different ways in which rhetorics of empathy can be employed and critiqued in social, political, and personal discourse, as demonstrated in the preceding chapters, show that the application of rhetorics of empathy do not always lead 
to the same conclusions. These are contested areas, and teaching an awareness of rhetorics of empathy allows one to better gauge and engage those contests. Furthermore, regarding the inducement of empathy as a pedagogical objective, I am inclined to view empathy as relatively value-neutral; which is not to say that such a pedagogy is valueneutral, because no pedagogy is. Empathy is a way of understanding and relating to others and to oneself. Its most significant value component is that simply of giving another human regard. There is value in that. I would think, unobjectionably so. Where that human regard entails, and how it is employed and to what ends, are exactly the sort of questions that should be addressed in pedagogy informed by rhetorics of empathy.

I do not wish to rehash here the more extensive arguments about pedagogies of social justice and schooling the emotions. Bracher does a fine job addressing many of the usual objections at the conclusion of his article "Teaching for Social Justice: Reeducating the Emotions Through Literary Study." The point I want to stress here, one Lynn Worsham makes, is that of purpose. She writes, "To be sure, our most urgent political and pedagogical task remains the fundamental reeducation of emotion" (216). I interpret the reeducation of emotion to be exactly the kind of work that Bracher calls for when he argues that we should teach to change how students read about, feel about, and appraise others. I understand why this view of education as changing students can be unsettling, although changing students in some way is exactly the point of education. Pedagogies of empathy — as rhetoric and as disposition—offer a way to educate the emotions at the juncture of the cognitive and the affective, the personal and the social, where emotions can be investigated, held accountable, and put toward action. Such pedagogies at their best hold the hope of contributing to social justice. Furthermore, rhetorics of empathy are 
already at work in the world. Teaching to and about them is a way of recognizing that work and of being better able to engage or resist it, as teachers and rhetoricians and as students. Pedagogies of empathy as disposition ask that students not only be more aware of how they read and write others and themselves but also that they try to direct those habits for purposeful and more compassionate ends. Seemingly small changes in such habits can over years contribute to significant results. This chapter opened with the question, Who could be against teaching empathy? The question supposes that we can either be for or against it. The more important questions are those of what does it mean to teach empathy, what are the values and strategies of such pedagogies, and how might we teach empathy responsibly? Here we can recognize the rhetorical and pedagogical places and functions of empathy. In doing so, teachers of rhetoric and composition may be able to begin employing pedagogies of empathy better and more purposefully and critically. 


\section{CHAPTER V}

\section{THE PARADOXES AND NEEDS OF A CRITICAL EMPATHY}

In working on rhetorics of empathy I often have been reminded of a famous line from F. Scott Fitzgerald's essay "The Crack-Up." "The test of a first-rate intelligence," Fitzgerald writes, "is the ability to hold two opposed ideas in the mind at the same time, and still retain the ability to function" $(520)$. The same double-mindedness could be attributed to empathy. There is a constant tension in empathy and in moves toward empathy in competing points of reference and in ways of thinking about them. Empathy is an unstable process. It shifts between self and other, the general and the specific, and the cognitive and the affective. This instability contributes to the critical value of rhetorics of empathy.

The tensions within rhetorics of empathy reach toward the level of paradox. In labeling these "paradoxes of empathy" I am thinking of the term much as Torill Strand does in writing about cosmopolitanism, which also shares strong correlations with empathy. Strand argues that the paradox of cosmopolitanism-that cosmopolitanism describes a world that both is and is not, in reality and as an impossible image_-allows the creation of new knowledge and new ways of thinking about cosmopolitanism as well as the world. Paradoxes of empathy hold similar functions. By examining these paradoxes through empathy we are forced to resist static positions of knowing. Instead 
we must constantly question the tensions within rhetorics of empathy, and we must maintain an awareness of the assumptions that would provide the foundation for a position of empathy. In these ways empathy itself becomes destabilizing. The paradoxes within rhetorics of empathy may be understood as true paradoxes in that they do not merely include seemingly contradictory positions but, when employed critically, do so in order to arrive at some insight or new understanding.

The most prominent of those paradoxes — and one that is paralleled in the tensions of the others-centers upon questions of identification with oneself and with another. As in the Fitzgerald quote, it is seemingly impossible to simultaneously identify with both oneself and with another. Yet this is exactly what empathy asks us to do. There exists a constant tension in identifying too much with the other or too much with oneself, making the other into the self or the self into an imagined other. This is a process of empathic identification that cannot be fully resolved. In examining this tension I rely heavily upon Burke's attention to identification in rhetoric and upon Hoffman's psychological models for identification as self- and other-focused. A related paradox is that of presence and absence as necessary conditions for empathy. Empathy requires some presence or detail or substance in order to enable identification. However, the work of empathy is such that it also requires absences in which to assert itself. Here I follow the lead of Lynch, who describes this paradox through the metaphor of imagining oneself in the shoes of another. This is a common metaphor for empathy. But, as Lynch notes, in order to imagine oneself in another's shoes one must first remove the other from the other's shoes. That is to say, we can only put ourselves in the shoes of another when that other is no longer in them. Another paradox of empathy exists in the relationship between difference and 
commonality, between individuals and communities. Empathy depends in part upon an assumption of some commonality across basic human experiences so that one might imagine an approximate understanding of the experiences of another. Yet, a more accurate and critical empathy also depends upon recognition of differences that cannot be transcended. We are left with an understanding that we are both similar and different. That may sound basic, but as a way of questioning our assumptions about others, the tensions between commonalities and differences become generative by making more apparent our assumptions. Burke is helpful here, too, in his attention to difference. The cosmopolitan philosopher and ethicist Kwame Appiah is also helpful in presenting a way of understanding commonality through difference. I arrive, with Burke, at an understanding of the tensions within commonalities and difference, among people and situations, as being constitutive of rhetorics of empathy. Rhetorics of empathy may help us see more clearly these tensions and their contributions to rhetoric.

I use these paradoxes of empathy to argue further for the importance and need of a critical empathy. A critical empathy is one that is always asking questions about the limits of understanding, moves to identification, the relationships between commonalities and differences, and, most importantly, how these paradoxes are put to rhetorical effect. A critical empathy always asks who is in the position to empathize and who is in the position to be empathized with and in what social conditions and to what ends. Here I build upon Todd DeStigter's concept of "critical empathy" and Min-Zhan Lu's use of "critical affirmation," and I incorporate the questions offered by Shuman in her critique of empathy. In the end I argue, similarly to Lynch, that empathy is a useful rhetorical concept precisely because of these paradoxes and the resulting critiques it prompts. 
Rather than limiting rhetorics of empathy, the tensions within empathy push to the foreground vital rhetorical questions about assumptions and relationships. The tensions foregrounded in rhetorics of empathy are tensions already present in much of our rhetorical work. Rhetorics of empathy, critically employed, are a means of better understanding those tensions and what is at stake within them.

\section{Identifying with Self and Other}

As discussed in the opening chapter, theories of identification occupy a central position within many ideas of rhetorics of empathy. Empathy may be understood in part as a process of identification with oneself and with another. The paradox that arises when understanding rhetorics of empathy in terms of identification is in the suggestion that one might identify simultaneously with oneself and with another. Such an identification would only be possible if one were to at the same time identify as two individualsoneself and another-or if identification with the one were the same as with the other, which is not the case.

To underscore the importance of identification to rhetorics of empathy, let us return to the work of Burke. Although Burke did not discuss empathy directly, he did place identification, such as implicated in empathy, at the heart of rhetoric. Burke located identification first with interests, so that if A finds his interests aligned with those of Bor is persuaded to so find them aligned—he will identify with B. In Burke's words, "In being identified with $\mathrm{B}, \mathrm{A}$ is 'substantially one' with a person other than himself. Yet at the same time he remains unique, an individual locus of motives. Thus he is both joined and separate, at once a distinct substance and consubstantial with another" (21). There is 
a seeming contradiction here in the idea that one could identify both with oneself and with another, remaining "both joined and separate," both "a distinct substance and consubstantial with another." Perhaps identification is a process of overlap, so that we identify with those actions and motivations of another insofar as they correspond to or overlap with our own. Burke attempts to explain this paradox in the way that paradoxes tend to be explained, which is through the use of examples or metaphors. He turns to that of children and parents:

While consubstantial with its parents, the "firsts" from which it is derived, the offspring is nonetheless apart from them. In this sense, there is nothing abstruse in the statement that the offspring both is and is not one with its parentage. Similarly, two persons may be identified in terms of some principle they share in common, an "identification" that does not deny their distinctness. (21)

This metaphor is not quite satisfying. While it makes sense that an offspring may be identified in part with both of his or her parents, the extension to individuals and principles is not entirely clear. The most direct way to make sense of this seeming contradiction is to focus upon Burke's linkage of identification with motives and to understand identification as akin to common cause. Yet even this is not satisfying, because elsewhere when Burke writes of identification he does not mean simply common cause but common ways of being and acting in the world. For example, Burke writes, "You persuade a man only insofar as you can talk his language by speech, gesture, tonality, order, image, attitude, idea, identifying your ways with his" (55). Identification thus is not limited to sharing motivations but is also connected to how those motivations are expressed in speech, action, idea, and gesture. We identify with others the more that they appear in their motivations and their actions to be like us. The strongest identification, then, would be with oneself at the present moment. This is a somewhat 
obvious observation that nonetheless points to the inherent difficulties and contradictions of identifying both with oneself and with another.

In proposing identification as a means to move others to action, Burke's attention is on the rhetorical. We can add to Burke's rhetorical understanding of identification the psychological understanding of Hoffman. Hoffman's theories role-taking add to Burke's work on identification by providing direction and by explaining a process of relations between ideas of self and other. One way a person might identify with oneself and with another-as Burke states, "both joined and separate"-would be through managing selfand other-focused perspectives. As discussed in the preceding chapter in the context of pedagogy, Hoffman defines self-focused role-taking as "when people observe someone in distress [and] they may imagine how they would feel in the same situation. If they can do this vividly enough, they may experience some of the same affect experienced by the victim" (54). Hoffman's emphasis here, as in most of his work on empathy, is on people in distress. However, the same process can apply to other situations and affective states. Hoffman provides in self-focused role-taking a process for how one might imagine how one's own self would feel in another's position. This applies one's own experiences and background-the narratives and interpretations that one carries to an affective state-to another's position. The focus remains on how the self would feel if the self were in that other's position. In contrast, Hoffman's "other-focused role-taking” is defined as when "learning of another's misfortune, people may focus directly on the victim and imagine how he feels; and doing this may result in their feeling something of the victim's feeling"' (54). Notice that Hoffman allows only that one may feel "something" of another's feelings. Other-focused role-taking is much more limited and more difficult than self- 
focused because one can have only partial and largely imagined access to another's affective states and what another makes of those affective states within the interpretive social conditions and narrativization of emotion. These two forms of role-taking parallel the identification moves presented in Burke's rhetorical theory by combining multiple forms of identification between self and other and in developing questions about how those forms of identifications might simultaneously exist. They add another layer to Burke's identification by providing concepts for who identifies with whom, and by raising the inherent limitations in doing so. In other words, the question unaddressed in the above references by Burke is that of who is consubstantial with whom. Hoffman provides a means of further development of this concern by providing different directions for identification or role-taking. In one instance, an individual imagines how he or she would feel in situation similar to that of another. In another instance, that individual imagines how the other might feel in the other's situation. The difference may seem slight but points to the paradoxical and blurry boundary between self and other in terms of identification.

The sometimes blurry and problematic nature of that boundary between self and other becomes more apparent in Hoffman's concept of egoistic drift. Egoistic drift was first discussed in the chapter on the nearly and newly homeless. Respondents to Jacobs's newspaper series would sometimes use empathy as an opportunity to drift from empathizing with another to telling again their own stories as a way of empathizing with themselves and even critiquing the experiences of another based upon their claims to empathy. Egoistic drift demonstrates the slippery nature of empathy and the tendency to slide through empathy toward the more comfortable and familiar. Hoffman theorizes that 
self-focused role-taking is particularly susceptible to egoistic drift because it is also particularly powerful as affect. Egoistic drift is a useful concept for its paradoxical workings in relation to self- and other-focused role-taking and identification. In describing egoistic drift, Hoffman writes,

When people take the victim's place and bring in emotionally charged personal memories, the memories may at times take control of their response and turn their attention away from the victim toward themselves...In other words, the observer is overwhelmed by the empathic connection with the victim, and the empathic connection is then severed, ironically, because the empathic affect resonates so effectively with the observer's own needs; and his focus, which was initially on the victim, shifts toward himself. Ruminating about his painful past, he becomes lost in egoistic concerns and the image of the victim that initiated the roletaking process slips out of focus and fades away, aborting or temporarily aborting the empathic process. (56)

Through this concept, empathic identification is seen as constantly in flux, shifting between self and other and among memories, situations, and affects. The irony described by Hoffman is that the very process of identification is the same that severs empathy as the observer responds more affectively to his own memories and associated affected states, which are initiated by the observation and by taking the perspective of another. There is the constant risk of slipping into egoistic drift or, for the sake of avoiding egoistic drift, limiting the affective power and accuracy of empathy. The paradox, then, is that in identifying with another one is also identifying with oneself and at risk of slipping further adrift. It is, in other words, the paradox of trying to see the world of another through one's own eyes. This double vision requires, as Nussbaum argues, "A kind of 'twofold attention,' in which one both imagines what it is like to be in the sufferer's place and, at the same time, retains securely the awareness that one is not in that place" (Upheavals 328). Here in the idea of a "twofold attention," which Nussbaum borrows 
from Richard Wollheim, is the echo of Fitzgerald's notion of a first-rate intelligence as simultaneously holding two conflicting ideas.

Hoffman has no easy solution to questions of conflicting identifications. He offers only caution. As with many paradoxes, there is a sense in which foregrounding the fluidity and the paradox inherent in self- and other-identification is the best way in which to handle such questions. We can guard against the risks by being aware of them. Moreover, the seeming contradiction of simultaneous self- and other-identification raises valuable questions about rhetorical moves toward identification, the relations implied and instigated by the moves, and their extent. It troubles very common assumptions about the stability of those empathic identifications. We see these questions and an attempt to negotiate them in Burke's notion of consubstantiality: "A doctrine of consubstantiality, either explicit or implicit, may be necessary to any way of life. For substance, in the old philosophies, was an act; and a way of life is an acting-together; and in acting together, men have common sensations, concepts, images, ideas, attitudes that make them consubstantial (21, emphasis original). We may be separate and together, Burke suggests, if we only act together. This goes beyond overlap to include created and shared experiences. People would thus be creating together, by acting together, their own shared opportunities for self- and other-identification. Identification then seems to be not something that happens before meeting, or at the point of meeting, but that happens through acting together after meeting.

Another way of confronting the question of shared identifications with self and other is offered through attention to the self-other overlap. In their investigation into the empathy-altruism hypothesis, psychologist Robert Cialdini et. al. describe the self-other 
overlap as "oneness-a sense of shared, merged, or interconnected personal identities" (483). These are interconnected identities such that could be created through Burke's acting together. Cialdini et. al. comment upon the fluid nature of identity in terms much like those of Burke, writing that "although our self-conceptions are fairly stable over long periods of time, they can be made to shift temporarily, flowing across established boundaries with changes in various factors, such as whom we are with, what immediate goals we have, which aspects of the self are currently prominent, and which roles we are instructed to play" (482). This is a highly social and contextual view of identity and one that, like Burke's use of consubstantiality, largely depends upon motivations and actions. The important move here is in placing consubstantiality and oneness not prior to action but as constituted by and contributing to action. Furthermore, Cialdini et. al. cite accumulative evidence that "suggests that a merging of self and other identity can occur and that it is most likely under conditions linked by the empathy-altruism model to feelings of attachment and altruistic motivation: relationship closeness and perspective taking" (482).

We are left with an understanding of empathic identification as not only raising questions about identification positions and perspective-taking but as necessarily and critically doing so. As Cialdini et. al. note, empathy is instrumental in blurring boundaries between self and other. Cialdini et. al. further support Burke in arguing that in order to accommodate simultaneously identifying with oneself and with others and accounting for motivation and contextualized actions, people need to move beyond identity as a static position. These are principally rhetorical concerns and are not new to rhetorical and critical theory; the idea of a unitary identity was long ago made suspect. What paradoxes 
of empathy allow in relation to identification and self- and other-focused role-taking, including the question of egoistic drift, is a common foregrounding of these questions. An explicit recognition and questioning of empathy as rhetoric forces one to ask questions not only about identities but also about social conditions, relations, and purposes. An understanding of the rhetorical work of empathy in identification includes an acknowledgement of identities as fluid and multiple. This recognition harkens back to Hume, who writes of the fiction of the self in comparing the self to a republic (Gross 117). Identification also is acknowledged as inextricably connected to motivation and ways of acting in the world. A critical form of rhetorics of empathy, in acknowledging the implied paradox of identifying simultaneously with self and other, asks that we see the world with the "twofold attention" of Nussbaum. This is an important shift, because in applying a "twofold attention" one is compelled to ask questions of relation and purpose that may not otherwise be so demanding. There is a sense, then, that like any paradox, that of empathic identification with self and other is paradoxical because in seeming contradictions it points to greater insights into the social negotiations of identities and work of rhetorics of empathy.

\section{In Another's Shoes: Presence and Absence}

The metaphor of walking in another's shoes is probably the most common metaphor for empathy. (The closest competition in the metaphor category might be seeing through another's eyes.) As such, it deserves special attention and presents additional possibilities for understanding rhetorics of empathy and the tensions and paradoxes held in rhetorics of empathy in moves toward self- and other-focused 
identification. The metaphor presents questions identification, especially as manifested in terms of presence and absence. The metaphor works by conjuring the idea of inhabiting another person's space and having to adjust oneself to the experiences of another in shoes that may not fit. These hold physical, spatial, personal, and affective associations. There is also presented in the metaphor of walking in another's shoes a physical sense movement and embodiment in the act of walking, which bring to mind the bodily dimension of rhetorics of empathy.

Lynch explores well the paradoxes presented in the metaphor when he considers criticism of empathy as an attempt to appropriate another's experience. He starts with the idea of empathy as getting into another's skin, another metaphorical example of the attempt to other-focused role-taking. This metaphor suggests that effective empathizing requires one almost to be a shape-shifter. If this is an uncomfortable idea, that may be because getting into another person's skin is usually presented in fiction as part of a dubious effort to get rid of the other or to act as the other in ways that the other would not. Getting inside another's skin can be a way to own another person's experiences and perspectives and to make that other person being unnecessary. The supposed empathizer is then in a position to act in the place of another, in the other person's name, under a presumed knowing of what the other wants or needs. Of course, there are also more positive reasons that one might want to "enter another's skin," such as to have access to another way of being and feeling and seeing in an effort for a more accurate empathy. Questions about entering another's skin lead to the ontological tension of presence and absence—and the metaphor of walking in another's shoes—-that Lynch suggests is "perhaps most paradoxical and most problematic about empathy" (10). As Lynch writes, 
When we desire to step into the shoes of someone else, under the usual conceptions of empathy I have been using, it is only possible if those shoes are empty; this desire makes empathy dependent on the physical, bodily displacement of the other. It assumes, in an odd way, that I will only be able to learn something about you once you are gone, out of sight, as though your bodily presence were just a distraction to the rhetorical task at hand. Traditional rhetorics often assume such a narrow relationship between who you are and the issue being discussed: only what is directly relevant about you needs to be articulated in the process of arguing. The role of empathy becomes, in this sense, that of draining the rhetorical situation of everything that might prevent me from properly abstracting what is relevant in your circumstances. (10)

Lynch is describing the unease that many feel with ideas of empathy that approach the appropriation of another's experiences. In referencing "traditional rhetorics," Lynch is pointing to a view of argumentation that attempts to reduce another's presence to only the necessary elements. We are left in this description with empathy as a way of both evoking and erasing a presence. We empathize in order to understand another's perspective, but then, as Lynch suggests, we may drain that presence of presence until we have only what we need to support our moves toward empathy. At least, this is the unease some feel about rhetorics of empathy within traditional models. As Lynch notes, this is "an odd way" to learn something about somebody. It is all the more odd because it is in opposition to much that people value in the idea of empathy as a way of connecting with another rather than erasing that other. As Lynch's metaphor implies, one way out of the paradox of self- and other-focused identification and presence and absence is to simply reduce and erase the other so that only the impression of a former presence is left. But this would negate the value of empathy as an attempt to identify with another beyond reduction. This examples also points to another example of the risk of egoistic drift, because the more that empathy loses attention to the other-to particulars of difference, 
specifics of context, and bodily presence-the more it risks erasing the other through appropriation.

To extend the metaphor, Lynch suggests that in order to walk in somebody else's shoes we must take that somebody out of his or her shoes and make those shoes our own. In this sense we have drained the rhetorical situation of the other to the point that we are left only with what is useful to our purposes. We could be left only with the other's shoes, at best reminders that they were not initially our own. Those are important reminders, however, because in walking in another's shoes we may feel differently and the walking and the road may be experienced differently. Shoes mold to fit our feet. They are worn through with patterns of use. To walk in another's shoes is to embody something of another's experiences and to be reminded of the felt presence of other feet, almost to walk with another's feet, even when they are no longer in the shoes. It other words, we cannot walk in another's shoes alone. This signals both the paradox and the potential promise of rhetorics of empathy. In this way the metaphor plays with the tension between presence and absence, the necessity of removal of the other as well as the impossibility of that removal. Each step in another's shoes is an experience both of another's and one's own absence and presence, one's own steps and those of another.

The metaphor of walking in another's shoes also suggests an additional tension, that between the particular and the general. The more specific the details of the other and the more they differ from one's own, the more difficult it is to empathize. To keep with the metaphor just a little longer, it is difficult to walk in another's shoes when those shoes are far from one's own size and are fitted almost perfectly to another's feet and another's stride. However, while a more general other may make for greater ease of empathy — the 
empathy of one size fits all-a general empathy is also less accurate or exact. Keen describes a similar tension at work with empathy and readers of fiction. "Empathy for fictional characters may require only minimal elements of identity, situation, and feeling, not necessarily complex or realistic characterization," Keen finds (Empathy and the Novel 69). In other words, at the risk of extending the metaphor too far, shoes and maybe a name to go with them are all we need to initiate an empathic response. Indeed, as Keen goes on to explain, too many details can begin to inhibit empathy. As Keen writes of the risk of telling too much in fiction, "sometimes the potential for character identification and readers' empathy decreases with sustained exposure to a particular figure's thoughts or voice" (96). Too much of the other's presence can actually get in the way of empathy, in the same way that one is unable to walk in another's shoes so long as another is still wearing them. But insufficient details inhibit empathy because there is nothing or nobody there to empathize with. Although Keen is working with empathy as it relates to readers of fiction, the tensions are much the same. Empathy fills gaps, requiring only a scaffold to get started, only shoes to conjure a body. A simultaneously powerful and accurate empathy is one that, paradoxically, requires both presence and absence, walking in another's shoes with another.

\section{Both Universal and Particular}

Just as rhetorics of empathy question the shifting boundaries between identification with the self and with another, so do they foreground tensions between the universal and the particular. They do so through one's relationship as an individual to a community as well as to one's own experiences. The importance of difference factors 
heavily in these questions, as those who empathize must rely upon some assumed commonalities among human experience even as they simultaneously recognize that the differences between individual and communal experiences cannot be ignored.

Empathy as a conscious process requires the basic assumption that we might even begin to approximate the perspectives, feelings, and experiences of another. For example, in Hoffman's "other-focused role-taking," how might one begin to assume how another feels in a situation unless one assumes to have some shared access to what another might feel? These are always dangerous assumptions. Assumptions of commonalities generally are safest when one is attempting to empathize with another whose background and experiences are closest to one's own. But even then they can be quite risky, because similarities of background and experience do not necessarily or even usually lead to shared affective states. The inherent risks of these assumptions contribute to the familiarity bias in empathy. It tends to be the case, for example, that empathic identification with a sibling who shares much of one's background and experiences is easier and likely truer than empathic identification with someone of a different family, different place, or different generation. Some of the most significant tests of empathy, and some of the instances in which assumptions of commonalities are riskiest, often occur across the greatest differences in cultures and contexts. (But people are sometimes—although not always-more aware of the empathic imaginative leaps they are making across such broad differences.) Because of this empathy is a vital component of theories of cosmopolitanism, which similarly struggle with the balance of universal principles and an idea of a common humanity while simultaneously recognizing that differences cannot be neglected or erased. The resulting slogan for cosmopolitanism, as 
offered by Appiah, is "universality plus difference" (151). The idea of "universality plus difference" is a felicitous phrasing here because it demonstrates the necessary and always present tensions between the universal and the particular. These tensions are necessary because cosmopolitanism - as well as empathy - can attempt to attain validity only through the simultaneous acknowledgement of universality and of difference, two concepts that are often placed in opposition.

The tensions between the universal and the particular are at play in our individual lives and reflected in our considerations of the personal as well as of the abstract. The role of the personal and the particular are important to Aristotle in his ethics of decision making and good action. To act ethically, Aristotle argues, requires a constant attention to the concrete. As Nussbaum interprets Aristotle's idea of phantasia and deliberation, "All thought, for Aristotle, is of necessity accompanied by an imagining that is concrete, even where the thought itself in abstract. This is just a fact of human psychology" (Love's Knowledge 77). There is, then, no way to parse the general from the particular, or the abstract from the concrete. The result is that the tension between the two becomes necessary and in fact constitutive of thought. The general and the particular attain meaning from their mutually constitutive natures, and with that meaning they become applicable as practical wisdom. The universal and the particular, then, are not in opposition but in concert. This makes clearer the idea of universality and difference, in which difference takes the place of the particular. The particular is always different in being particular. It is also necessary in order to add significance to the universal, which is developed in conversation with the particular. Nussbaum builds upon Aristotelian theory in writing that practical wisdom is more than simply applying or deriving a principle: 
the person of practical wisdom will not neglect the concrete deliverances of imagination when thinking about virtue and goodness. Instead of ascending from particular to general, deliberative imagination links particulars without dispensing with the particularity. It would involve, for example, the ability to recall past experience as one with, as relevant to, the case at hand, while still conceiving of both with rich and vivid concreteness. We are now prepared to understand that the Aristotelian will hold this concrete focusing to be not dangerously irrational, but an essential ingredient of responsible rationality, to be cultivated by educators. (Love's Knowledge 77-78)

By "linking particulars" "instead of ascending from particular to general," processes of practical wisdom allow one to approach the universal without losing awareness of difference. Both universality and difference are thus simultaneously put in relation through an accumulation of particulars that is never inductively left behind in an attempt for the perfectly universal. The application to rhetorics of empathy is clear in the idea of holding multiple instances of the particular-including those of past experiences-in mind simultaneously "while still conceiving of both with rich and vivid concreteness." This is a form of directed attention and imagination that, again like a first-rate intelligence, is able to keep in mind clearly two particulars that might otherwise cancel one another in their competing concreteness. With this applied to empathic identification, one might keep in mind both one's own perspective and an empathic identification with the perspectives of another. This is another example of a "twofold attention," which is necessary in employing a critical empathy. Like Appiah's slogan of "universality plus difference," the dual imagination locates the abstract in multiples of the concrete, always maintaining an awareness of difference. This is not an easy move to accomplish, to hold multiple particulars or the universal and difference in mind at the same time. Its instigation, maintenance, and effect are rhetorical as such a move is the product of directed attention, purposeful imagination and perspective-taking, and holds 
consequences for persuasive action. We can move and can be moved to hold such paradoxical positions through rhetorics of empathy. Indeed, an ethically responsible rhetorics of empathy demands such conditions.

To negotiate the seeming paradox of maintaining an awareness of the particular and the universal as a linking of multiple particulars, one must attend to the central role of difference in rhetorics of empathy. Attention to difference in particulars protects against a full embrace of the universal, which can be disastrous when universalism becomes a way to remake the world and anybody else in one's own image and imagination. The particular both supports empathic imagination and helps free us from the limitations of that empathic imagination. Difference thus is an essential quality of empathy. Without difference there would be no need for empathy because the perspectives of another would be the same as one's own. Empathy and narcissism would be indistinguishable. The importance of difference is emphasized in Appiah's slogan for cosmopolitanism; Burke likewise assigns difference a vital role in processes of identification. Burke uses the key term division, which resonates strongly with difference, when he writes, "Identification is compensatory to division. If men were not apart from one another, there would be no need for the rhetorician to proclaim their unity. If men were wholly and truly of one substance, absolute communication would be of man's very essence" (22). For Burke, communication is defined by difference. Communication is determined by context, as it is "embodied in material conditions and partly frustrated by these same conditions" (22). Perfect communication remains an ideal associated with perfect existence and perfect harmony, so that the only "prototypes of communication" are the "theologian's angels, or 'messengers"' (22). Difference or division is fundamental 
to rhetoric and to empathy, which makes sense given Burke's argument for the centrality of identification within rhetoric. It is because of difference that we must pay attention to communication's embodiment and frustrations and limited successes. The same applies to empathy in that difference is both a defining quality of empathy and among empathy's chief and insurmountable obstacles to attaining perfect empathic identification.

Burke goes on to similarly make an argument for the importance of universalism or some common ground in rhetoric, writing, "Likewise, there would be no strife in absolute separateness, since opponents can join battle only through a mediatory ground that makes their communication possible, thus providing the first condition necessary for their interchange of blows" (25). Just as a complete lack of difference would make rhetoric mute through total, unmediated, de-contextualized and angelic communication, so would a lack of at least a limited common ground make communication impossible because there would be no grounds for communication. Communication depends upon some common expectations and experiences-such as even a limited but shared vocabulary, as slippery as that may be, in some form. Burke credits commonality and difference-or, in his terms, identification and division - as being constitutive of rhetoric. It is through the constant tension of commonality and difference, seen also in the universal and the particular, that rhetoric acquires social purpose and artistry. As Burke writes, "Put identification and division ambiguously together, so that you cannot know for certain just where one ends and the other beings, and you have the characteristic invitation to rhetoric" (25).

Like the paradox of simultaneous identification with self and other, or absence and presence; the questions concerning negotiation of the universal and the particular, or 
with commonalities and difference, are not questions with direct answers. Instead it is the foregrounding of those fertile tensions and questions that allows the best understanding of how rhetorics of empathy and rhetoric in general might function among people, for purposes, and in social contexts. These paradoxes are themselves rhetorical because by attending to those sometimes paradoxical tensions we are better able to resist sliding either into a universalism that can destroy difference or a fetishization of difference that would deny human community and thereby disallow common rhetorical ground in the shared experiences, values, and motivations that enable effective communication.

\section{The Necessary and Constant Critique of Empathy}

The tensions and paradoxes within rhetorics of empathy are both problems and assets. They are problems because they represent liabilities within rhetorics of empathy. Perhaps more importantly, they are also assets because they push us toward a foregrounded awareness of those inherent problems in rhetorics of empathy and a more productive consideration of how rhetorics of empathy work. A foregrounded awareness of those problems allows us to not only be cautious in regard to rhetorics of empathy but also to employ rhetorics of empathy in ways that highlight critical rhetorical questions. With this awareness we are better enabled to reflect upon, question, be cautious of, and put to critical use those tensions. An awareness of the limitations of rhetorics of empathy is a necessary and reflective move. It is only enabled through a critical empathy that is constantly questioning the limits and uses of rhetorics of empathy.

Although scholars in the humanities have recently seized upon empathy as perhaps best representing the hopes, values, and social possibilities of a liberal arts 
education, especially in a democratic society, empathy itself has not escaped useful academic skepticism and criticism. As discussed earlier, Kulbaga, for example, criticizes the rhetorics of empathy that circulate in popular book clubs and can hide feel-good neoliberal or colonial agendas. Such rhetorics can focus too much on individuals while not acknowledging the ways in which empathy and identification and politics, as well as individual agency and possibilities, are embedded within different social systems. Kulbaga considers Nafisi's Reading Lolita in Tehran and its American readership as a particular case, but she is criticizing any rhetoric that gives the emotional satisfaction of an easy kind of empathizing. "The contemporary book club offers the edifying experience of difference while ultimately promising a life-affirming look in the mirror," she writes (510). Kulbaga is describing an uncritical empathy that is more about projecting one's own idea of another upon that other than it is about reflecting upon the means, ends, and limits of empathy. Kulbaga adds that Nafisi's "rhetoric of empathy invites readers to remain in the realm of the individual imagination, where affect remains divorced from either critical reflection or political action. Instead, the memoir offers 'lifeaffirming' messages of uplift" (517). Kulbaga is specifically critiquing Nafisi's memoir and the book clubs in which it was read. She warns us that an unchecked and unquestioned rhetoric of empathy can actually be dangerous as it allows cultural assumptions and perhaps neoconservative political agendas (such as an increasingly aggressive and militaristic move toward regime change in Iran) to operate under s seemingly positive empathic response. It is easy to find in international human rights discourses other examples of rhetorics of empathy that assume to know too much about another's position by omitting social and cultural factors and allowing the dominant 
expression of one's own cultural or political agenda. The ways in which commentators talk about the rights of women, or the political desires of the people of another country, are common occasions for such assumptions of an easy empathy that may be based too much upon a projection of one's own self into the positions of others.

Shuman likewise calls for a critique of empathy in the circulation and telling of other people's stories. She finds liberatory possibilities in empathy through critiquing dominant narratives, even as "empathy is always open to critique as serving the interests of the empathizer rather than the empathized" (18). Empathy may be a way for some tellers to claim ownership, knowledge, or privilege of another's story. At the same time, Shuman notes that stories need to travel beyond their owners in order to accomplish cultural work. This is part of the paradox, Shuman writes, because "Empathy is one of the failed promises of narrative, but in that failure, it provides the possibility of critique and counternarrative, providing whatever redemptive, emancipatory, or liberatory possibilities narrative holds" (19). Rhetorics of empathy demonstrate both promise and failed promise. But just as the liabilities of rhetorics of empathy can prove to be a productive asset, so can the failed promise of empathy as narrative also allow some redemption through the possibilities of counternarratives, as seen, for example, in the chapter on Obama's speeches. Kulbaga and Shuman argue that in order to guard against the failure of rhetorics of empathy we must constantly question those moves to empathy. The primary question that needs to be asked, Kulbaga argues, is "Empathy to what ends?" (518). This gets to the purposes of rhetorics of empathy with social contexts and help raise further questions about the relationships between empathizers and the 
empathized. Explaining her idea of a critique of empathy, as well as the possibilities of empathy, Shuman writes,

Empathy offers the possibility of understanding across space and time, but it rarely changes the circumstances of those who suffer. If it provides inspiration, it is more often for those in the privileged position of empathizer rather than empathized. Storytelling needs a critique of empathy to remain a process of negotiating, rather than defending, meaning. The critique of empathy, and the recognition of the inevitably failed promises of storytelling, avoids an unchallenged shift in the ownership of experience and interpretation to whoever happens to be telling the story and instead insists on obligations between tellers, listeners, and the stories they borrow. (5)

The biggest risk then is a neglect of the obligations between tellers and listeners, in which storytelling becomes a process of defending meaning. A critique of empathy foregrounds the relationships among those who are involved with the story, its provenance, its telling, and its rhetorical and social work. It shifts storytelling to a process of negotiation.

Shuman's critique of empathy is also a way to guard against the erasure or removal of the other within the work of rhetorics of empathy. The critique of empathy is an attempt to maintain the positive social potential of empathy as a means of understanding and as a mover to action, even while guarding against the liabilities of empathy. In their criticisms of rhetorics of empathy, Kulbaga and Shuman are not entirely discounting empathyindeed, they have hope for it—but are arguing for a more reflective and responsible understanding and use of rhetorics of empathy.

Kulbaga and Shuman are not alone in pushing toward a more critical empathy. Those who advocate for some form of critical empathy do so because of how empathy functions, how it is situated socially and culturally, and how the questions of a critical empathy can themselves help us investigate larger rhetorical issues. I borrow the term 
"critical empathy" from DeStigter, who credits the idea to Jay Robinson. Critical empathy, as DeStigter defines it,

refers to the process of establishing informed and affective connections with other human beings, of thinking and feeling with them at some emotionally, intellectually, and socially significant level, while always remembering that such connections are complicated by sociohistorical forces that hinder the equitable, just relationships that we presumably seek. (240)

DeStigter's definition is notable for being both hopeful and realistic. He, like Shuman, is proposing a form of critical empathy that seeks to fulfill the promise of more just relationships while maintaining awareness of the severe limitations and complications that are always part of that empathic seeking of justice. DeStigter's critical empathy is of additional value because it focuses upon the context of empathy as always situated within sociohistorical forces. This brings attention to the circumstances that inform and limit rhetorics of empathy and the differences in social positions among those involved.

DeStigter defines empathy as a way of thinking and feeling, which is in line with how Nussbaum as well as many psychologists, including Hoffman, define empathy. To define empathy as thinking and feeling is significant because it points to the ways in which rhetorics of empathy disrupt the traditional Cartesian division between the cognitive and the affective, as discussed in the opening chapter. It also positions DeStigter's definition of empathy as contra those who would define empathy as a purely affective response. In a similar way, Fleckenstein argues that the thinking and feeling aspects of empathy uniquely situate empathy for reflective and rhetorical work, especially in the social and public spheres. Fleckenstein writes, "As a complicated mixture of affect and rationality, empathy lends itself to deliberative discourse - to negotiation, debate, and persuasion-in the public sphere and serves as the foundation for social justice" (707). 
Fleckenstein is responding here to Matthew Newcomb's essay on compassion in the rhetoric of Hannah Arendt, who defines compassion as purely affective and as creating silences and impeding discourse. Arguing against Arendt, Newcomb writes that a "Critical compassion can note the issues of appropriating the stories of others and question the need to actually feel like the other" (128). Fleckenstein supports this position but through a much more direct argument that empathy already involves thinking; we do not have to rely upon a critical compassion in order to open that rhetorical and evaluative space in empathy. She cites ideas of "realistic empathy" and "critical affirmation" as illustrating the feeling and thinking elements of empathy and the critical roles empathy plays in deliberative discourse. As Fleckenstein argues, "Whether we call it empathy, compassion, realistic empathy, critical affirmation, or critical empathy, the experience of sharing another's suffering is essential to deliberative discourse, to negotiation, and to persuasion in the public sphere" (714). The critical function of rhetorics of empathy within the public sphere in particular was demonstrated in earlier chapters analyzing Obama's use of rhetorics of empathy in support of his political agenda, and in the public writing of Jacobs in trying to get readers to empathize with him as he faced homelessness. As demonstrated in analysis of these cases, a definition of critical empathy such as provided by Fleckenstein better allows one to acknowledge the interplay and tensions that always exist in thinking and feeling with others and in the ways in which we come to judgment and social action, as they are strongly influenced by that thinking and feeling.

Employing critical empathy also enables one to better question and acknowledge differences in economic, political, social, and cultural positions. These are elements of 
the "complicated sociohistorical forces" that DeStigter references and the emotional economies that determine how any emotion is socially constituted and interpreted. Among the greatest liabilities of rhetorics of empathy is how it can enable the elision or diminishment of these differences as one individual empathizes with another as though there were no differences in context. Kulbaga already has pointed to his problem in rhetorics of empathy in the case of relatively more privileged Western readers enjoying identification with others without also reflecting upon the significant differences in experiences and positions. Kulbaga does not want easy political alliances based upon a faulty imagination of another's perspective; she would seem more supportive of alliances such as those promoted through Lu's use of "critical affirmation," a term she borrows from Cornel West. Lu proposes critical affirmation as a form of literacy in which reading and writing are employed for the following goals:

(1) To end oppression rather than to empower a particular form of self, group, or culture; (2) To grapple with one's privileges as well as one's experience of exclusion; (3) To approach more respectfully and responsibly those histories and experiences which appear different from what one calls one's own; and (4) To affirm a yearning for individual agency shared by individuals across social divisions without losing sight of the different material circumstances which shape this shared yearning and the different circumstances against which each of us must struggle when enacting such a yearning. (173)

Lu proposes these critical affirmation practices in response to how the personal has been abused politically. Hers is a reflective approach that allows acknowledgment and revision of one's own affective responses. Critical affirmation is affirmative, hopeful, and politically progressive in the ways in which it allows for the building of coalitions based upon shared yearning for individual agency. And, crucially, Lu's critical affirmation is critical because it is always keeping affirmation—or empathy—from overreaching by 
foregrounding historical, material, and situational differences. Critical affirmation is of greatest applicability in how we read and write one another's stories, which serve as our sites for empathy. As Lu writes, "I join others to mark writing, especially personal narratives, as a site for reflecting on and revising one's sense of self, one's relations with others, and the conditions of one's life" (173). Lu is arguing for critical affirmation as literate and rhetorical practices that bring one's life and relationships continually into reflection and potential revision. These practices are of particular use in the writing classroom. I add to these rhetorical questions, such posed by Kulbaga and Shuman, best represented by the question of empathy to what ends? By foregrounding questions of social positions, differences, and the ends of empathy, a critical empathy guards against the significant risk of appropriating the experiences of others, especially to unknowingly validate or serve one's own interests.

The paradoxes and tensions in rhetorics of empathy necessitate the use of a critical empathy because of the inherent instability of any semi-reflective empathy. The questions posed in a critical are about the limits of knowledge and differences in experiences and situations; how rhetorics of empathy are positioned, how they function, and what their results are; how emotion, reflection, and evaluation interact; and what the personal and social effects are of rhetorics of empathy. These are fundamentally epistemological and rhetorical questions that deal with our relations to one another. Because rhetorics of empathy, if they are to be reflective at all, demand such questions in a critical empathy, these inherent liabilities can be seen as an asset. Rhetorics of empathy, and critical empathy in particular and as a consequence, require us to ask the rhetorical questions that we already should be asking in many instances. I am adding here upon the 
position of Lynch, who argues that the necessary move to a critical reflection is among the best reasons to return to the study of rhetorics of empathy. As Lynch writes, "I do not wish to treat empathy as the master concept of rhetoric, nor will I defend empathy against the serious questions that have been raised about it as a practice. I will argue instead that empathy is rhetorically productive not in spite of but because of the dangers to which it is prone" (7). Those dangers push us toward employing a critical empathy that in turn requires us to be more reflective generally of questions of rhetoric, differences, and relations. A critical empathy continually reminds us that empathy is always at best a careful and purposeful approximation of another's experience within a social context.

There is a lot of hope for rhetorics of empathy and for empathy broadly. Empathy is supposed strengthen relations, contribute to altruistic actions, and make us better people and communities. There is likewise a lot of criticism of empathy for its frequent failure to deliver on those promises and for its tendency to obscure differences and social relations in favor of a feel-good personal identification. The most meaningful and productive paradox within rhetorics of empathy is found in the ways that the liabilities of empathy enable rhetorics of empathy to be of even greater critical and rhetorical use, including their pedagogical use in the writing classroom. Fleckenstein ends her argument for empathy as a critical rhetorical and pedagogical tool by writing, "As a rich amalgamation of feelings and rationality, empathy does not prevent dialogue; it enables it. It recognizes differences in the midst of identification, and it motivates other-centered social action" (714). This ultimately is the promise of rhetorics of empathy, that they might help lead to realizing some of that shared yearning that Lu writes about to "end oppression rather than to empower a particular form of self, group, or culture." This is a 
tantalizing promise. If we ever begin to achieve such promise with rhetorics of empathy, it will only be through a necessary and constant attention to a critical empathy that allows for common ground and common cause while never getting too comfortable with the idea. 


\section{REFERENCES}

"The 1992 Campaign; Verbatim; Heckler Stirs Clinton Anger: Excerpts from the Exchange." The New York Times. The New York Times, 27 Mar. 1992. Web. 30 May 2011.

Appiah, Kwame Anthony. Cosmopolitanism: Ethics in a World of Strangers. New York: W.W. Norton, 2007. Print.

Applegarth, Risa. “Genre, Location, and Mary Austin's Ethos.” Rhetoric Society Quarterly 41.1 (2011): 41-63. Print.

Aristotle. The Nicomachean Ethics. Trans. David Ross. New York: Oxford UP, 1998. Print.

---. Rhetoric. Trans. W. Rhys Roberts. Princeton, NJ: Princeton UP, 1991. Print.

Arnett, Ronald C. "Rogers and Buber: Similarities, Yet Fundamental Differences." Western Journal of Communication 46.4 (1982): 358-72. Print.

B., Clifton. "Tragedy Pimpin': Natoma Canfield Turns Out to be a Prop." Another Black Conservative. Another Black Conservative, 16 Mar. 2010. Web. 15 May 2011.

Baker, Peter. "In Court Nominees, Is Obama Looking for Empathy by Another Name?" The New York Times. The New York Times, 25 April 2010. Web. 20 May 2011.

Batson, C. Daniel. The Altruism Question: Toward a Social-Psychological Answer. London: Psychology Press, 1991. Print.

Batson, C. Daniel, Johee Change, Ryan Orr, and Jennifer Rowland. "Empathy, Attitudes, and Action: Can Feelings for a Member of a Stigmatized Group Motivate One to Help the Group?" Personality and Social Psychology Bulletin 28.12 (2002): 1656-1666. Print.

Berman, Jeffrey. Empathic Teaching: Education for Life. Boston: University of Massachusetts Press, 2004. Print.

Booth, Wayne. The Company We Keep: An Ethics of Fiction. Berkeley, CA: University of California Press, 1988. Print. 
Bracher, Mark. "How to Teach for Social Justice: Lessons from Uncle Tom's Cabin and Cognitive Science." College English 71.4 (2009): 363-88. Print.

---. Radical Pedagogy. New York: Palgrave Macmillan, 2009. Print.

---. "Teaching for Social Justice: Reeducating the Emotions Through Literary Study." JAC 26.3/4 (2006): 463-512. Print.

Bruce, Susan. "Two Paychecks Away from Homelessness.” Main Street. Working America, Community Affiliate of the AFL-CIO. 1 Oct. 2010. Web. 3 Feb. 2011.

Burke, Kenneth. A Rhetoric of Motives. Berkeley, CA: University of California Press, 1969. Print.

Burks, Don M. "The Most Significant Passage in George Campbell's Philosophy of Rhetoric." Rhetoric Society Quarterly 13.1 (1983): 15-17. Print.

Chismar, Douglas. "Empathy and Sympathy: The Important Difference." The Journal of Value Inquiry 22.4 (1988): 257-266. Print.

Cialdini, Robert, et al. "Reinterpreting the Empathy-Altruism Relationship: When One Into One Equals Oneness." Journal of Personality and Psychology 73.3 (1997): 481-494. Print.

Cooper, Marilyn. "Rhetorical Agency as Emergent and Enacted." College Composition and Communication 62.3 (2011): 420-49. Print.

DeStigter, Todd. "Public Displays of Affection: Political Community through Critical Empathy." Research in the Teaching of English 33 (1999): 235-244. Print.

Dickerson, John. “The Empathy Trap.” Slate Magazine. Slate, 12 May 2011. Web. 12 May 2011.

Elbow, Peter. "The Believing Game-Methodological Believing." Draft. The Selected Works of Peter Elbow. 20 March 2009. Web. $2008<$ http://works.bepress.com/ peter_elbow/20>.

Fitzgerald, F. Scott. "The Crack-Up." The Art of the Personal Essay. Ed. Phillip Lopate. New York: Anchor Books, 1994. 520-32. Print.

Fleckenstein, Kristie. "Once Again with Feeling: Empathy in Deliberative Discourse." $J A C$ 27.3/4 (2007): 701-16. Print.

Fortenbaugh, W. W. Aristotle on Emotion. New York: Harper \& Row, 1975. Print. 
Galinsky, Adam D., Gillian $\mathrm{Ku}$, and Cynthia S. Wang. "Perspective-Taking and SelfOther Overlap: Fostering Social Bonds and Facilitating Social Coordination." Group Processes \& Intergroup Relations 8.2 (2005). 109-24. Print.

Gerrig, Richard J. and Phillip B. Zimbardo. Psychology and Life. 16th ed. Boston: Allyn and Bacon, 2002. American Psychological Association. Web. 14 July 2011.

Gross, Daniel M. The Secret History of Emotion: From Aristotle's Rhetoric to Modern Brain Science. Chicago: University of Chicago Press, 2006. Print.

Harwood, John. "Obama, Empathy and the Midterms." The New York Times. The New York Times, 25 Sept. 2010. Web. 26 Sept. 2010.

Hedges, Chris. "The Obama Deception: Why Cornel West Went Ballistic." truthdig. Truthdig, 16 May 2011. Web. 16 May 2011.

Hoffman, Martin L. Empathy and Moral Development: Implications for Caring and Justice. New York: Cambridge UP, 2001. Print.

Hu, Winnie. "Gossip Girls and Boys Stop to Empathize." The New York Times. The New York Times, 5 Apr 2009. Web. 4 Apr 2009.

Hume, David. Treatise of Human Nature. Ed. L. A. Selby-Bigge. New York: Oxford UP, 1960. Print.

Iacoboni, Marco. Mirroring People: The Science of Empathy and How We Connect with Others. New York: Picador, 2008. Print.

Jacobs, Rodger. "Homelessness and the Indignity of Hurtful Speech." Las Vegas Sun. Las Vegas Sun, 5 Dec. 2010. Web. 3 Feb. 2011.

---. "Hostile Toward Homelessness.” Las Vegas Sun. Las Vegas Sun, 26 Sept. 2010. Web. 3 Feb. 2011

---. “I Am Frightened.” Las Vegas Sun. Las Vegas Sun, 26 Aug. 2010. Web. 3 Feb. 2011.

Keen, Suzanne. Empathy and the Novel. New York: Oxford UP, 2007. Print.

---. "Strategic Empathizing: Techniques of Bounded, Ambassadorial, and Broadcast Narrative Empathy." Deutsche Vierteljahrs Schrift 82.3 (2008): 477-93. Print.

Konrath, Sara, and Edward H. O'Brien and Courtney Hsing. "Changes in Dispositional Empathy over Time in American College Students: A Meta-Analysis." University of Michigan. Presented at the Association for Psychological Science Annual Convention, Boston, May 27-30, 2010. Web. 28 Aug 2010 $<$ http://sitemaker.umich.edu/skonrath/home>. 
Konrath, Sara. "The End of Empathy?" Psychology Today. Psychology Today, 20 June 2010. Web. 26 Aug $2010<$ http://www.psychologytoday.com/blog/the-empathygap>.

Kulbaga, Theresa A. "Pleasurable Pedagogies: Reading Lolita in Tehran and the Rhetoric of Empathy." College English 70.5 (2008): 506-21. Print.

Lakoff, George. Moral Politics: How Liberals and Conservatives Think. 2nd ed. Chicago: University of Chicago Press, 2002. Print.

---. "What Made Obama's Speech Great." AlterNet. AlterNet. 26 Mar. 2008. Web. 15 May 2011.

Lithwick, Dahlia. "Once More, Without Feeling." Slate Magazine. Slate, 11 May 2009. Web. 15 May 2001.

Lu, Min-Zhan. "Redefining the Literate Self: The Politics of Critical Affirmation." College Composition and Communication 51.2 (1999): 172-194. Print.

Lynch, Dennis A. "Rhetorics of Proximity: Empathy in Temple Grandin and Cornel West." Rhetoric Society Quarterly 28.1 (1998): 5-23. Print.

Massumi, Brian. Parables for the Virtual: Movement, Affect, Sensation. Durham, NC: Duke UP, 2002. Print.

Nussbaum, Martha. "Compassion: The Basic Social Emotion." Social Philosophy and Policy 13 (1996): 27-58. Print.

---. Love's Knowledge. New York: Oxford UP, 1990. Print.

---. Not for Profit: Why Democracy Needs the Humanities. Princeton: Princeton UP, 2010. Print.

---. Upheavals of Thought: The Intelligence of Emotions. New York: Cambridge UP, 2003. Print.

McLeod, Susan. Notes on the Heart: Affective Issues in the Writing Classroom. Carbondale: Southern Illinois UP, 1997. Print.

Micciche, Laura R. Doing Emotion: Rhetoric, Writing, Teaching. Portsmouth, NH: Boynton/Cook, 2007. Print.

---. "The Trouble with Affect." JAC 26.1/2 (2006): 264-275. Print. 
Monroe, Kristen Renwick. The Heart of Altruism: Perceptions of a Common Humanity. Princeton, NJ: Princeton UP, 1996. Print.

Nafisi, Azar. Reading Lolita in Tehran. New York: Random House, 2003. Print.

Newcomb, Matthew. "Totalized Compassion: The (Im)possibilities for Acting out of Compassion and the Rhetoric of Hannah Arendt." JAC 27.1/2 (2007): 105-33. Print.

Obama, Barack. The Audacity of Hope. New York: Crown Publishers, 2006. Print.

---. Dreams from My Father: A Story of Race and Inheritance. New York: Time Publishers, 1995. Print.

---. "The Great Need of the Hour." Real Clear Politics. Real Clear Politics, 21 Jan. 2008. Web. 15 May 2011.

---. "Press Briefing by Press Secretary Robert Gibbs." whitehouse.gov. The White House, 1 May 2009. Web. 19 June 2011.

---. "Remarks by the President on Health Care Reform in Strongsville, Ohio." whitehouse.gov. The White House, 15 Mar. 2010. Web. 18 Mar. 2010.

---. "Remarks by the President at the Holocaust Days of Remembrance Ceremony." whitehouse.gov. The White House, 23 April 2009. Web. 7 Aug. 2010.

---. "Remarks by the President to a Joint Session of Congress on Health Care." whitehouse.gov. The White House, 9 Sept. 2009. Web. 26 Mar. 2010.

---. "Remarks of Senator Barack Obama: 'A More Perfect Union."' The Huffington Post. The Huffington Post, 18 Mar. 2008. Web. 15 May 2011.

O’Reilly, Mary Rose. The Peaceable Classroom. Portsmouth, NH: Boyton/Cook, 1993. Print.

Perelman, Chaim and Lucie Olbrechts-Tyteca. The New Rhetoric. Notre Dame, IN: Notre Dame UP, 1969. Print.

Potter, Nancy Nyquist. "Can Sex Offenders Learn Victim Empathy in Prison?" Putting Peace into Practice. Amsterdam: Rodopi, 2004. 55-72. Print.

---. "Moral Tourists and World Travelers: Some epistemological Issues in Understanding Patients' Worlds." Philosophy, Psychiatry, and Psychology 10.3 (2004): 209-23. Print. 
Ratcliffe, Krista. "Rhetorical Listening: A Trope for Interpretive Invention and a 'Code of Cross-Cultural Conduct."' College Composition and Communication 51.2 (1999): 195-224. Print.

Rogers, Carl. "Communication: Its Blocking and Its Facilitation." From Critical Thinking to Argument. $2^{\text {nd }}$ Edition. Eds. Sylvan Barnet and Hugo Bedau. Boston: Bedford / St. Martins, 2008. 314-320. Print.

---. A Way of Being. Boston: Houghton Mifflin, 1980. Print.

Shuman, Amy. Other People's Stories: Entitlement Claims and the Critique of Empathy. Champaign, IL: University of Illinois Press, 2005. Print.

Sicha, Choire. "Why is American Selfishness So Widespread Now?" The Awl. The Awl, 30 Aug. 2010. Web. 3 Feb. 2011.

Slote, Michael. The Ethics of Care and Empathy. New York: Routledge, 2007. Print.

Strand, Torill. "The Making of a New Cosmopolitanism." Studies in Philosophy and Education 29 (2010): 229-42. Print.

Teich, Nathaniel, ed. Rogerian Perspectives: Collaborative Rhetoric for Oral and Written Communication. Norwood, NJ: Ablex, 1992. Print.

Tobin, Lad. "Self-Disclosure as a Strategic Teaching Tool; What I Do-and Don't-Tell My Students." College English 73.2 (2010): 196-206. Print.

Vetlesen, Arne Johan. Perception, Empathy, and Judgment: An Inquiry into the Preconditions of Moral Performance. State College, PA: Pennsylvania State UP, 1994. Print.

Waal, Frans de. The Age of Empathy: Nature's Lessons for a Kinder Society. New York: Harmony, 2009. Print.

Walton, Douglas N. Appeal to Pity: Argumentum Ad Misericordiam. Albany, NY: SUNY Press, 1997. Print.

Wand, Bernard. "A Note on Sympathy in Hume's Moral Theory." The Philosophical Review 64.2 (1955): 275-9. Print.

Woodward, Kathleen. "Liberal Compassion, Compassionate Conservatism." Statistical Panic: Cultural Politics and the Poetics of the Emotions. Durham, NC: Duke UP, 2009. 109-133. Print.

Worsham, Lynn. "Going Postal: Pedagogic Violence and the Schooling of Emotion." JAC 18.2 (1998): 213-45. Print. 
Yankee, Confederate. "Dear Mr. President: Thank You for Creating Natoma Canfield's Problems." Confederate Yankee. Confederate Yankee, 15 Mar. 2010. Web. 15 May 2011. 


\section{CURRICULUM VITAE}

NAME: $\quad$ Eric Wallace Leake

ADDRESS: 937 Shelby Pkwy.

Louisville, KY 40204

DOB: $\quad$ Las Vegas, Nevada - Feb. 6, 1980

EDUCATION

\& TRAINING: $\quad$ B.A., English

University of Nevada, Las Vegas

1998-2002

M.A., English

University of Nevada, Las Vegas

2005-2007

Ph.D., Rhetoric and Composition

University of Louisville

2007-2011 